\title{
REGULATION OF LACTATE DEHYDROGENASE AND \\ GLYCEROL-3-PHOSPHATE DEHYDROGENASE IN \\ MAMMALIAN HIBERNATION
}

\author{
Anthony A. Ruberto \\ B.A., 2013 \\ Hamilton College (NY)
}

\begin{abstract}
A Thesis Submitted to the Faculty of Graduate Studies and Research in partial fulfillment of the requirements for the degree of
\end{abstract}

Master of Science

Department of Biology

Carleton University

Ottawa, Ontario, Canada

(C) Copyright 2015

Anthony A. Ruberto 
The undersigned hereby recommend to the Faculty of Graduate Studies and Research acceptance of this thesis

\section{“REGULATION OF LACTATE DEHYDROGENASE AND GLYCEROL-3- PHOSPHATE DEHYDROGENASE IN MAMMALIAN HIBERNATION" submitted by \\ Anthony Agostino Ruberto, B.A.}

in partial fulfillment of the requirements for the degree of Master of Science

Chair, Department of Biology

Thesis Supervisor

Carleton University 


\begin{abstract}
Hibernation is a winter survival strategy for many small mammals. Animals sink into deep torpor, body temperature falls to near $0^{\circ} \mathrm{C}$ and physiological functions are strongly suppressed. Enzymes are the catalysts of metabolic pathways in cells and their appropriate control is critical to hibernation success. This thesis explores the properties and regulation of two key enzymes of carbohydrate metabolism (lactate dehydrogenase, LDH) and lipid metabolism (glycerol-3-phosphate dehydrogenase, G3PDH) purified from liver and skeletal muscle of ground squirrels (Urocitellus richardsonii). The studies showed that changes in $\mathrm{pH}$, temperature, and inhibitors play roles in differentially regulating these enzymes between euthermic and torpid states. Furthermore, reversible protein phosphorylation proved to be a significant regulatory mechanism, producing a reduced activity state of skeletal muscle LDH and increased activity state of G3PDH in both skeletal muscle and liver during torpor. Overall, these studies showed that multiple mechanisms of enzyme regulation, particularly protein phosphorylation, contribute to reorganizing fuel metabolism during hibernation.
\end{abstract}




\section{Acknowledgements}

010010000110010101111001001011100010000001001001011001100010000001111001011011110111010100100000011101000110111101101111011010110010 000001110100011010000110010100100000011101000110100101101101011001010010000001110100011011110010000001100011011011110110111001110110 011001010111001001110100001000000111010001101000011010010111001100100000011000100110100101101110011000010111001001111001001000000111 010001101111001000000111010001100101011110000111010000100000010010010010000001100001011011010010000001100111011011110110100101101110 01100111001000001110100011011110010000001100111011011110010000001101111011101010111010000100000011011110110111000100000011000010010 000001101100011010010110110101100010001000000110000101101110011001000010000001110011011000010111100100100000011110010110111101110101 001000000110000101100011011101000111010101100001011011000110110001111001001000000110001101100001011100100110010100100000011101000110 111100100000011100100110010101100001011001000010000001101101011110010010000001100001011000110110101101101110011011110111011101101100 011001010110010001100111011001010110110101100101011011100111010001110011001000000111001101101111001000000110100001100101011100100110 010100100000011010010111010000100000011001110110111101100101011100110010111000100000010001100110100101110010011100110111010000100000 011000010110111001100100001000000110011001101111011100100110010101101101011011110111001101110100001011000010000001001001001000000111 011101100001011011100111010000100000011101000110111100100000011101000110100001100001011011100110101100100000010010110110010101101110 001000000110011001101111011100100010000001100111011010010111011001101001011011100110011100100000011011010110010100100000011101000110 100001100101001000000110111101110000011100000110111101110010011101000111010101101110011010010111010001111001001000000111010001101111 001000000110001101101111011011100110010001110101011000110111010000100000011100100110010101110011011001010110000101110010011000110110 100000100000011010010110111000100000011010000110100101110011001000000110110001100001011000100010000001100001011011100110010000100000 011000110110100001100001011011000110110001100101011011100110011101101001011011100110011100100000011011010110010100100000011101000110 111100100000001001110101010001101000011010010110111001101011001000000110110001101001011010110110010100100000011000010110111000100000 011001010110111001111010011110010110110101100101001001110010111000100000010110010110111101110101011100100010000001110000011000010111 001101110011011010010110111101101110001000000110100101101110011100110111000001101001011100100110010101110011001000000110110101100101 001011000010000001111001011011110111010101110010001000000111011101101111011100100110101100100000011001010111010001101000011010010110 001100100000011010010111001100100000011000110110111101101101011011010110010101101110011001000110000101100010011011000110010100101100 001000000110000101101110011001000010000001111001011011110111010101110010001000000111011001100001011100110111010000100000011010110110 111001101111011101110110110001100101011001000110011101100101001000000110011001110010011010010110011101101000011101000110010101101110 011100110010000001101101011001010010111000100000001000000100111001100101011110000111010000101100001000000100101001100001011011100011 101000100000010010010010000001110100011010000110100101101110011010110010000001101001011101000010000001101001011100110010000001110011 011000010110011001100101001000000111010001101111001000000111001101100001011110010010000001110100011010000110000101110100001000000111 011101101001011101000110100001101111011101010111010000100000011110010110111101110101001000000100101101100101011011100010000001110111 011011110111010101101100011001000010000001100010011001010010111000101110001011100111011101100101011011000110110000101110001011100010 111000100000011011000110010101110100001001110111001100100000011010100111010101110011011101000010000001110011011000010111100100101100 001000000110111001101111011101000010000001001011011001010110111000101110001000000101100101101111011101010010000001101000011000010111 011001100101001000000111010001101000011001010010000001110000011000010111010001101001011001010110111001100011011001010010000001101111 011001100010000001100001001000000111001101100001011010010110111001110100001000000110000101101110011001000010000001110100011010000110 010100100000011011000110000101100010001000000111011101101111011101010110110001100100001000000110111001101111011101000010000001100010 011001010010000001110111011010000110010101110010011001010010000001101001011101000010000001101001011100110010000001110100011011110110 010001100001011110010010000001110111011010010111010001101000011011110111010101110100001000000111100101101111011101010010111000100000 010110010110111101110101001000000110000101110010011001010010000001101001011101000111001100100000011000100110000101100011011010110110 001001101111011011100110010100100000011100110110111100100000011100000110110001100101011000010111001101100101001000000110010001101111 011011100010011101110100001000000110010101110110011001010111001000100000011000100111001001100101011000010110101100100000011110010110 111101110101011100100010000001110011011100000110100101101110011001010010111000100000010101000110100001100001011011100110101101110011 001000000110011001101111011100100010000001100101011101100110010101110010011110010111010001101000011010010110111001100111001000010010 000001001110011001010111100001110100001011000010000001001001001000000111011101100001011011100111010000100000011101000110111100100000 011101000110100001100001011011100110101100100000011000010110110001101100001000000110111101100110001000000111010001101000011001010010 000001010011011101000110111101110010011001010111100100100000010011000110000101100010001000000110110101100101011011010110001001100101 011100100111001100100000011001100110111101110010001000000111000001110101011101000111010001101001011011100110011100100000011101010111 000000100000011101110110100101110100011010000010000001101101011110010010000001100001011011100111010001101001011000110111001100100000 011011110111011001100101011100100010000001110100011010000110010100100000011100000110000101110011011101000010000001110100011101110110 111100100000011110010110010101100001011100100111001100101110001000000100100101100110001000000111011101100101001000000110010101110110 011001010111001000100000011000110111001001101111011100110111001100100000011100000110000101110100011010000111001100100000011000010110 011101100001011010010110111000100000010010010010000001110011011101110110010101100001011100100010000001001001001000000111011101101111 011011100111010000100000011000100110111101110100011010000110010101110010001000000111100101101111011101010010110000100000011010010110 110101101101011101010110111001101001011101000111100100100000011001110111001001100001011011100111010001100101011001000010111000100000 010011000110000101110011011101000010110000100000010010010010000001110111011000010110111001110100001000000111010001101111001000000111 010001101000011000010110111001101011001000000110110101111001001000000110011001100001011011010110100101101100011110010010000001100001 011011100110010000100000011001100111001001101001011001010110111001100100011100110010000001100110011011110111001000100000011100000111 001001101111011101100110100101100100011010010110111001100111001000000110110101100101001000000111011101101001011101000110100000100000 011101000110100001100101001000000110110101101111011100100110000101101100001000000111001101110101011100000111000001101111011100100111 010000100000011000010110111001100100001000000111000001110010011001010111010001100101011011100110010001101001011011100110011100100000 011101000110111100100000011101010110111001100100011001010111001001110011011101000110000101101110011001000010000001110111011010000110 000101110100001000000111010001101000011001010010000001101000011001010110110001101100001000000100100100100000011000010110110100100000 011101000110000101101100011010110110100101101110011001110010000001100001011000100110111101110101011101000010000001100101011101100110 010101110010011110010010000001110100011010010110110101100101001000000100100100100000011001010111100001110000011011000110000101101001 011011100010000001101101011110010010000001110010011001010111001101100101011000010111001001100011011010000010111000100000010011000110 111101110110011001010010000001100001011011000110110000100000011110010010011101100001011011000110110000101110001000000100000101110011 001000000110001001100001011001000010000001100001011100110010000001110100011010000110010100100000010011110111010001110100011000010111 011101100001001000000111011101101001011011100111010001100101011100100111001100100000011100110110010101100101011011010110010101100100 001011000010000001001001001000000111011101101111011101010110110001100100001000000110111001101111011101000010000001110100011100100110 000101100100011001010010000001101101011110010010000001100101011110000111000001100101011100100110100101100101011011100110001101100101 001000000110100001100101011100100110010100100000011001100110111101110010001000000110000101101110011110010111010001101000011010010110 111001100111001000000110100101101110001000000111010001101000011001010010000001110111011011110111001001101100011001000010111000100000 010000010110111001101111011101000110100001100101011100100010000001100011011010000110000101110000011101000110010101110010001000000111 011101110010011010010111010001110100011001010110111000101100001000000110000101101110011011110111010001101000011001010111001000100000 011000100110110001100001011011100110101100100000011100000110000101100111011001010010000001100001011101110110000101101001011101000111 001100101110 Sleep fast, carpe diem, no regrets. Jones out. 
Table of Contents

Title Page

Acceptance Sheet II

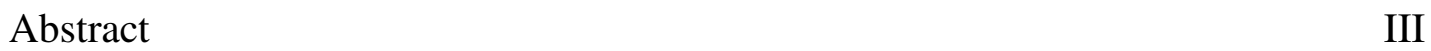

$\begin{array}{lll}\text { Acknowledgements } & \text { IV }\end{array}$

Table of Contents $\quad$ V

List of Abbreviations $\quad$ VI

List of Figures $\quad$ IX

List of Tables $\quad$ XI

List of Appendices $\quad$ XII

Chapter 1 General Introduction 1

Chapter 2 Purification and Properties of Lactate Dehydrogenase 17

from the Skeletal Muscle of the Hibernating Ground

Squirrel, Urocitellus richardsonii

Chapter 3 Purification and Properties of Glycerol-3-Phosphate 48

Dehydrogenase from the Liver of the Hibernating

Ground Squirrel, Urocitellus richardsonii

Chapter 4 Purification and Properties of Glycerol-3-Phosphate

81

Dehydrogenase from Skeletal Muscle of the Hibernating

Ground Squirrel, Urocitellus richardsonii

Chapter 5 General Discussion

$\begin{array}{ll}\text { References } & 112\end{array}$

$\begin{array}{ll}\text { Appendices } & 125\end{array}$ 


\section{List of Abbreviations}

\begin{tabular}{|c|c|}
\hline$\beta$-GP & $\beta$-glycerophosphate \\
\hline$\beta-\mathrm{MeSH}$ & $\beta$-mercaptoethanol \\
\hline ADP & Adenosine diphosphate \\
\hline ANOVA & One-way analysis of variance \\
\hline AMP & Adenosine monophosphate \\
\hline AMPK & AMP-activated protein kinase \\
\hline $\mathrm{AP}$ & Alkaline phosphatase \\
\hline ATP & Adenosine triphosphate \\
\hline BAT & Brown adipose tissue \\
\hline CaMK & Calcium-calmodulin dependent kinase \\
\hline cAMP & 3'-5'-cyclic adenosine monophosphate \\
\hline cGMP & 3'-5'-cyclic guanosine monophosphate \\
\hline $\mathrm{CM}^{-}$ & Carboxymethyl \\
\hline DEAE $^{+}$ & Diethylaminoethyl \\
\hline DHAP & Dihydroxyacetone phosphate \\
\hline $\mathrm{E}_{\mathrm{a}}$ & Activation energy \\
\hline ECL & Enhanced chemiluminescence \\
\hline EDTA & Ethylenediamine-tetraacetic acid \\
\hline EGTA & Ethylene glycol-bis(2-aminoethylether)-N,N, $\mathrm{N}^{\prime}, \mathrm{N}^{\prime}$-tetraacetic acid \\
\hline FA & Fatty acid \\
\hline FABP & FA binding protein \\
\hline FAS & Fatty acid synthase \\
\hline G3P & Glycerol-3-phosphate \\
\hline G3PDH & Glycerol-3-phosphate dehydrogenase \\
\hline GAPDH & Glyceraldehyde-3-phosphate dehydrogenase \\
\hline GK & Glycerol kinase \\
\hline $\mathrm{GuHCl}$ & Guanidine hydrochloride \\
\hline HA & Hydroxyapatite \\
\hline
\end{tabular}




\begin{tabular}{|c|c|}
\hline HK & Hexokinase \\
\hline HSL & Hormone-sensitive lipase \\
\hline $\mathrm{IC}_{50}$ & Concentration producing half-maximal inhibition \\
\hline $\mathrm{K}_{m}$ & Substrate concentration producing half-maximal enzyme velocity \\
\hline $\mathrm{LDH}$ & Lactate dehydrogenase \\
\hline MOE & Molecular Operating Environment \\
\hline MP & Melting point \\
\hline MR & Metabolic rate \\
\hline $\mathrm{NADH}$ & $\beta$-Nicotinamide adenine dinucleotide, reduced form \\
\hline NST & Non-shivering thermogenesis \\
\hline PAGE & Polyacrylamide gel electrophoresis \\
\hline $\mathrm{PDH}$ & Pyruvate dehydrogenase \\
\hline PDK4 & PDH kinase isoenzyme 4 \\
\hline PI3K & Phosphoinositide-3 kinase \\
\hline PK & Pyruvate kinase \\
\hline PKA & Cyclic AMP dependent protein kinase A \\
\hline PKG & Cyclic GMP dependent protein kinase G \\
\hline PMSF & Phenylmethylsulfonyl fluoride \\
\hline PP1 & Protein phosphatase 1 \\
\hline $\mathrm{PP} 2 \mathrm{~A}$ & Protein phosphatase $2 \mathrm{~A}$ \\
\hline PP2B & Protein phosphatase $2 \mathrm{~B}$ \\
\hline $\mathrm{PP} 2 \mathrm{C}$ & Protein phosphatase $2 \mathrm{C}$ \\
\hline PTL & Pancreatic triacylglycerol lipase \\
\hline PTM & Post-translational modification \\
\hline PUFA & Polyunsaturated fatty acid \\
\hline PVDF & Polyvinylidene difluoride membrane \\
\hline $\mathrm{Q}_{10}$ & $\begin{array}{l}\text { Ratio of the rate of a reaction at one temperature divided by the } \\
\text { rate at a temperature } 10^{\circ} \mathrm{C} \text { less }\end{array}$ \\
\hline RGS & Richardson's ground squirrel \\
\hline RPP & Reversible protein phosphorylation \\
\hline
\end{tabular}




$\begin{array}{ll}\text { RQ } & \text { Respiratory quotient } \\ \text { SDS } & \text { Sodium dodecyl sulfate } \\ \mathrm{T}_{50} & \text { Temperature at which half of the protein is irreversibly denatured } \\ \mathrm{T}_{b} & \text { Body temperature } \\ \text { TBS } & \text { Tris-buffered saline } \\ \text { TBST } & \text { Tris-buffered saline containing the detergent Triton-X } \\ \text { TKin } & \text { Total endogenous kinases } \\ \text { TPPase } & \text { Total endogenous phosphatases } \\ \text { WAT } & \text { White adipose tissue } \\ \text { 13-LGS } & \text { 13-Lined ground squirrel }\end{array}$




\section{List of Figures}

\section{Page}

Figure 1.1. Body temperature as a function of time over one year starting in June for a golden-mantled ground squirrel (Callospermophilus lateralis).

Figure 2.1. Typical Cibacron Blue elution profiles for LDH activity from muscle of euthermic (control) and hibernating $U$. richardsonii.

Figure 2.2. 10\% SDS-PAGE gel with silver staining of samples taken at each step in the purification of LDH from muscle of euthermic $U$. richardsonii.

Figure 2.3. Effects of in vitro incubations to stimulate the activities of endogenous (a) protein kinases or (b) protein phosphatases on the $K_{m}$ for L-Lactate for LDH from euthermic $U$. richardsonii muscle.

Figure 2.4. Quantification of post-translational modifications of

Purified LDH from muscle of euthermic and hibernating U. richardsonii.

Figure 2.5. Michaelis-Menten curves for (a) forward (lactate-utilizing, $5^{\circ} \mathrm{C}$ ) and (b) reverse (pyruvate-utilizing, $5^{\circ} \mathrm{C}$ ) reactions catalyzed by purified euthermic and hibernating $\mathrm{LDH}$; and (c) Arrhenius plots for the forward reaction $\mathrm{LDH}$ at three temperatures: $5^{\circ} \mathrm{C}, 22^{\circ} \mathrm{C}, 37^{\circ} \mathrm{C}$.

Figure 3.1. Typical elution profiles for G3PDH activity from liver of euthermic (control) and hibernating $U$. richardsonii.

Figure 3.2. $\quad 10 \%$ SDS-PAGE gel with silver staining of samples taken at each step in the purification of G3PDH from liver of euthermic $U$. richardsonii.

Figure 3.3. Quantification of post-translational modifications of purified G3PDH from liver of euthermic and hibernating $U$. richardsonii via (a) phosphorylation, and (b) methylation, acetylation, and ubiquitination. 
Figure 3.4. The predicted structure of G3PDH from liver of hibernating

Richardson's ground squirrel using SWISS-MODEL with human G3PDH as reference (PDB identifier: 1x0v.pdb1.gz).

Figure 3.5. Michaelis-Menten curves for substrates of the G3P-utilizing

$\left(22^{\circ} \mathrm{C}, \mathrm{pH} 8.0\right)$ reaction catalyzed by purified euthermic $(\mathrm{a}, \mathrm{b})$ and hibernating (c,d) G3PDH.

Figure S3.1. Amino acid alignment of thirteen-lined ground squirrel G3PDH cytoplasm isoform X1 (tVariant1; Accession: XP_005324992.1) with isoform X2 (tVariant2; Accession: XP_005324993.1).

Figure S3.2. Multiple alignment of the deduced amino acid sequence of thirteen-lined ground squirrel (13LGS; I. tridecemlineatus) $\mathrm{G} 3 \mathrm{PDH}$ as compared to G3PDH sequences from three non-hibernating mammalian species.

Figure S3.3. Predicted phosphorylation sites for 13-LGS G3PDH cytoplasm

(a) isoform X1 and (b) isoform X2 using NetPhos 2.0 server (Blom et al., 1999).

Figure S3.4. Crystal structure of human glycerol-3-phosphate dehydrogenase 1-like protein (PBD ID: 1X0V).

Figure S3.4. Kinetic values obtained from multiple independent determinations for the $\mathrm{G} 3 \mathrm{P}$-utilizing $\left(22^{\circ} \mathrm{C}, \mathrm{pH} 8.0\right)$ reaction catalyzed by purified euthermic (a,b) and hibernating (c,d) G3PDH.

Figure 4.1. Typical elution profiles for G3PDH activity from muscle of euthermic (control) and hibernating $U$. richardsonii.

Figure 4.2. $\quad 10 \%$ SDS-PAGE gel with silver staining showing FroggaBio molecular weight ladder $(\mathrm{kDa})$ (left) and purified euthermic $U$. richardsonii skeletal muscle G3PDH (right).

Figure 4.3. Quantification of post-translational modifications of purified G3PDH from muscle of euthermic and hibernating U. richardsonii via phosphorylation.

Figure 4.4. The predicted structure of muscle G3PDH from hibernating

Richardson's ground squirrels using I-TASSER (Yang et al., 2015; Roy et al., 2010; Zhang, 2008) with the 13-LGS G3PDH amino acid sequence as reference (NCBI Reference Sequence: XP_005324992.1).

Figure S4.1. Kinetic values obtained using direct-linear plots (Eisenthal, 1974). 


\section{List of Tables}

Page

Table 2.1. $\quad$ Purification and yield of $U$. richardsonii LDH from muscle of (a) euthermic and (b) hibernating ground squirrels.

Table 2.2. Kinetic parameters of purified muscle LDH from euthermic and hibernating $U$. richardsonii.

Table 2.3. Effects of $\mathrm{pH}$ on purified muscle LDH from (a) euthermic and (b) hibernating $U$. richardsonii.

Table 3.1. Purification and yield of $U$. richardsonii G3PDH from liver of (a) euthermic and (b) hibernating animals.

Table 3.2. Kinetic parameters of purified liver G3PDH from euthermic and hibernating $U$. richardsonii.

Table 3.3. Effects of $\mathrm{pH}$ on purified liver G3PDH from (a) euthermic and (b) hibernating $U$. richardsonii.

Table 4.1. Purification and yield of $U$. richardsonii G3PDH from skeletal muscle of (a) euthermic and (b) hibernating.

Table 4.2. Kinetic parameters of purified muscle G3PDH from euthermic and hibernating $U$. richardsonii.

Table 4.3. Effects of $\mathrm{pH}$ on purified muscle G3PDH from (a) euthermic and (b) hibernating $U$. richardsonii. 


\section{List of Appendices}

Page

Appendix I Communications at Scientific Meetings 125

Appendix II R you ready for this? A Biochemist's Guide to Enzyme

127

Kinetic Parameter Analyses Using the Programme R 


\section{Chapter 1}

\section{General Introduction}




\section{Mammalian Hibernation}

The ability of mammals to produce internal heat for the maintenance of an ideal and constant body temperature $\left(\mathrm{T}_{\mathrm{b}}\right)$ has allowed them to survive in some of the most extreme environments. Surely, the independence that these endotherms have from restrictions imposed by the thermal environment is quite advantageous. However, the maintenance of a metabolically favourable temperature comes with a high energetic cost and, during times of low food availability, such energy demands may not be met, particularly when cold environmental temperatures create high demands for thermogenesis. A coping strategy that various species of mammals have developed over evolutionary time is hibernation, a hypometabolic state where physiological and biochemical activities are suppressed and energy expenditure is minimized.

\section{Hypometabolism}

Although a wide range of invertebrates and vertebrates are capable of entering a hypometabolic state of suspended animation when environmental conditions are too harsh for normal function and behaviour (Storey \& Storey, 2004, 2007), perhaps the most complex form of natural hypometabolism is mammalian hibernation. This remarkable feat is marked not only by entrance into a torpid state but also by the inhibition of thermogenesis, allowing $\mathrm{T}_{\mathrm{b}}$ to fall to near ambient temperature. Whether it be seasonal torpor (hibernation) where a species undergoes multiple bouts of multi-day torpor over the winter, or daily torpor-induced at any time of the year by adverse conditions, there is a degree of phenotypic and metabolic plasticity that hibernating species endure. For clarity 
purposes, the information that follows is in reference to the seasonal form of torpor, hibernation.

Some common mammals that exhibit hibernation include genera such as marmots and woodchucks (Marmota), hedgehogs (Erinaceous), bats (Eptesicus and Myotis), and ground squirrels (Ictidomys and Urocitellus). As mentioned previously, seasonal torpor is comprised of multiple torpor bouts lasting several days or weeks while being interrupted by short, periodic arousals (French, 1988) (Fig.1.1). Current theories as to why hibernators awake from dormancy for short periods of time throughout the hibernating season are described below in section iv. Interbout arousal.

Phenotypic plasticity associated with hibernation

\section{i. $\quad$ Key Physiological Changes}

Entry in to torpor is marked a decrease in heart rate, a decrease in respiratory rate, and an increase in vasoconstriction to maintain proper blood pressure, all while the hypothalamic temperature set point is reset to allow $\mathrm{T}_{\mathrm{b}}$ fall at a progressive, controlled rate (Carey et al., 2003). Once in torpor, $\mathrm{T}_{\mathrm{b}}$ is maintained near ambient temperature (Carey et al., 2003), while physiological functions such as heart rate and breathing rate may be reduced to as little as 3\% (Zatzman, 1984) and 1\% (McArthur and Milsom, 1991), respectively, relative to euthermic values. Along with these physiological adaptations during torpor, there is a reduction in immune function (Prendergast et al., 2002) and a reduction in metabolic rate to as low as just $1-5 \%$ of the corresponding euthermic rate (Geiser, 2004). Torpor arousal—whether it be interbout or exit out of hibernation at the end of the season-is dynamic (much quicker than torpor entry) and is usually 
accomplished within 20-30 minutes in small rodents. During this time, $\mathrm{T}_{\mathrm{b}}$ rises, initially driven via non-shivering thermogenesis (NST) in brown adipose tissue (BAT), and then skeletal muscle shivering is also initiated after $\mathrm{T}_{\mathrm{b}}$ reaches $\sim 20^{\circ} \mathrm{C}$; high rates of thermogenesis continue until the animal reaches normothermy, substrates are mobilized for energy production, and the cardiovascular system is stimulated (Carey et al., 2003).

\section{ii. $\quad$ Pre-hibernation adjustments}

Despite the fact that basal metabolic rates are reduced significantly during hibernation, species must build up sufficient fuel reserves to last them through the hibernating season which is often more than half the year. Some species opt to store food in their burrows and eat during interbout arousals, however many do not. For the latter individuals, hibernation is effectively a state of long term starvation and therefore metabolic adjustments must be made to meet essential energy demands. Hibernators, such as marmots and ground squirrels, go through a period of intense eating (hyperphagia) in the late summer and early fall months to prepare themselves for the hibernation season (Davis, 1976). During this period, body mass is increased by approximately $50 \%$ largely due to the deposition of triglycerides in white adipose tissue (WAT). Elevated activities of lipogenic enzymes support this preparatory phase. For example, fatty acid synthase (FAS) activity in hibernator lipogenic tissue is highest in the prehibernating phase, suggesting high rates of fatty acid (FA) synthesis (Anderson et al., 1989; Turner et al., 1989; Mostafa et al., 1993).

During the prehibernating fattening period, hormonal controls on lipid storage and satiety are modified. An important hormone that is associated with the buildup of adipose 
tissue is leptin, the satiety hormone. This hormone serves as a feedback controller by signaling the hypothalamus with information about body fat levels and energy balance (Ahima et al., 1996). Produced and secreted by adipose cells, its levels are normally positively correlated with body adiposity (Considine et al., 1996; Maffei et al., 1995). Because adiposity is expected to increase before hibernation, an increase in leptin would serve as a problem for hibernators since this hormone generally decreases food intake, increases energy expenditure, and decreases body mass. However, hibernating species are capable of building adipose tissue while circumventing the effects of leptin. Opposite of the normal response to increasing adiposity in nonhibernating species, research by Kronfeld-Schor et al. (2000) revealed that leptin secretion and sensitivity decreased during the prehibernating phase in little brown bats (Myotis lucifugus). These findings suggest that during the prehibernatory phase these animals somehow overcome the satiety and metabolic signals associated with leptin to deposit large fat stores.

Another key hormone that aids in the prehibernating fat storage period is insulin. As hyperphagic mammals ingest food, the pancreas secretes insulin-the key metabolic hormone that stimulates circulating blood glucose uptake, promotes glycogen anabolism, and stimulates the storage of excess fuel as fat. Previous research has shown that prior to hibernation, insulin levels are elevated and then fall during hibernation $(<1 \mathrm{ng} / \mathrm{ml})$ (Tokuyama et al. 1991; Buck et al., 2002). The increased levels of insulin serve to play an important role in triglyceride synthesis within WAT. The binding of insulin to adipocyte membrane receptors kicks off a cascade of events which includes both cyclic AMP (cAMP)-dependent and cAMP-independent pathways that decrease hormone-sensitive 
lipase (HSL) activity and thereby facilitate the accumulation of triglycerides (Stralsfor and Honner, 1989).

Along with modifications that promote fat storage, hibernators must be able to mobilize and utilize lipids at low $\mathrm{T}_{\mathrm{b}}$. Since lipid depots in most mammals have melting points (MPs) around $25^{\circ} \mathrm{C}$, these lipids would be solid and therefore be difficult to utilize at hibernating $\mathrm{T}_{\mathrm{b}}$ (Wang, 1979). With this in mind, lipid fluidity-which is largely dependent on the lipid degree of unsaturation (unsaturation is proportional to fluidity) —is an important factor in determining hibernation success. By eating a diet rich in mono unsaturated (ie. oleic acid [18:1]) and polyunsaturated fatty acids (PUFAs) (ie. linoleic acid [18:2] and $\alpha$-linolenic acid [18:3]) which have MPs in the range of 5 and $-6.5^{\circ} \mathrm{C}$, hibernating species are capable of incorporating these lipids into their triglycerides to create adipose fuel depots that can be mobilized over the wide range of $T_{b}$ values that they endure during their torpor-arousal periods (Harlow and Frank, 2001, Frank et al., 2008). Lipids are particularly important as fuels for the intense periods of thermogenesis by BAT and skeletal muscle that are necessary to rewarm the hibernator body to euthermia. Many questions still remain unexplored regarding lipid fluidity. For instance, the natural sensing mechanism for fat depot PUFA content remains unknown as well as how the fluidity of phospholipids in membranes is adjusted to maintain functionality at the low $\mathrm{T}_{\mathrm{b}}$ values endured during hibernation.

During the brief interbout arousal phases of hibernators, carbohydrate oxidation reasserts itself as a main source of fuel for energy production in most tissues as indicated by a respiratory quotient (RQ; the ratio of the volume of carbon dioxide eliminated to the volume of oxygen consumed by an animal) that increases to a value near 1 . As reported by 
Carey et al. (2003), RQ values during hibernation fall to a value closer to 0.7 , indicating a switch to lipid oxidation to meet energy demands. Given the fact that during arousal RQ values are around 1 and, that protein catabolism is unfavourable for energy production, it is expected that proteolysis and amino acid catabolism is generally limited throughout hibernation.

\section{iii. Hibernation}

Successful hibernation is sensitive not only to the quantity of stored fat but also the quality of stored fat. Various studies have shown that torpor-arousal cycles either do not occur or are disturbed if fat stores are insufficient or if the amounts of necessary fatty acids are too low (Cranford, 1978; Geiser et al., 1994; Frank, 1992; Florant, 1992; Florant et al., 1993). Other than tissues that are highly specialized to use carbohydrates as fuels (e.g. brain, red blood cells), most carbohydrate metabolism is spared in hibernator organs during torpor. The switch from carbohydrate to lipid metabolism has been confirmed via studies measuring glycolytic, lipogenic, and lipolytic enzyme activities. First, research by Brooks and Storey (1992) suggested that the covalent modification of liver glycogen phosphorylase in the golden-mantled ground squirrels (Callospermophilus lateralis) during hibernation decreased enzymatic activity and thereby limited the amount of available glucose in blood. Furthermore, this research found that pyruvate dehydrogenase $(\mathrm{PDH})$ activity in heart and kidney was dramatically decreased during hibernation, implicating a strong inhibition of carbohydrate oxidation during torpor. Secondly, research by Frank et al. (1998) showed that liver FAS activity in the black-tailed prairie dog (Cynomys ludovicianus) is reduced during hibernation, limiting the overall rate of fatty acid synthesis. Last, the restoration of HSL activity, along with the activity of pancreatic 
triacylglycerol lipase (PTL) in WAT during hibernation further supports the importance of lipids for energy production while torpid (Bauer et al., 2001). Together, these findings suggest that glycolysis is suppressed and there is a greater dependence on fuel metabolism based primarily on lipid oxidation during hibernation.

During hibernation, blood glucose and insulin levels are reduced and are lowest during mid-winter due to halted food intake during dormancy (Bauman et al., 1987). Previous research has shown that the phosphoinositide-3-kinase (PI3K)-Akt pathway is mediated by insulin binding to insulin receptors and during hibernation, as insulin levels decrease, PI3K mediated activation of Akt is suppressed (Cai et al, 2004, Abnous et al., 2008). The resulting downstream events of suppressed Akt signaling include decreases in both glycogen synthesis and lipogenesis (Porstmann et al. 2008; Laplante and Sabatini, 2010). The drop in insulin levels and subsequent decrease in glucose uptake by tissues, combined with the down regulation of several glycolytic enzymes, serve as important factors in the reduced glycolytic output during hibernation.

One might expect that to make up for the decrease in plasma glucose levels during hibernation that glucagon activity would be stimulated. However, previous research in ground squirrels suggests that glucagon levels remain constant in hibernators (Bauman et al., 1987). Furthermore, this finding suggests that the plasma glucagon to insulin ratio is increased during hibernation which may in turn have an influence in the shift of fuel usage during this period. Most notably, glucagon activates protein kinase A (PKA) that in turn phosphorylates many metabolic enzymes. For example, glucagon acts on WAT to active PKA mediated phosphorylation of HSL (Moreau-Hamsany et al., 1988). The activation of PKA by glucagon also leads to the phosphorylation and subsequent inhibition of pyruvate 
kinase (PK) (Pilkis and Claus, 1991). Furthermore, glucagon inhibits PK mRNA transcription as well as increases degradation of existing PK mRNA (Pilkis and Claus, 1991). The combination of glycolytic suppression and lipolysis activation during hibernation leads to an increase in circulating plasma FAs and facilitates the reorganization of fuel metabolism to favour a heavy reliance on lipid catabolism.

\section{iv. Interbout Arousal}

Much of the stored fuel used by hibernators is consumed for thermogenesis during the periodic arousals. It is estimated that the re-warming process and the time spent in short periods of arousal consume approximately $40-70 \%$ of the energy budget for the whole hibernation season (Wang, 1979). As stated previously, lipid oxidation is thought to mediate the initial steps of the rewarming process, with increased reliance on carbohydrates usage as $\mathrm{T}_{\mathrm{b}}$ rises. A shift in RQ from 0.7 to $>0.85$ during the short interbout arousal periods supports the idea of increased carbohydrate usage (Buck and Barnes, 2000; Karpovich et al., 2009). Furthermore, interbout arousal periods occur in all hibernating species and are essential for survival; however, their function is still debated. Current theories as to why periodic arousals occur include: the necessity to restore metabolic imbalances accruing at low $\mathrm{T}_{\mathrm{b}}$, to restore sleep patterns, and to reactivate the immune system to fight any pathogens that have accumulated during hibernation (French, 1985; Daan et al., 1991; Prendergast et al., 2002).

\section{Reversible Post-translational Modifications}

Many cellular proteins are altered by covalent modifications after they are translated. The covalent addition of different functional groups to a protein alters its structural properties and may influence its functionality also. With more than 30 post- 
translational modifications (PTMs) known to date, the combinatory effects of various PTMs make the proteome one of the most dynamic biological systems.

Probably the most studied post-translational modification in mammals is reversible protein phosphorylation (RPP). RPP is a major mechanism used for regulatory control proteins involved in virtually every cellular process (Storey and Storey, 2004a). Protein kinases and protein phosphatases mediate the addition and removal of a phosphate group, respectively, to specific serine, threonine or tyrosine residues of a target protein. In this way, fine tuning by phosphorylation/dephosphorylation serves as quick, energetically cheap (relative to the cost of gene expression) method that can have profound effects on a protein's biological activity, interaction with other proteins, stability, movement between subcellular compartments, or cellular fate (Cohen, 2002). The dynamic nature of this process helps explain why almost all eukaryotic cells utilize reversible phosphorylation as a general regulatory mechanism. Studies in our lab have demonstrated that reversible phosphorylation is a crucial regulatory mechanism in animal responses to several types of environmental stress (Storey and Storey, 2004a), including mammalian hibernation (MacDonald and Storey, 1999; Bell and Storey, 2010; Bell et al., 2014). For example, RPP alters the activity of $\mathrm{Na}^{+} / \mathrm{K}^{+}$ATPase to help reduce energy expenditure during global metabolic rate depression (MacDonald and Storey, 1999), controls PDH activity to regulate carbohydrate oxidation (Tessier et al., 2015), regulates amino acid metabolism at glutamate dehydrogenase (Thatcher and Storey, 2001; Bell and Storey, 2010), regulates multiple cell signaling cascades and transcription factors (Luu et al., 2014; Cowen and Storey, 2003; and reviewed in Tessier and Storey, 2014), contributes to cell cycle suppression (Wu and Storey, 2012), etc. 


\section{Model Animal}

Richardson's ground squirrel (Urocitellus richardsonii) is the hibernator model used in this thesis. Also known as prairie gophers, this species can be found in portions of Manitoba, Saskatchewan, Alberta, North Dakota, South Dakota, Montana, and Minnesota. The diet of Richardson's ground squirrels consists of seeds, insects, flowers, and leaves. The weight of these ground-dwelling, burrowing mammals varies between 0.2 and 0.4 kilograms when they are euthermic and as high as 0.75 kilograms when they enter hibernation. Their meandering burrows are approximately 3.5 inches in diameter, $4-5$ feet below the surface, and span 15-20 meters in length. Richardson's ground squirrels hibernate alone in a chamber called a hibernaculum. The hibernation season of these species varies between males and females since the males generally come out of torpor 816 days earlier than female squirrels (Michener, 1983); however, on average, this species hibernates for 7-9 months, beginning in September and ending as late as May. My research in this thesis is focused on enzyme regulation in liver and skeletal muscle tissue of Richardson's ground squirrels comparing euthermic and torpid animals to assess changes the enzyme properties as a function of hibernation.

\section{Target tissues}

\section{Skeletal Muscle}

Both long periods of inactivity and limited fuel availability are two problems that skeletal muscle must manage when a species enters a hibernating state. In non-hibernating species (including man), long periods of inactivity such as occur during torpor would lead to significant atrophy of skeletal muscle. However, hibernators experience much less 
muscle atrophy during torpor than would be expected from such prolonged periods of inactivity. Research by Wicker et al. (1991), measured muscle mass and levels of an enzyme whose activity reflects aerobic capacity, citrate synthase (CS), in hibernating golden-mantled ground squirrels. Their results indicated that mass-specific activity of this enzyme increased in the hibernating state (Wicker et al., 1991). Although CS may not contribute to strength of skeletal muscle directly, it serves to help preserve mechanisms associated with heat production required during the arousal rewarming process (Wicker et al., 1991). As shivering thermogenesis commences during the rewarming process in hibernators, heart rate drastically increases. With that in mind, muscles that are well supplied with blood oxygen and both white and red fibers contribute to heat production (Ambid and Agid, 1975; Feist, 1970; Lyman, 2013). Research by Postnikova et al. (1999) revealed that a very high myoglobin content in muscle of hibernators relative to their nonhibernator counterparts can contribute to the explosive rewarming process during arousal. Furthermore, to support muscle contractility and shivering thermogenesis during hibernation, both of which involve ATP hydrolysis by myosin ATPase, Fahlman et al. (2000) reported hibernation-responsive up-regulation of the transcript levels of myosin light chain $1\left(\mathrm{MLC1}_{\mathrm{v}}\right)$ in skeletal muscle of hibernating golden-mantled ground squirrels. Up-regulation of the expression of gene products coding for metabolic proteins also occurs in skeletal muscle during hibernation. The up-regulation of FA binding protein (FABP) and PDH kinase isoenzyme 4 (PDK4) suggest that hibernator skeletal muscle relies on enhanced lipid metabolism during torpor (Hittel and Storey, 2001; Buck et al., 2002). These data indicate that adaptive changes to selected cellular functions in skeletal muscle are required for successful hibernation. 
ii. Liver

The liver is a vital organ that plays a major role in coordinating and regulating a wide range of functions that affect the whole body - these include detoxification reactions, protein synthesis, glycogen storage, and hormone production. It should be expected that during hibernation, important metabolic changes occur in liver tissue to meet new cellular demands. Many of the lipolytic enzymes and proteins involved FA transport are synthesized in the liver. Regulation of these proteins is essential as hibernators rely largely on the triacylglycerol fuels stored in adipose tissue during winter dormancy. Like in hibernator skeletal muscle, FABP activity and expression increases during torpor in hibernator liver (Stewart et al., 1998; Epperson et al., 2004).

\section{Hypotheses}

Given the well documented changes in carbohydrate and lipid metabolism between various stages of hibernation, I propose that the metabolism of these fuels is regulated at the enzyme level in Richardson's ground squirrel skeletal muscle and liver. Furthermore, I propose that reversible post-translational modification which serves as a rapid, energetically feasible mechanism of enzyme control plays an important role in optimizing the structural and functional properties of metabolic enzymes as they switch between euthermic and hibernating states. Two main hypotheses guide the research in this thesis:

1. In a depressed metabolic state, Richardson's ground squirrels will modify the key glycolytic enzyme, $\mathrm{LDH}$, in a way that decreases its enzymatic activity. 
2. In a depressed metabolic state, glycerol-3-phosphate dehydrogenase (G3PDH), a key enzyme connecting lipid metabolism and carbohydrate metabolism, will be activated as indicated by an increase in enzymatic activity.

\section{Objectives}

The torpor bouts that occur during the hibernation season are highly regulated events that not only include physiological changes but also metabolic plasticity to support long term survival at low $\mathrm{T}_{\mathrm{b}}$ in the absence of food intake. One aspect of metabolic regulation in a mammalian hibernator that has not been studied is the role that posttranslational modifications can play in the differential function of central dehydrogenase enzymes between euthermic and hibernating states. Research in this thesis explores this by investigating the structural, functional, and regulatory properties of skeletal muscle LDH and liver and muscle G3PDH. LDH converts pyruvate and (reduced $\beta$-Nicotinamide adenine dinucleotide) NADH, two products of glycolysis, to lactate and $\mathrm{NAD}^{+}$when oxygen is absent or in short supply. Chapter 2 presents an analysis of this important enzyme associated with carbohydrate metabolism to provide us with a more clear understanding of the state of glycolysis during ground squirrel hibernation.

G3PDH is an important enzyme that connects lipid metabolism to carbohydrate metabolism - by catalyzing the reversible conversion of glycerol-3-phosphate (G3P) and $\mathrm{NAD}^{+}$to dihydroxyacetone phosphate (DHAP) and NADH. With increase importance of lipid catabolism during hibernation, examination of this enzyme is of interest to determine its potential differential regulation during ground squirrel torpor. Studies of this enzyme from liver and muscle of euthermic and hibernating ground squirrels are present in Chapters 3 and 4, respectively. 
Overall, the studies in this thesis are aimed to elucidate the structural and functional properties of key metabolic enzymes in skeletal muscle and liver during hibernation. A greater understanding of how these enzymes are regulated can add to previous research conducted on the metabolic adaptations that hibernating species undergo as part of this unique mammalian survival strategy. 


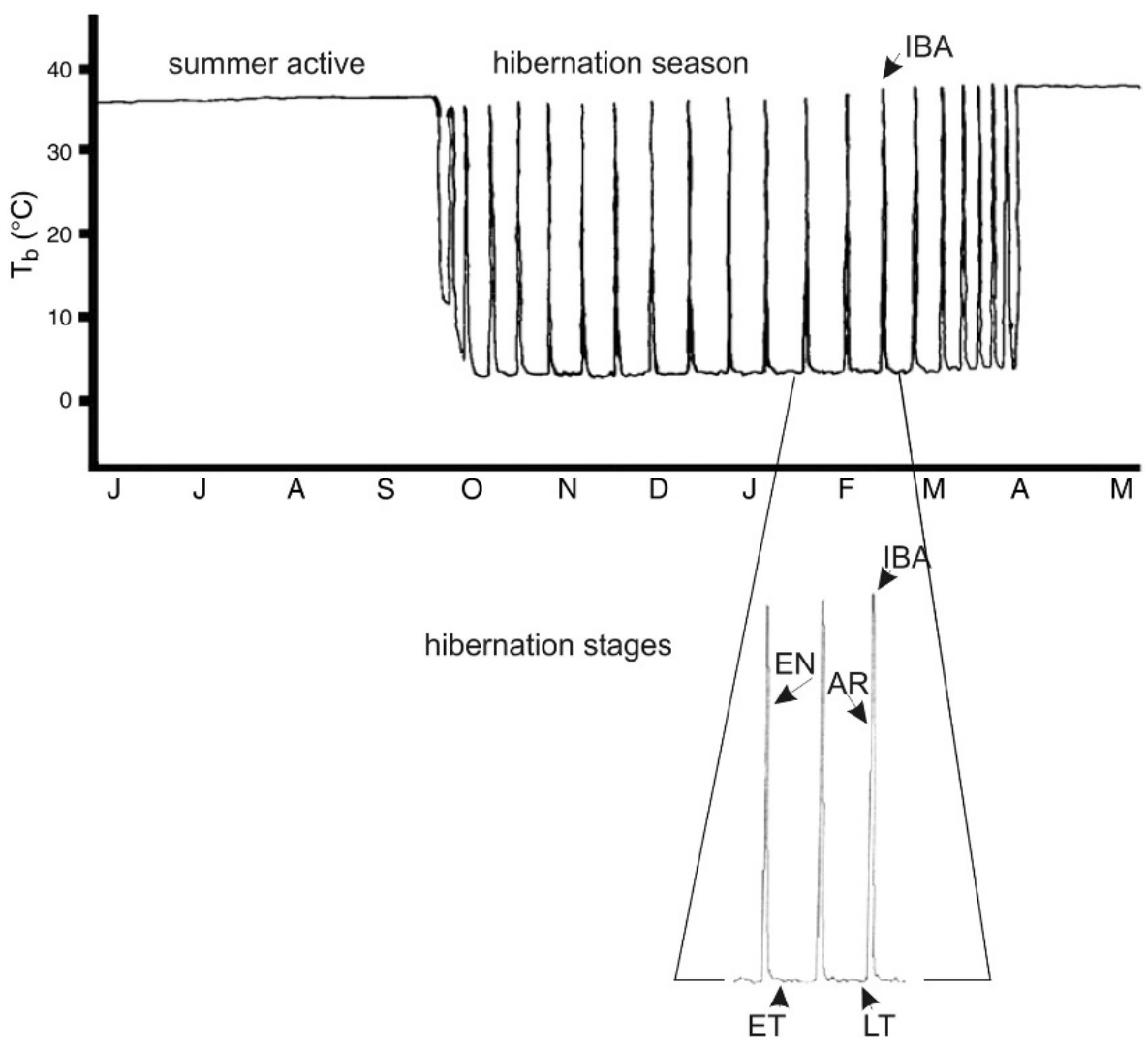

Figure 1.1. Body temperature as a function of time over one year starting in June for a golden-mantled ground squirrel (Callospermophilus lateralis). Inset depicts the entrance into torpor (EN), early torpor (ET), late torpor (LT), arousal (AR), and interbout arousal (IBA) (Taken from Carey et al., 2003). 


\section{Chapter 2}

\section{Purification and Properties of Lactate Dehydrogenase from the Skeletal Muscle of the Hibernating Ground Squirrel, Urocitellus richardsonii}




\section{Introduction}

Lactate dehydrogenase (LDH; E.C. 1.1.1.27), the terminal enzyme of anaerobic glycolysis, catalyzes the following reversible reaction:

$$
\text { L-lactate }+\mathrm{NAD}{ }^{+} \leftrightarrow \text { pyruvate }+\mathrm{NADH}+\mathrm{H}^{+}
$$

LDH plays a critical role in energy metabolism as it facilitates the production of ATP via glycolysis during low oxygen conditions by recycling the essential coenzyme $\mathrm{NAD}^{+}$ (nicotinamide adenine dinucleotide). Skeletal muscle (particularly white muscle fibers) is a tissue that relies heavily on carbohydrate catabolism to produce ATP and power intense muscle work. Here, the LDH reaction favours lactate formation using the pyruvate and NADH output of glycolysis (Hochachka and Somero, 2014).

During mammalian hibernation, greater emphasis is placed on lipid oxidation to meet energy demands, and ATP generation via carbohydrate catabolism is thought to be suppressed (Buck and Barnes, 2000; Tashima et al., 1970). Mitochondria instead rely on acetyl-CoA generated from lipid breakdown as the main source of carbon to supply the Krebs cycle. Previous research has shown that pyruvate dehydrogenase (PDH) is regulated during hibernation showing heavy suppression to strongly limit entry into the Krebs cycle by carbohydrate coming from glycolysis (Brooks and Storey, 1992). With this in mind, it is proposed that other fates for glycolytic carbon could also be suppressed during hibernation which could include regulation of LDH to help minimize/coordinate the glycolytic rate and limit lactate buildup in hibernating mammals.

The LDH reaction has long been known to play a major role in cellular redox balance, being responsible for regenerating the $\mathrm{NAD}^{+}$needed to allow anaerobic glycolysis to run. More recently, intracellular $\mathrm{NAD}^{+}$has been shown to play a major role as a 
metabolite capable of regulating the transcription of genes associated with metabolism and circadian rhythms (Cantó et al., 2009; and reviewed in Takahashi et al., 2008; Chaudhary and Pfluger, 2009). Specifically, new research on NAD-dependent deacetylase sirtuin-1 (SIRT1), a protein that regulates circadian genes (Asher et al., 2008), shows that the activity of this enzyme is activated by $\mathrm{NAD}^{+}$(Imai et al., 2000). These discoveries could tie together cellular nutrient status, metabolic substrate use, and metabolic plasticity during hibernation.

Richardson's ground squirrels, Urocitellus richardsonii, have an amazing ability to survive winter conditions-marked by harsh environmental temperatures and low food availability - by entering into hibernation. While in this hypometabolic state, core body temperature $\left(\mathrm{T}_{\mathrm{b}}\right)$ falls (often to as low as $0-5{ }^{\circ} \mathrm{C}$ ), and there is a strong suppression of all physiological processes (e.g. heart rate and breathing rate), suppression of aerobic cellular respiration, a reprioritization of energy expensive processes (e.g. transcription, translation, and ion pumping), and reorganization of fuel metabolism (McArthur and Milsom, 1991; Zatman, 1984; and reviewed in Carey et al., 2003, Staples and Brown, 2008, Storey and Storey, 2004b; Geiser, 2004).

Reversible phosphorylation of functional proteins and enzymes is a major regulatory mechanism that mediates the plasticity of metabolic reactions when animals enter hypometabolic states. This process has been studied extensively in hibernating species, with ion motive ATPases (MacDonald and Storey, 1999), glycolytic enzymes (Brooks and Storey, 1992), ribosomal proteins (van Breukelen et al., 2004), and transcription factors (reviewed in Carey et al., 2003; Storey, 1997) all showing differential regulation via reversible phosphylation. 
In this chapter, I reasoned that the transition from active euthermia to a low $\mathrm{T}_{\mathrm{b}}$, hibernating state should lead to control of $\mathrm{LDH}$ in a manner that promotes $\mathrm{NAD}^{+}$ production. Previous research has shown that during entrance in to torpor, $\mathrm{NAD}^{+}$levels increase (Serkova et al. 2011). Furthermore, this signaling molecule has been shown to upregulate proteins that aid in torpor survival (reviewed in Melvin and Andrews, 2009). Despite an overall decrease in carbohydrate catabolism, maintenance of NAD ${ }^{+}$levels could have profound effects that allow ground squirrels to survive throughout the hibernating season. Furthermore, such control could contribute to the reorganization of fuel metabolism to favor lipid oxidation, thereby allowing fat catabolism to contribute to energy needs during torpor.

In a previous study, Dawson et al. (2013) documented significant differences in the kinetic and physical properties of purified white muscle LDH from of normoxic versus anoxic red-eared sliders, Trachemys scripta elegans, due to reversible protein phosphorylation. The present study demonstrates that ground squirrel skeletal muscle LDH is also regulated by reversible protein phosphorylation. Furthermore, the changes in the phosphorylation state of LDH occurring during hibernation make significant changes to the enzyme's structural and functional properties.

\section{Materials and Methods}

\section{Animals}

The protocols used for care and handling of Richardson's ground squirrels, $U$. richardsonii, were as reported previously (MacDonald and Storey, 1998; Thatcher and Storey, 2001). Briefly, animals were captured in late summer near Calgary, Alberta. All 
animals were individually housed in rat cages with free access to food and water at $22^{\circ} \mathrm{C}$ and on an autumn photoperiod (10 h light, $14 \mathrm{~h}$ dark). After 8 weeks under this regime, half of the animals were maintained under these control (euthermic) conditions. The others were moved into a $4^{\circ} \mathrm{C}$ cold room that was maintained in darkness; free access to water was maintained but food was removed. Squirrels were allowed to enter torpor and animals were sampled after $2 \mathrm{~d}$ continuous torpor (rectal temperature $5-8^{\circ} \mathrm{C}$ ). Euthermic animals were sampled on the same day. Both hibernating and euthermic animals were killed by decapitation and tissues were immediately excised, frozen in liquid nitrogen and then stored in $-80^{\circ} \mathrm{C}$.

\section{Preparation of tissue extracts}

Frozen hind leg skeletal muscle samples were homogenized 1:5 w:v in buffer A (20 mM potassium phosphate, $\mathrm{pH}$ 7.2, 1 mM EDTA, 1 mM EGTA, 15 mM $\beta$-glycerophosphate ( $\beta$-GP), $15 \mathrm{mM} \beta$-mercaptoethanol ( $\beta$-MeSH), $10 \% \mathrm{v}: \mathrm{v}$ glycerol) and a few crystals of phenylmethylsulphonyl fluoride (PMSF) (added just prior to homogenization) using a Polytron homogenizer (Brinkmann Instruments, Rexdale, ON, Canada). Homogenates were centrifuged at $10,000 \times \mathrm{g}$ for 30 minutes at $5^{\circ} \mathrm{C}$, after which supernatants were decanted and held on ice until use.

\section{Purification of LDH}

A $1.5 \mathrm{~mL}$ sample of muscle extract containing $\sim 28 \mathrm{mg}$ of total protein was applied to a $\mathrm{DEAE}^{+}$column $(1 \mathrm{~cm}$ [Diameter] $\mathrm{x} 5 \mathrm{~cm}$ [Height] $)$ previously equilibrated in buffer $\mathrm{A}$. The column was then washed with $30 \mathrm{~mL}$ of buffer $\mathrm{A}$ and $4 \mathrm{~mL}$ fractions were collected. From each fraction, a small aliquot was diluted 1:10 v:v in buffer $\mathrm{A}$ and then $2 \mu \mathrm{L}$ from each 
diluted fraction was assayed to detect LDH activity. The active fractions were pooled and applied to a Cibacron Blue 3GA (Sigma-Aldrich) column (1 x $5 \mathrm{~cm})$ equilibrated with buffer A. The Cibacron Blue 3GA column was washed with $30 \mathrm{~mL}$ of buffer A to remove unbound proteins and then a linear gradient of $0-6 \mathrm{mM}$ sodium pyruvate and NADH was applied to elute bound proteins. Fractions of $1.20 \mathrm{~mL}$ were collected and $5 \mu \mathrm{L}$ from each fraction was assayed to detect LDH activity. After fractions containing maximal LDH activity were pooled, low molecular weight metabolites were removed from the sample via centrifugation (2 min @ 2000 rpm) through small columns of Sephadex G-25 (SigmaAldrich) equilibrated in buffer A. The sample was then loaded on to a second Cibacron Blue 3GA column $(1 \times 5 \mathrm{~cm})$ in a similar fashion, although in this case proteins were eluted with a linear gradient of $0-2 \mathrm{M} \mathrm{KCl}$ in buffer $\mathrm{A}$. The fractions were assayed for $\mathrm{LDH}$ activity, and the active fractions were pooled and desalted using an Amicon® Ultra Filter (Millipore). The purity of the LDH sample was checked by denaturing and reducing gel electrophoresis followed by silver staining as described below. LDH from the muscle tissue of euthermic and hibernating ground squirrels were purified in the same manner.

\section{Detection of LDH via Silver Staining Technique}

Silver staining procedure was adapted from Blum et al. (1987). In short, after electrophoresis, the SDS-polyacrylamide gel was incubated for 3 hours in fixing solution containing $50 \%(\mathrm{v} / \mathrm{v})$ methanol, $12 \%(\mathrm{v} / \mathrm{v})$ acetic acid, and $0.05 \%(\mathrm{v} / \mathrm{v})$ formalin $(35 \%$ formaldehyde). Next, the fixative solution was discarded and the gel was washed in $20 \%$ $(\mathrm{v} / \mathrm{v})$ methanol $(3 \times 6 \mathrm{~min})$ before incubating with the sensitizing solution $[0.02 \%(\mathrm{w} / \mathrm{v})$ sodium thiosulphate $\left.\left(\mathrm{Na}_{2} \mathrm{~S}_{2} \mathrm{O}_{3}\right)\right]$ for 2 minutes. The sensitizing solution was discarded and the gel was washed ( $2 \times 1 \mathrm{~min})$ with $\mathrm{ddH}_{2} \mathrm{O}$. Next, the gel was incubated in cold silver stain 
[0.6\% (w/v) silver nitrate, $0.076 \%(\mathrm{v} / \mathrm{v})$ formalin] with gentile shaking for 20 minutes. The silver stain was then discarded and the gel was washed $(2 \times 30 \mathrm{sec})$ with $\mathrm{ddH}_{2} \mathrm{O}$ followed by addition of developing solution $\left[6 \%(\mathrm{w} / \mathrm{v})\right.$ sodium carbonate $\left(\mathrm{Na}_{2} \mathrm{CO}_{3}\right), 0.04 \%(\mathrm{w} / \mathrm{v})$ sodium thiosulphate $\left(\mathrm{Na}_{2} \mathrm{~S}_{2} \mathrm{O}_{3}\right), 0.05 \%$ (v/v) formalin] to the gel. Once desired band intensity on the gel was reached, developing was stopped by adding a terminating solution $[12 \%(\mathrm{v} / \mathrm{v})$ acetic acid] to the gel. Lastly, bands on the gel were visualized under light and an image was captured using a ChemiGenius BioImaging system with GeneSnap software (Syngene, Frederick, MD, USA).

\section{LDH assay}

LDH activity was measured as the rate of production or consumption of NADH using a microplate based assay by measuring absorbance at $340 \mathrm{~nm}$ using a Thermo Labsystems Multiskan spectrophotometer (Thermo Scientific, Waltham, MA, USA). Optimal assay conditions for $\mathrm{LDH}$ in the lactate-oxidizing direction were $30 \mathrm{mM}$ potassium phosphate buffer ( $\mathrm{pH} 7.5$ / 8.0), $60 \mathrm{mM}$ L-lactate, and $2 \mathrm{mM} \mathrm{NAD}^{+}$in a total volume of $200 \mu \mathrm{L}$ with $5 \mu \mathrm{L}$ of purified enzyme added to start the assay. The optimal conditions for $\mathrm{LDH}$ in the pyruvate-reducing direction were $30 \mathrm{mM}$ potassium phosphate, $1 \mathrm{mM}$ pyruvate, and $0.2 \mathrm{mM} \mathrm{NADH}$ in a total volume of $200 \mu \mathrm{L}$ with $2 \mu \mathrm{L}$ of purified LDH. The $K_{m}$ and $I C_{50}$ values for lactate, $\mathrm{NAD}^{+}$or pyruvate were determined by holding the co-substrate constant at $2 \mathrm{mM} \mathrm{NAD}+60 \mathrm{mM}$ lactate, or $0.2 \mathrm{mM} \mathrm{NADH}$. All kinetic analyses were conducted at $5^{\circ} \mathrm{C}, 22^{\circ} \mathrm{C}$, and $37^{\circ} \mathrm{C}$ in phosphate buffer at $\mathrm{pH} 7.5$ and 8.0. 


\section{SDS Polyacrylamide Gel Electrophoresis and Immunoblotting}

After concentrating 5x using a Amicon® Ultra Filter (Millipore), purified euthermic and hibernating LDH samples were mixed 1:1 (v:v) with SDS loading buffer (100 mM Tris buffer, pH 6.8, 4\% w:v SDS, 20\% v:v glycerol, $0.2 \% \mathrm{w}: \mathrm{v}$ bromophenol blue, and $10 \% \mathrm{v}: \mathrm{v} \beta-\mathrm{MeSH}$ ) and boiled for 5 minutes, cooled on ice and frozen at $-20^{\circ} \mathrm{C}$ until use. SDS resolving gels (10\% v/v acrylamide, $400 \mathrm{mM}$ Tris, $\mathrm{pH} 8.8,0.1 \% \mathrm{w} / \mathrm{v}$ SDS, $0.2 \%$ w/v ammonium persulfate [APS], $0.04 \% \mathrm{v} / \mathrm{v}$ TEMED) were prepared with a $5 \%$ stacking gel (5\% acrylamide, $190 \mathrm{mM}$ Tris, $\mathrm{pH} 6.8,0.1 \%$ w/v SDS, 0.15\% w/v APS, $0.1 \%$ v/v TEMED). Purified samples were loaded onto these gels and separated electrophoretically in SDS-PAGE running buffer (25 mM Tris-base, $\mathrm{pH} 8.5,190 \mathrm{mM}$ glycine, and $0.1 \% \mathrm{w} / \mathrm{v}$ SDS) at $180 \mathrm{~V}$ for $45 \mathrm{~min}$. A $2 \mu \mathrm{L}$ aliquot of protein ladder (FroggaBio) was added to one lane of every gel to provide molecular weight markers. Commercially purified rabbit muscle LDH (Boehringer Mannheim) was also loaded onto the gel to confirm the correct location of LDH subunits. Following electrophoresis, proteins were electroblotted onto polyvinylidiene difluoride (PVDF) membranes (Millipore) by wet transfer and used for immunoblotting.

PVDF membranes were equilibrated in methanol before the wet transfer of proteins from $10 \%$ SDS gels. Electroblotting was performed in transfer buffer (25 mM Tris, pH 8.5, $192 \mathrm{mM}$ glycine, and $20 \% \mathrm{v} / \mathrm{v}$ methanol) at room temperature for $1.5 \mathrm{~h}$ at $160 \mathrm{~mA}$. Following protein transfer, PVDF membranes were blocked with 5.0\% skim milk for 10 minutes. Membranes were washed three times with Tris-buffered saline (100 mM Trisbase, $140 \mathrm{mM} \mathrm{NaCl}$, pH 7.6) containing 0.05\% Tween-20 (TBST) for 5 min each before one of the following primary antibodies (all from Invitrogen, Carlsbad, CA, USA) were 
applied: (1) rabbit anti-phosphoserine (Cat. \#618100); (2) rabbit anti-phosphothreonine (Cat. \#718200); (3) rabbit anti-phosphotyrosine (Cat. \#615800). All primary antibodies were diluted 1:1000 v:v in TBST with a small amount of sodium azide added. Primary antibodies were applied to membranes and allowed to incubate overnight at $4^{\circ} \mathrm{C}$ with gentle rocking. Membranes were washed with TBST ( $3 \mathrm{x} 5 \mathrm{~min})$, and incubated with a 1:2000 v:v dilution of goat anti-rabbit IgG-peroxidase secondary antibody for $60 \mathrm{~min}$ at room temperature. Blots were washed with TBST ( $3 \times 5 \mathrm{~min})$ prior to chemiluminescence visualization on the ChemiGenius Bioimaging System (Syngene, Frederick, MD, USA). The band intensities were quantified using GeneTools software (Syngene, Frederick, MD, USA). To confirm equal protein loading of samples, Coomassie blue staining was subsequently performed on the membranes and used to standardize immunoblot band intensities. Protein-standardized band intensities for hibernator LDH were then expressed relative to the standardized signal intensities for control LDH samples.

\section{In vitro Incubations that Stimulate Protein Kinases or Protein Phosphatases}

Crude muscle extracts were prepared as described above, and then subsequently filtered through a small G-50 Sephadex column that had been pre-equilibrated in buffer B (25 mM potassium phosphate, 10\% v:v glycerol, $15 \mathrm{mM}$ 2-mercaptoethanol, $\mathrm{pH}$ 7.0). Aliquots of the filtered supernatants were incubated overnight at $4^{\circ} \mathrm{C}$ with specific inhibitors and stimulators of protein kinases or protein phosphatases, as described in MacDonald and Storey (1999). Aliquot from extracts of both control and hibernator muscle were mixed 1:2 v:v with the following additions: 
a. STOP condition (inhibits all protein kinases and protein phosphatases): $2.5 \mathrm{mM}$ EGTA, $2.5 \mathrm{mM}$ EDTA and $30 \mathrm{mM} \beta$-glycerophosphate.

b. Stimulation of total endogenous kinases (TKin): $30 \mathrm{mM} \beta$-glycerophosphate, 2 mM AMP, 2 mM cAMP, 10 mM ATP, 2 mM cGMP, 2.6 mM CaCl $2,14 \mu \mathrm{g} / \mathrm{mL}$ phorbol myristate acetate, $20 \mathrm{mM} \mathrm{MgCl}_{2}$ and $10 \mathrm{mM} \mathrm{Na}_{3} \mathrm{VO} 4$.

c. Stimulation of total endogenous phosphatases (TPPase): $10 \mathrm{mM} \mathrm{MgCl} 2$ and 10 $\mathrm{mM} \mathrm{CaCl}$.

d. Stimulation of endogenous AMP-activated kinase (AMPK): 1 mM AMP, 5 mM ATP, $10 \mathrm{mM} \mathrm{MgCl} 2,30 \mathrm{mM} \beta$-glycerophosphate, $5 \mathrm{mM} \mathrm{Na} \mathrm{VO}_{4}$.

e. Stimulation of endogenous calcium-calmodulin dependent kinase (CaMK): 1 $\mathrm{U}$ of calf intestine calmodulin, $1.3 \mathrm{mM} \mathrm{CaCl}_{2}, 5 \mathrm{mM}$ ATP, $10 \mathrm{mM} \mathrm{MgCl}$, 30 $\mathrm{mM} \beta$-glycerophosphate, $5 \mathrm{mM} \mathrm{Na} 3 \mathrm{VO}_{4}$.

f. Stimulation of endogenous cyclic-AMP dependent protein kinase (PKA): 1 mM cAMP, 5 mM ATP, $10 \mathrm{mM} \mathrm{MgCl} 2,30 \mathrm{mM} \beta$-glycerophosphate, $5 \mathrm{mM}$ $\mathrm{Na}_{3} \mathrm{VO}_{4}$.

g. Stimulation of endogenous cyclic-GMP dependent protein kinase $\mathrm{G}(\mathrm{PKG})$ : 1 mM cGMP, 5 mM ATP, 10 mM MgCl 2,30 mM $\beta$-glycerophosphate, $5 \mathrm{mM}$ $\mathrm{Na}_{3} \mathrm{VO}_{4}$.

h. Stimulation of endogenous protein phosphatases $1+2 \mathrm{~A}(\mathrm{PP} 1+\mathrm{PP} 2 \mathrm{~A}): 2 \mathrm{mM}$ EDTA, 2 mM EGTA, $30 \mathrm{mM} \mathrm{Na}_{3} \mathrm{VO}_{4}$.

i. Stimulation of endogenous protein phosphatase 2B (PP2B): 2 mM EDTA, 1 $\mu \mathrm{M}$ okadaic acid, $5 \mathrm{mM} \mathrm{Na} \mathrm{VO}_{4}$. 
j. Stimulation of endogenous protein phosphatase 2C (PP2C): 2 mM EGTA, 1 nM cypermethrin, $1 \mu \mathrm{M}$ okadaic acid, $5 \mathrm{mM} \mathrm{Na}_{3} \mathrm{VO}_{4}$.

After incubation, LDH activities were analyzed in the lactate-oxidizing direction as described above $\left(30 \mathrm{mM}\right.$ potassium phosphate buffer, $\mathrm{pH} 8.0,2 \mathrm{mM} \mathrm{NAD}{ }^{+}$, and varying lactate) and $K_{m}$ lactate values for $\mathrm{LDH}$ were determined and compared to the STOP condition.

\section{Data Analyses}

Maximal $\mathrm{LDH}$ activity was determined at $5^{\circ} \mathrm{C}, 22^{\circ} \mathrm{C}$ and $37^{\circ} \mathrm{C}$. The reaction temperature was altered by placing the Thermo Labsystems Multiskan spectrophotometer into a VWR International BOD 2020 Incubator (Sheldon Manufacturing Inc., Oregon USA) set to the desired temperature. Microplates filled with assay mixture (excluding the enzyme) were equilibrated in the same incubator for several minutes until the desired temperature was reached (as measured by a telethermometer). Plates were then placed into the spectrophotometer and reactions were initiated by the addition of enzyme.

Protein concentrations of all samples and fractions were measured using the BioRad protein assay dye reagent (Bio-Rad, Hercules, CA, USA) with serial dilutions of bovine serum albumin as the standard according to the manufacturer's instructions. Enzyme activities were analyzed with a Microplate Analysis program (Brooks, 1994) and kinetic parameters were determined using a nonlinear least squares regression computer program (Kinetics v. 3.51) fully described in (Brooks, 1992). All points were fitted to a curve determined by the Hill equation $(\mathrm{h}>0)$ within the Kinetics program. Data are expressed as mean \pm S.E.M. from multiple independent determinations of kinetic parameters on separate preparations of enzyme. Data for euthermic versus hibernating 
comparisons, $\mathrm{pH}$ comparisons, and western blots were analyzed using the Student's t-test (two-tailed). Data for kinetic parameters in response to temperature changes were analyzed using one-way analysis of variances (ANOVAs) followed by a Tukey post hoc test. A probability value of $<0.05$ was considered significant.

\section{Results}

\section{Purification of LDH from the muscle of euthermic and hibernating $\boldsymbol{U}$. richardsonii}

Purification of LDH from the skeletal muscle of euthermic and hibernating $U$. richardsonii was accomplished by three chromatography steps with a $\mathrm{DEAE}^{+}$column (enzyme eluted in the unbound fraction), a Cibacron blue affinity column (elution with a 0-6 mM NADH and sodium pyruvate gradient), and lastly, a second Cibacron blue affinity column (elution with 0-2 $\mathrm{M} \mathrm{KCl}$ gradient) (Table 2.1). Collection of the flow through fractions from the $\mathrm{DEAE}^{+}$column resulted in a 0.70 - and 1.71 - fold purification of recovered activity for the $\mathrm{LDH}$ from the muscle of euthermic and hibernating squirrels, respectively. Elution of euthermic and hibernator LDH from the Cibacron blue column using a metabolite gradient gave a 3.8- and 21.48- fold purification, respectively (Fig. 2.1a). Furthermore, the elution of euthermic and hibernator LDH from the second Cibacron blue column using a $\mathrm{KCl}$ gradient resulted in a 28.9- and 11.20- fold purification, respectively (Table 2.1; Fig. 2.1b). The overall purification resulted in final specific activities of $11,832 \mathrm{mU} \mathrm{mg}^{-1}$ protein for euthermic $\mathrm{LDH}$, and 9,313 $\mathrm{mU} \mathrm{mg}^{-1}$ for hibernator LDH (Table 2.1). As a result of this three-step purification scheme, LDH was purified to $>95 \%$ homogeneity, as determined by gel electrophoresis and staining with silver nitrate 
(Fig. 2.2). The purified LDH had an apparent subunit molecular weight of $38 \mathrm{kDa}$ (Fig. 2.2).

\section{Reversible phosphorylation of muscle LDH}

It was hypothesized that reversible protein phosphorylation might be the mechanism underlying the kinetic differences between LDH from euthermic and hibernating muscle reported in Table 2.2. To test this hypothesis, crude muscle extracts were incubated under conditions that stimulated the actions of endogenous protein kinases (Fig. 2.3a) or protein phosphatases (Fig. 2.3b) and the resulting effects on an LDH kinetic parameter $\left(K_{m}\right.$ lactate) were measured. Incubation of euthermic extracts under conditions that stimulated the activities of endogenous protein kinases PKG and PKC did not change LDH $K_{m}$ lactate (Fig. 2.3a). However, stimulation of AMPK, CaMK, or PKA significantly increased euthermic $K_{m}$ lactate (ie. decreased affinity for lactate). Relative to the STOP condition $\left(K_{m}\right.$ lactate $\left.=1.66 \pm 0.05 \mathrm{mM}\right)$, AMPK, CAMK or PKA stimulation resulted in 2.0-, 1.7-, and 2.1-fold increases in the $K_{m}$ for crude euthermic LDH, respectively $(\mathrm{P}<0.05)$ (Fig. 2.3a).

The effect of incubating $\mathrm{LDH}$ under conditions that stimulated the actions of various protein phosphatases was also tested. Incubation of extracts under conditions that stimulated protein phosphatases decreased the $K_{m}$ lactate of LDH in extracts from euthermic animals under conditions that stimulated PP1 or PP2B; values decreased to about 60 and $70 \%$ of the unstimulated $K_{m}$ value, relative to the STOP condition (Fig. 2.3b).

Immunoblotting was used to assess possible differences in phosphorylation of purified muscle LDH from euthermic and hibernating conditions. Phosphorylation at serine 
residues of hibernating $\mathrm{LDH}$ was $2.2 \pm 0.30$ fold higher compared to euthermic $\mathrm{LDH}(1 \pm$ 0.07, $\mathrm{P}<0.05$, Fig. 2.4). In addition to an increase in phosphorylation at serine residues, there was a $1.29 \pm 0.05$ fold increase in threonine phosphorylation of hibernating LDH relative to euthermic LDH $(1 \pm 0.07, \mathrm{P}<0.05$, Fig. 2.4). Comparable analysis of phosphotyrosine residues found no significant difference in tyrosine phosphorylation between euthermic and hibernating $\mathrm{LDH}(\mathrm{P}>0.05$, data not shown).

\section{Kinetic activity of purified LDH from euthermic and hibernating muscle}

i. Effects of reversible post-translational modifications on LDH kinetic parameters

Analysis of the kinetic parameters of LDH from the muscle of euthermic and hibernating animals showed that the enzyme displayed hyperbolic substrate saturation curves with respect to both lactate and pyruvate (Fig. 2.5a,b). Distinct differences in $K_{m}$ values were found in some instances. In the lactate-oxidizing direction, the $K_{m}$ for lactate of $\mathrm{LDH}$ at $5^{\circ} \mathrm{C}$ was 1.8 -fold higher for the hibernating $(4.87 \pm 0.45 \mathrm{mM})$ condition compared with the euthermic value $(2.67 \pm 0.17 \mathrm{mM})(\mathrm{P}<0.05$, Table 2.2, Fig. 2.5a). Although there were no significant differences found in the $K_{m}$ values for lactate between euthermic and hibernating $\mathrm{LDH}$ at $22^{\circ} \mathrm{C}$ and $37^{\circ} \mathrm{C}$, the $V_{\max }$ values at these temperatures increased 1.5- and 2.6- fold, respectively, for hibernating LDH as compared to euthermic LDH (Table 2.2). Furthermore, analysis of the $K_{m}$ for $\mathrm{NAD}^{+}$across the three temperatures revealed that the values for hibernating $\mathrm{LDH}$ enzyme were not significantly different from the $K_{m}$ values for euthermic LDH at any assay temperature (Table 2.2).

The maximal activity of $\mathrm{LDH}$ at the three temperatures $\left(5^{\circ} \mathrm{C}, 22^{\circ} \mathrm{C}\right.$ and $\left.37^{\circ} \mathrm{C}\right)$ was also analyzed by an Arrhenius plot to determine the activation energy $\left(E_{a}\right)$ for both the 
lactate-oxidizing and pyruvate-reducing reactions of LDH. Examining the lactateoxidizing direction for euthermic $\mathrm{LDH}$, the $E_{a}(34.52 \pm 6.68 \mathrm{~kJ} / \mathrm{mol})$ was not significantly different $(\mathrm{P}>0.05)$ than the $E_{a}$ for hibernating $\mathrm{LDH}(48.61 \pm 13.19 \mathrm{~kJ} / \mathrm{mol}$, Table 2, Fig. 2.5c). For the pyruvate-reducing direction, comparable value for $E_{a}$ were $35.10 \pm 12.62$ $\mathrm{kJ} / \mathrm{mol}$ for euthermic $\mathrm{LDH}$ and $55.26 \pm 15.69 \mathrm{~kJ} / \mathrm{mol}$, again not significantly different.

In the pyruvate-reducing direction, at $22^{\circ} \mathrm{C}$ and $37^{\circ} \mathrm{C}$ there was no difference in the $K_{m}$ for pyruvate between euthermic and hibernating $\mathrm{LDH}$. However, at $5^{\circ} \mathrm{C}$ the affinity for pyruvate was greater (ie. $K_{m}$ lower) for hibernating $\mathrm{LDH}(0.067 \pm 0.005 \mathrm{mM})$ as compared to euthermic $\mathrm{LDH}(0.09 \pm 0.01 \mathrm{mM}, \mathrm{P}<0.05$, Table 2.2, Fig. 2.5b). When comparing the $V_{\max }$ values of euthermic and hibernating $\mathrm{LDH}$ at $5{ }^{\circ} \mathrm{C}$ there was a significant decrease in the hibernating $\mathrm{LDH} V_{\max }(2.19 \pm 0.29 \pm 1.47 \mathrm{mU} / \mu \mathrm{g})$ as compared to euthermic $\mathrm{LDH}(2.93$ $\pm 0.15 \mathrm{mU} / \mu \mathrm{g}, \mathrm{P}<0.05$, Table 2.2). However, at $37^{\circ} \mathrm{C}$, there was a significant increase in the $V_{\max }$ for hibernating $\mathrm{LDH}(26.97 \pm 2.89 \mathrm{mU} / \mu \mathrm{g})$ as compared to euthermic LDH $(14.66$ $\pm 2.33 \mathrm{mU} / \mu \mathrm{g}$, Table 2.2 ). Lastly, the inhibitory effects of pyruvate on LDH activity did not change between euthermic and hibernating forms of the enzyme at $5^{\circ} \mathrm{C}$ and $37^{\circ} \mathrm{C}$ (Table 2.2). However, at $22^{\circ} \mathrm{C}$ there was a significant decrease in the $I C_{50}$ (inhibitor concentration that reduces activity by $50 \%)$ for pyruvate for hibernating $\mathrm{LDH}(4.42 \pm 0.19 \mathrm{mM})$ as compared to euthermic $\mathrm{LDH}(7.52 \pm 0.14 \mathrm{mM}, \mathrm{P}<0.05$, Table 2.2).

\section{ii. Temperature effects on euthermic and hibernator forms of $L D H$}

As the temperature decreased from $37^{\circ} \mathrm{C}$ to $5^{\circ} \mathrm{C}$, there was a general decrease in most of the kinetic parameters in the lactate-oxidizing direction for both euthermic and hibernating LDH. In the euthermic state, $K_{m}$ for lactate changed 0.51 - fold as temperature decreased from $37^{\circ} \mathrm{C}(5.21 \pm 0.66 \mathrm{mM})$ to $5^{\circ} \mathrm{C}(2.67 \pm 0.17 \mathrm{mM}, \mathrm{P}<0.05$, Table 2.2$)$. 
Likewise, there was a significant decrease in the $K_{m}$ for $\mathrm{NAD}^{+}$in the euthermic condition (Table 2.2). An increase in substrate affinity (decreased $K_{m}$ ) was also seen in the hibernating condition when comparing $37^{\circ} \mathrm{C}$ to $5^{\circ} \mathrm{C}$ (Table 2.2). However, unlike in the euthermic condition, a decrease in temperature did not significantly affect the affinity for lactate of hibernator $\mathrm{LDH}$ as the temperature decreased $(\mathrm{P}>0.05$, Table 2.2). The change in temperature from $37^{\circ} \mathrm{C}$ to $5^{\circ} \mathrm{C}$ also lead to 0.21 - and 0.11 - fold changes in the $V_{\max }$ values in the lactate-oxidizing direction for euthermic and hibernator enzymes, respectively (Table 2.2).

In the pyruvate-reducing direction, the affinity for pyruvate in euthermic and hibernator LDH did not change with a decrease in temperature (Table 2.2). However, like observed in the lactate-oxidizing direction, the change in temperature from $37^{\circ} \mathrm{C}$ to $5^{\circ} \mathrm{C}$ lead to a decrease in $V_{\max }$ values for the pyruvate-reducing direction. The change in $V_{\max }$ was 0.20- fold for euthermic LDH, and 0.08- fold for hibernator LDH $(\mathrm{P}<0.05$, Table 2.2).

\section{iii. $\quad$ Effects of changing $\mathrm{pH}$ on euthermic and hibernator forms of $\mathrm{LDH}$}

Differences in the $\mathrm{pH}$ of the buffering system revealed interesting changes in substrate affinities and reaction velocities for both euthermic and hibernator LDH. When comparing the change in $\mathrm{pH}$ from 8.0 to 7.5 in the lactate-oxidizing direction, both euthermic and hibernator $\mathrm{LDH}$ showed a decrease in affinity for $\mathrm{NAD}^{+}$with at least a 2fold increases in $K_{m}$ values across all three temperatures (Table 2.3a,b). Changes in pH did not affect the enzyme's affinity for lactate across any of the temperatures in the euthermic condition. These trends are also seen for hibernator $\mathrm{LDH}$ at $22^{\circ} \mathrm{C}$ and $37^{\circ} \mathrm{C}$. However, at $5^{\circ} \mathrm{C}$ a decrease in $\mathrm{pH}$ from 8.0 to 7.5 lead to a 1.4 - fold increase in the $K_{m}$ for lactate (Table 2.3b). At $37^{\circ} \mathrm{C}$, the reaction velocities increased significantly for both euthermic and 
hibernator $\mathrm{LDH}$ as $\mathrm{pH}$ decreased; however, at $5^{\circ} \mathrm{C}$ there was no significant change in $V_{\max }$ values across both conditions with a change in $\mathrm{pH}$ (Table 2.3a,b).

In the pyruvate-reducing direction at $5^{\circ} \mathrm{C}$, a decrease in $\mathrm{pH}$ did not affect pyruvate affinity, reaction velocity, or inhibition by pyruvate in either euthermic or hibernating conditions (Table 2.3a,b). However, at $37^{\circ} \mathrm{C}$, a decrease in the $\mathrm{pH}$ lead to a significant increase in pyruvate affinity, as well as a significant decrease in the $I C_{50}$ of pyruvate for both euthermic and hibernator forms of the enzyme (Table 2.3a,b). 
Table 2.1. Purification and yield of $U$. richardsonii LDH from muscle of (a) euthermic and (b) hibernating ground squirrels.

(a)

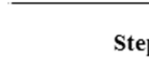

Step

Total Protein (mg)

Total Activity

Specific Activity (mU/mg)

Fold

Purification

\%yield

\begin{tabular}{ll} 
& \\
\hline Crude & 27.84
\end{tabular}

DEAE

13.58

11389

409

$-$

100

Cibacron Blue

(Pyruvate +NADH)

0.56

Cibacron Blue

0.04

3869

285

0.70

34.0

875

1572

3.84

7.7 (KCl)

(b)

\begin{tabular}{r}
\hline Step \\
\hline Crude \\
DEAE \\
Cibacron Blue \\
(Pyruvate + NAD
\end{tabular}

\section{Total Protein}

(mg)

461

11832

28.9

4.1

(Pyruvate + NADH)

30.36

10.82

Total Activity

Specific Activity

Fold

Purification

\%yield

Cibacron Blue

(KCl)

0.27

0.03

$(\mathrm{mU})$

(mU/mg)

25235

15408

831.2

1424

1.71

100

4897

17852

21.48

19.40

298

9313

11.20

1.18 
Table 2.2. Kinetic parameters of purified muscle LDH from euthermic and hibernating $U$. richardsonii.

\begin{tabular}{|c|c|c|}
\hline Enzyme parameter & Euthermic & Hibernating \\
\hline \multicolumn{3}{|c|}{ Forward reaction (lactate $\rightarrow$ pyruvate, $p$ H 8.0) } \\
\hline $\mathrm{Km}$ lactate, $37^{\circ} \mathrm{C}(\mathrm{mM})$ & $5.21 \pm 0.66$ & $5.55 \pm 0.79$ \\
\hline $\mathrm{Km}$ lactate, $22^{\circ} \mathrm{C}(\mathrm{mM})$ & $4.07 \pm 0.31$ & $3.19 \pm 0.35$ \\
\hline $\mathrm{Km}$ lactate, $5^{\circ} \mathrm{C}(\mathrm{mM})$ & $2.67 \pm 0.17^{b}$ & $4.87 \pm 0.45^{a}$ \\
\hline $\mathrm{Km}$ NAD, $37^{\circ} \mathrm{C}(\mathrm{mM})$ & $0.19 \pm 0.02$ & $0.14 \pm 0.02$ \\
\hline $\mathrm{Km}$ NAD, $22^{\circ} \mathrm{C}(\mathrm{mM})$ & $0.12 \pm 0.01^{b}$ & $0.06 \pm 0.01^{b}$ \\
\hline $\mathrm{Km} \mathrm{NAD}, 5^{\circ} \mathrm{C}(\mathrm{mM})$ & $0.06 \pm 0.01^{b}$ & $0.06 \pm 0.01^{b}$ \\
\hline Activation Energy $(\mathrm{kJ} / \mathrm{mol})$ & $34.52 \pm 6.68$ & $48.61 \pm 13.19$ \\
\hline $\operatorname{Vmax}, 37^{\circ} \mathrm{C}(\mathrm{mU} / \mu \mathrm{g})$ & $1.86 \pm 0.30$ & $4.91 \pm 0.46^{a}$ \\
\hline $\operatorname{Vmax}, 22^{\circ} \mathrm{C}(\mathrm{mU} / \mu \mathrm{g})$ & $0.72 \pm 0.06^{b}$ & $1.11 \pm 0.05^{a, b}$ \\
\hline$V \max , 5^{\circ} \mathrm{C}(\mathrm{mU} / \mu \mathrm{g})$ & $0.39 \pm 0.05^{b}$ & $0.54 \pm 0.09^{b}$ \\
\hline \multicolumn{3}{|c|}{ Reverse reaction (pyruvate $\rightarrow$ lactate, $p H$ 7.5) } \\
\hline Km pyruvate, $37^{\circ} \mathrm{C}(\mathrm{mM})$ & $0.13 \pm 0.01$ & $0.13 \pm 0.01$ \\
\hline $\mathrm{Km}$ pyruvate, $22^{\circ} \mathrm{C}(\mathrm{mM})$ & $0.12 \pm 0.01$ & $0.12 \pm 0.03$ \\
\hline $\mathrm{Km}$ pyruvate, $5^{\circ} \mathrm{C}(\mathrm{mM})$ & $0.09 \pm 0.01$ & $0.07 \pm 0.01^{a}$ \\
\hline Activation Energy $(\mathrm{kJ} / \mathrm{mol})$ & $35.10 \pm 12.62$ & $55.26 \pm 15.69$ \\
\hline $\operatorname{Vmax}, 37^{\circ} \mathrm{C}(\mathrm{mU} / \mu \mathrm{g})$ & $14.66 \pm 2.33$ & $26.97 \pm 2.89^{a}$ \\
\hline $\operatorname{Vmax}, 22^{\circ} \mathrm{C}(\mathrm{mU} / \mu \mathrm{g})$ & $4.43 \pm 0.32^{b}$ & $4.83 \pm 0.57^{b}$ \\
\hline$V \max , 5^{\circ} \mathrm{C}(\mathrm{mU} / \mu \mathrm{g})$ & $2.93 \pm 0.15^{b}$ & $2.19 \pm 0.29^{a, b}$ \\
\hline $\mathrm{IC}_{50}$ pyruvate, $37^{\circ} \mathrm{C}(\mathrm{mM})$ & $13.66 \pm 1.46$ & $15.16 \pm 2.06$ \\
\hline $\mathrm{IC}_{50}$ pyruvate, $22^{\circ} \mathrm{C}(\mathrm{mM})$ & $7.52 \pm 0.14^{b}$ & $4.42 \pm 0.19^{a, b}$ \\
\hline $\mathrm{IC}_{50}$ pyruvate, $5^{\circ} \mathrm{C}(\mathrm{mM})$ & $8.57 \pm 1.16$ & $9.71 \pm 2.09$ \\
\hline
\end{tabular}


Table 2.3. Effects of $\mathrm{pH}$ on purified muscle LDH from (a) euthermic and (b) hibernating U. richardsonii.

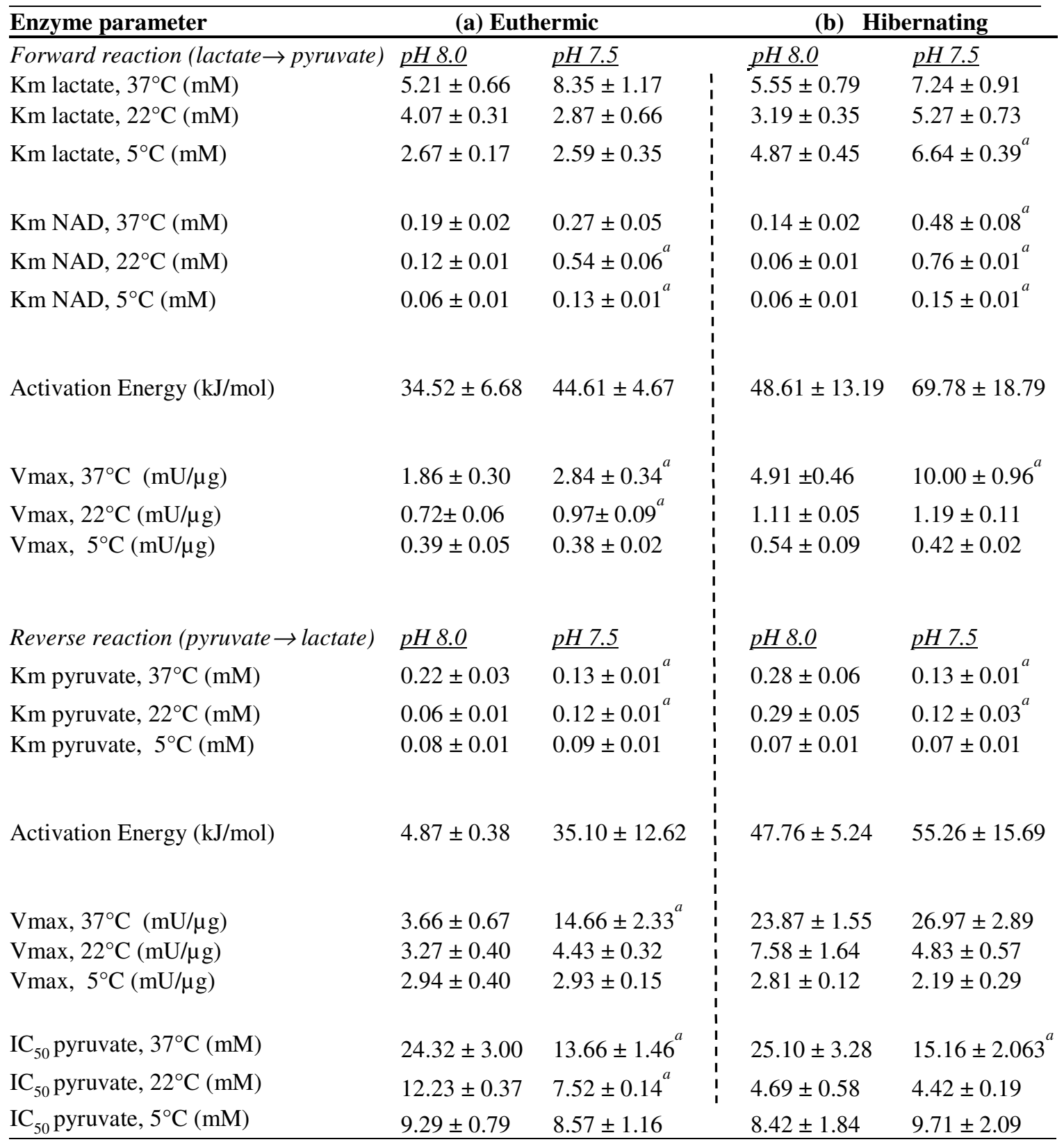

$a$ indicates a significant difference from $\mathrm{pH} 8.0$ in each corresponding condition, Student's $\mathrm{t}$ test, two tailed, $\mathrm{P}<0.05$ 


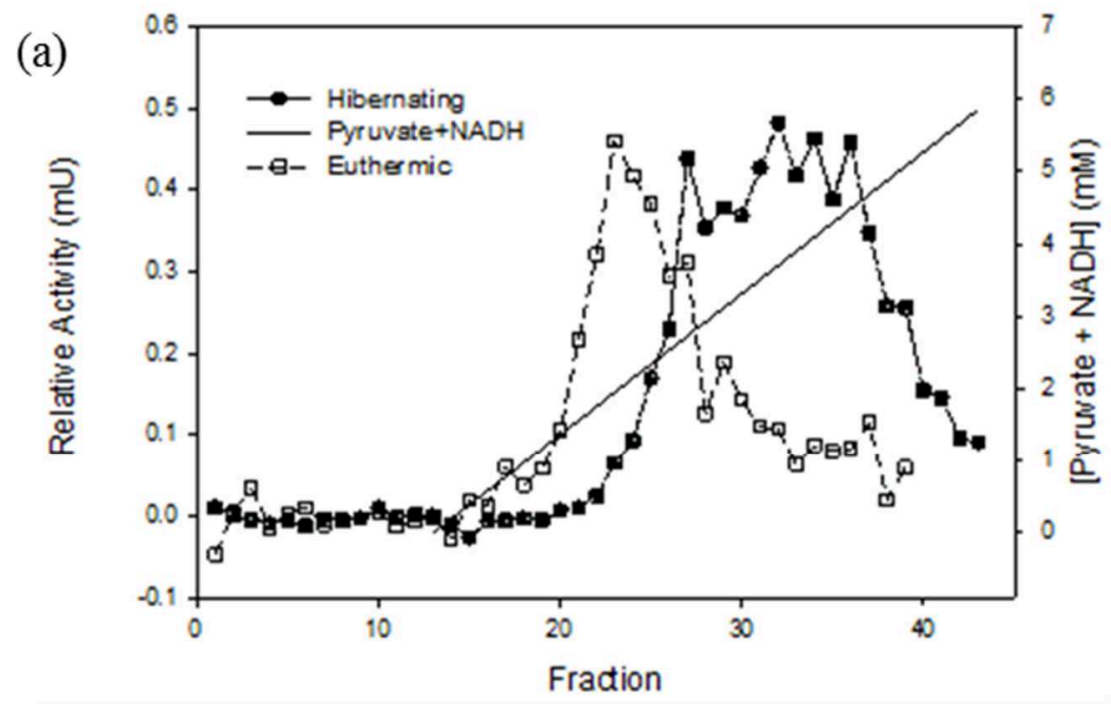

(b)

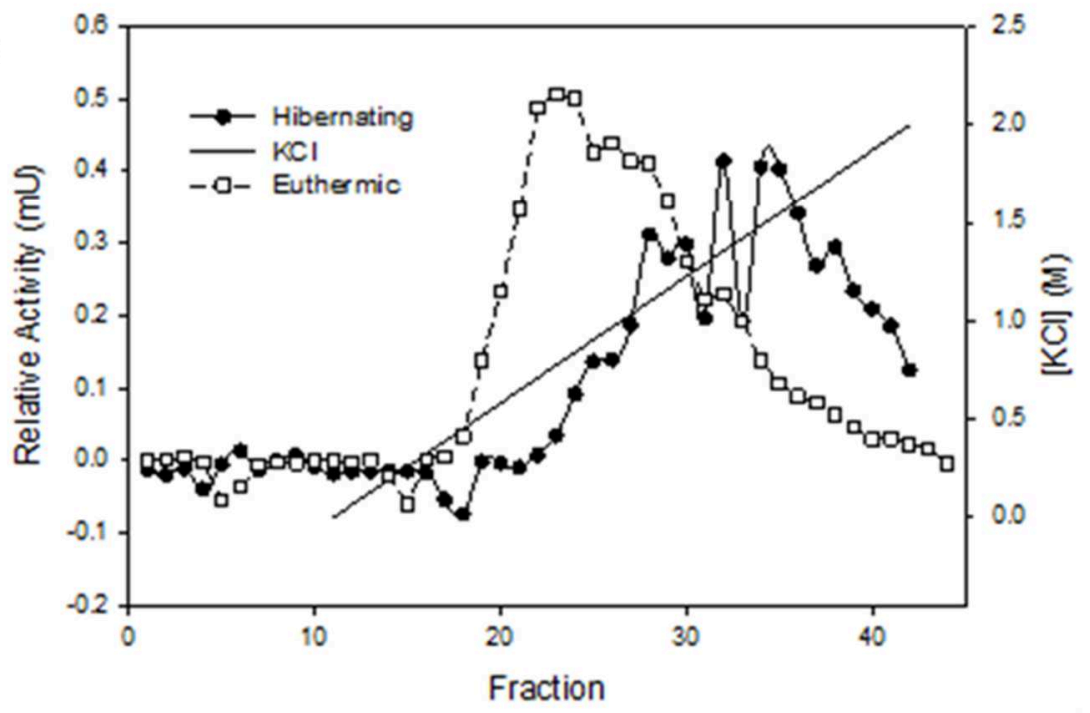

Figure 2.1. Typical Cibacron Blue elution profiles for LDH activity from muscle of euthermic (control) and hibernating $U$. richardsonii using (a) 0-6 mM gradient of pyruvate + NADH and; (b) 0-2 $\mathrm{M}$ gradient of $\mathrm{KCl}$ as the elutant. Elution profiles are from separate runs of euthermic and hibernating enzyme but are superimposed here for viewing. 


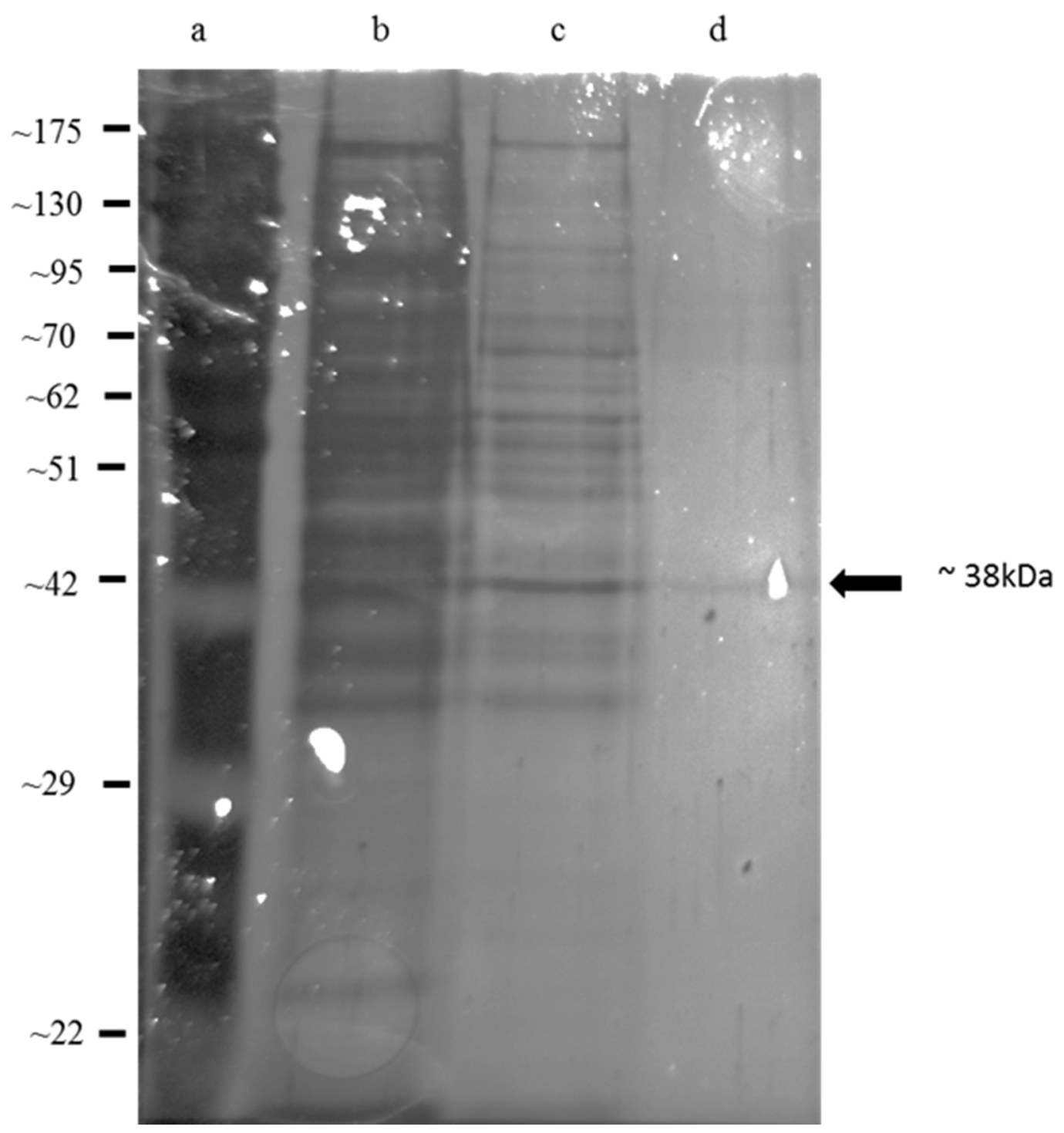

Figure 2.2. 10\% SDS-PAGE gel with silver staining of samples taken at each step in the purification of LDH from muscle of euthermic $U$. richardsonii. Lanes (a) molecular weight ladder (FroggiaBio); (b) 1:100 diluted crude extract; (c) pooled LDH peak fractions after elution from the Cibacron blue agarose column with NADH+Pyruvate; (d) pooled LDH peak fractions from the Cibacron Blue agarose column after elution with $\mathrm{KCl}$. 

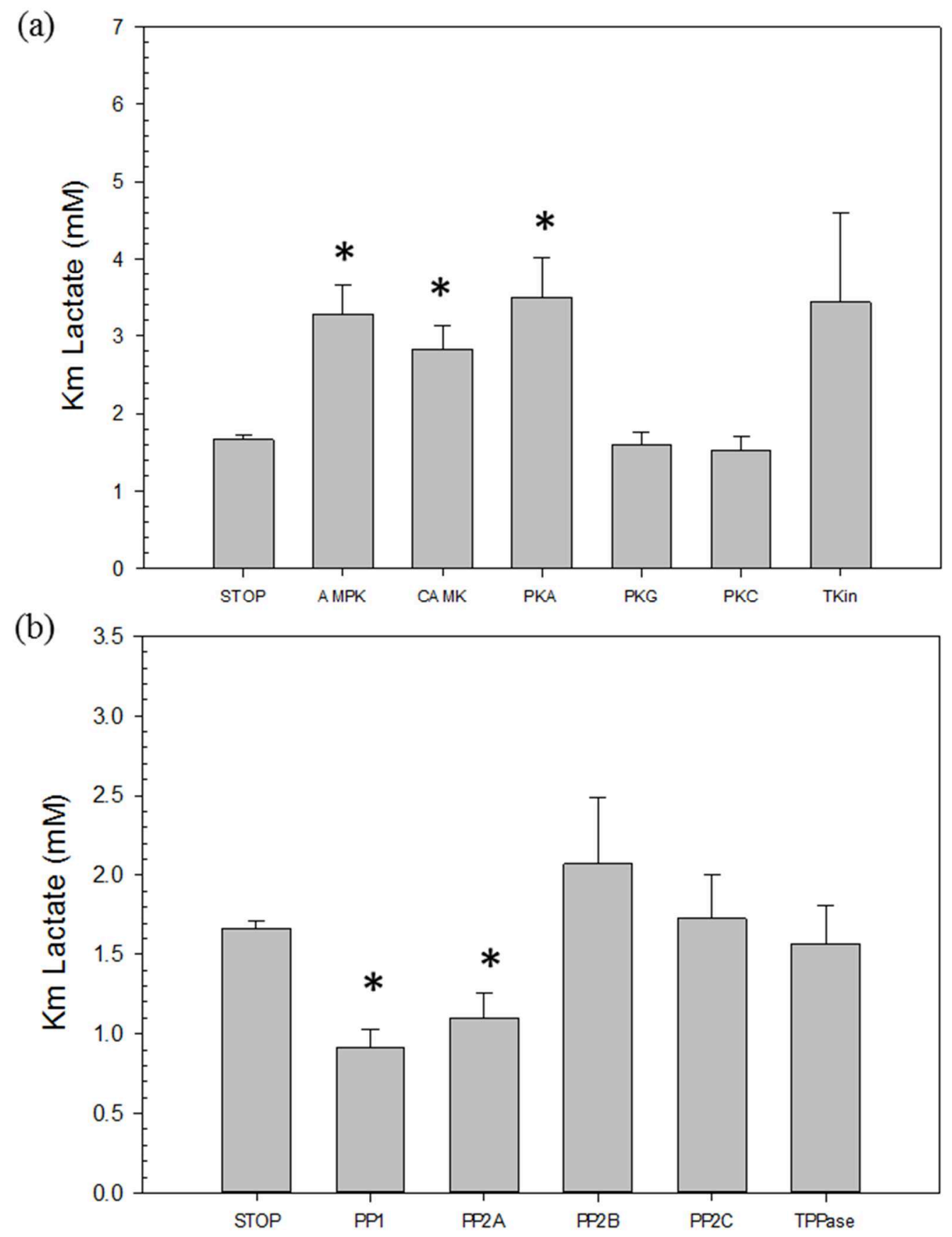

Figure 2.3. Effects of in vitro incubations to stimulate the activities of endogenous (a) protein kinases or (b) protein phosphatases on the $K_{m}$ for L-Lactate for LDH from euthermic $U$. richardsonii muscle. Crude extracts were incubated for $24 \mathrm{~h}$ before assay at $5^{\circ} \mathrm{C}$. Data are means $\pm \mathrm{SEM}$, with at least $\mathrm{n}=3$ separate determinations on enzyme isolated from different individuals. Conditions are defined in the Materials and Methods. Asterisks indicate significant differences from the 'STOP' condition, Student's t-test, two-tailed, P $<0.05$. 

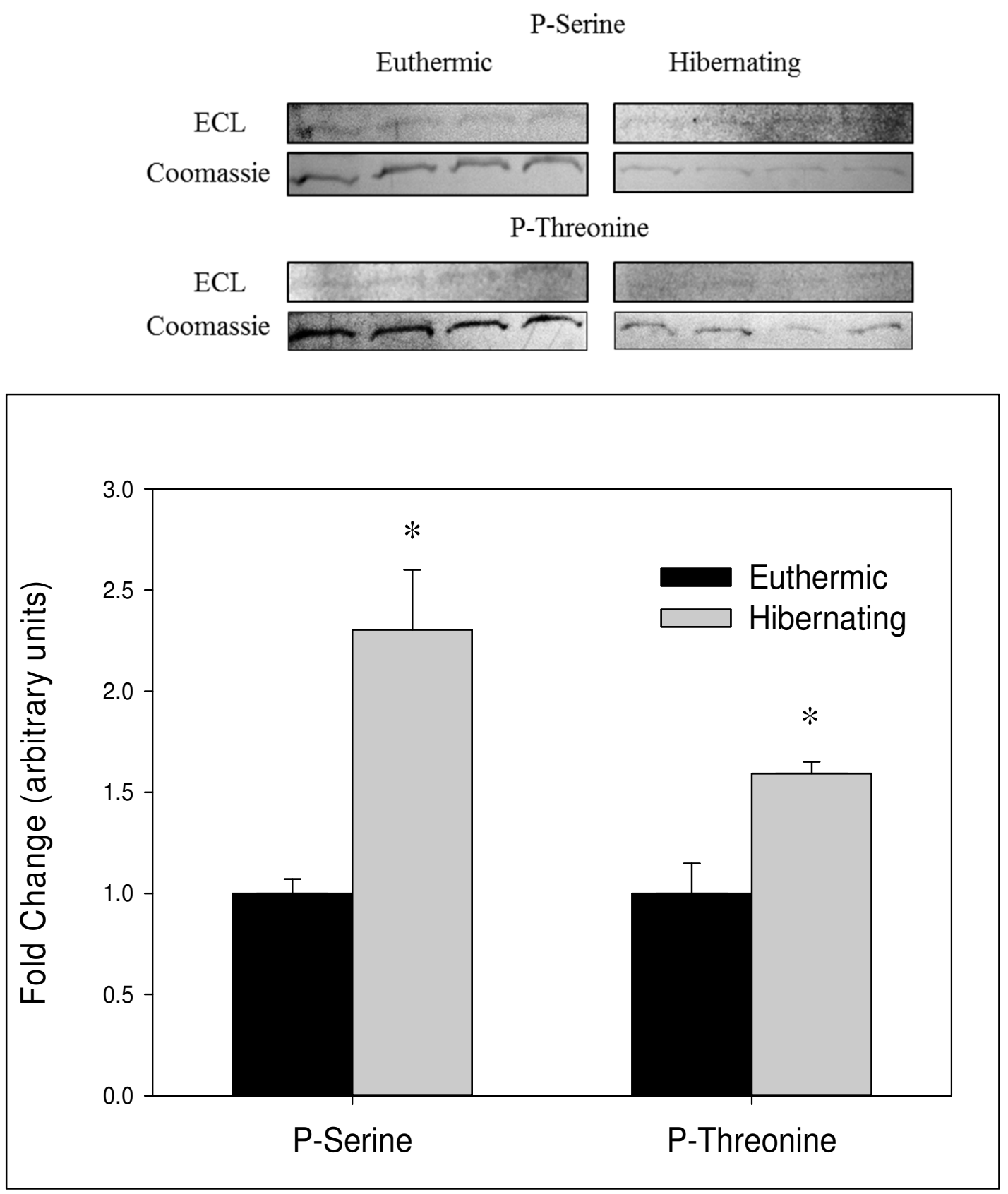

Figure 2.4. Quantification of post-translational modifications of purified LDH from muscle of euthermic and hibernating $U$. richardsonii. Chemiluminescence signal intensities were standardized to protein amount, and the value for hibernating LDH was expressed relative to the control value that was set to 1 . Data are mean $\pm S E M, n=3-4$ determinations on purified enzyme samples. Asterisks indicate significant differences from the corresponding control LDH, Student's t-test, two-tailed, $\mathrm{p}<0.05$. 
(a)

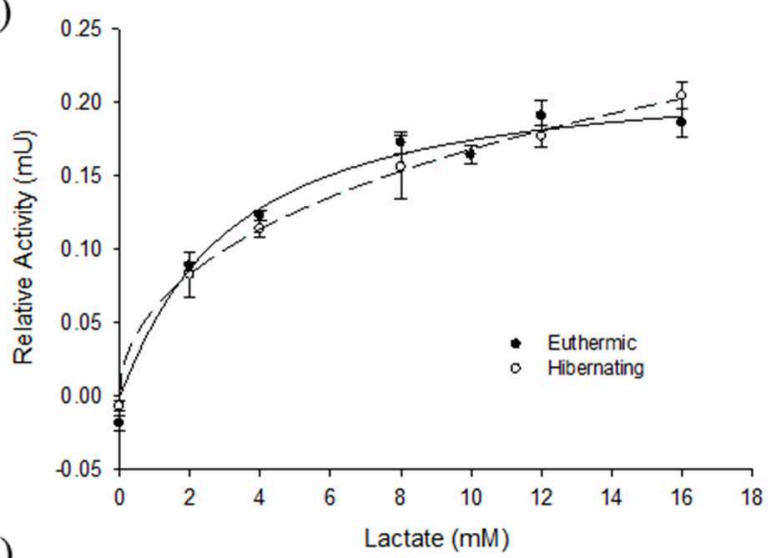

(b)

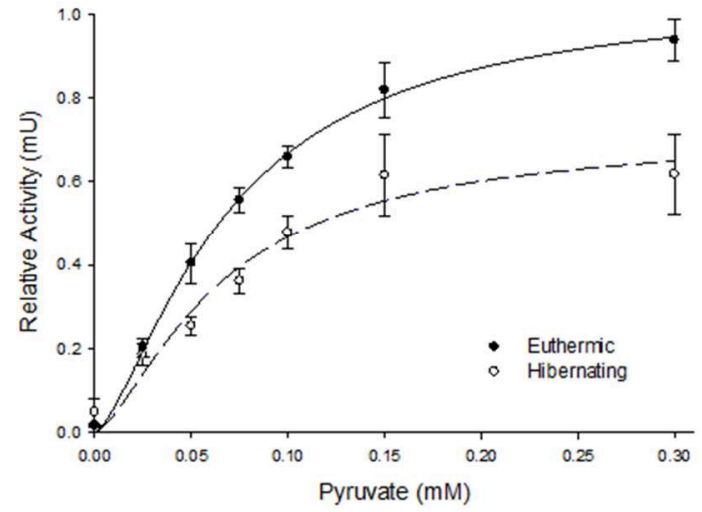

(c)

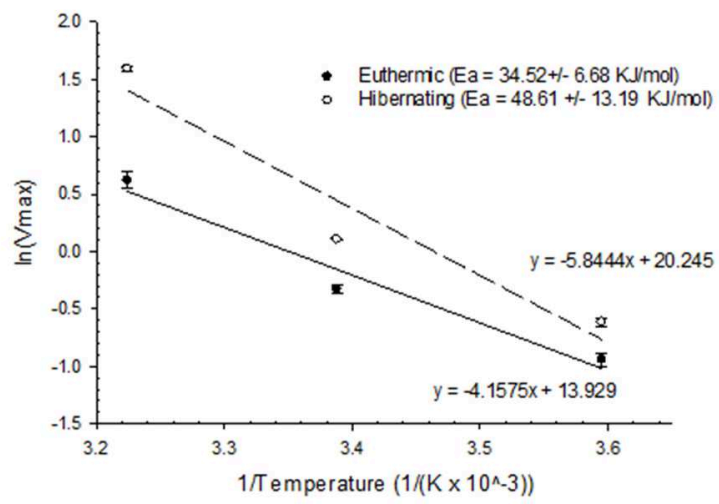

Figure 2.5. Michaelis-Menten curves for (a) forward (lactate-utilizing, $5^{\circ} \mathrm{C}$ ) and (b) reverse (pyruvate-utilizing, $5^{\circ} \mathrm{C}$ ) reactions catalyzed by purified euthermic and hibernating $\mathrm{LDH}$; and (c) Arrhenius plots for the forward reaction $\mathrm{LDH}$ at three temperatures: $5^{\circ} \mathrm{C}, 22^{\circ} \mathrm{C}$, $37^{\circ} \mathrm{C}$. Michaelis-Menten curves for euthermic LDH (black circles) and hibernating LDH (open circles). Plots are fitted with a three-parameter Hill coefficient curve using SigmaPlot 12. Data are mean \pm SEM, $n=3-4$ individual determinations on purified enzyme samples 


\section{Discussion}

LDH is the terminal enzyme in anaerobic glycolysis; it facilitates the continuing generation of ATP during oxygen deficient times by regenerating the $\mathrm{NAD}^{+}$that is needed to maintain glycolytic flux and producing an end product (lactate) that can be accumulated and stored in high levels in tissues or transported for catabolism by other tissues (Hochachka and Somero, 2014). Its role in the production of the important redox molecule $\mathrm{NAD}^{+}$makes $\mathrm{LDH}$ an interesting target for analysis. Like other small mammalian hibernators, Richardson's ground squirrels are capable of depressing their metabolism by entering into cycles of torpor and arousal over the winter months. Despite the depression of metabolism, these species must maintain vital physiological processes. With no food intake during the winter hibernation months, these animals must reorganize their fuel metabolism to maintain cell and tissue viability (Buck and Barnes, 2000). This reorganization is essential not only for the maintenance of muscle energetics throughout the hibernating season, but also critical for the arousal process since shivering thermogenesis plays a major role in the restoration of euthermic $T_{b}$ when animals arouse from a torpor bout (Wang and Lee, 1996). The present chapter shows that skeletal muscle LDH from euthermic versus hibernating animals displays different kinetic properties, different responses to temperature, and appears to be regulated via reversible protein phosphorylation.

\section{i. $\quad$ LDH purification}

Ground squirrel skeletal muscle LDH was purified to electrophoretic homogeneity by using a combination of ion-exchange and affinity chromatography. The end result was an enzyme preparation that was purified 29-fold to a specific activity of $11832 \mathrm{mU} / \mathrm{mg}$ 
protein (Table 2.1; Fig 2.1). The fold purification and specific activity values for this LDH are in accordance with the values obtained using the same three-step purification scheme to purify LDH from the liver of Xenopus laevis (Katzenback et al., 2014). Thus, the results presented here shed light on the reproducibility of the ion-exchange and affinity chromatography purification scheme across different tissues and species and is the first of its kind for a mammalian hibernator.

\section{ii. $\quad$ Post-translational modification of $L D H$}

Although LDH is known to have multiple isozymes (Markert and Møller, 1959), skeletal muscle LDH is mainly a homotetramer of the muscle (M)-type subunit (LDH-5). To date, no differential regulation of LDH subunit gene expression has been reported that may contribute to the enzyme's structural, functional, and/or regulatory properties in euthermic versus hibernating states. Furthermore, the high energetic costs associated with creating new proteins makes differential gene expression an unlikely event because during hibernation ground squirrels need to be in an energy-conserving state. With that in mind, structural and functional differences between euthermic and hibernating forms of LDH are likely due to reversible post-translational modifications of the protein. In the present study, the phosphorylation state of LDH was assessed through Western blot analysis using phosphospecific antibodies. The analysis using anti-phospho-serine and anti-phosphothreonine antibodies demonstrated that LDH from torpid animals showed significantly greater serine and threonine phosphorylation as compared to euthermic conditions (Fig. 2.4). LDH has been found to be differentially phosphorylated in other species capable of depressing their metabolism (Xiong and Storey, 2012; Dawson et al., 2013; Katzenback et al., 2014). In Xiong and Storey (2012), the hypometabolic (anoxic) form of liver LDH 
from anoxia-tolerant turtles showed greater phosphorylation as compared to the control enzyme. The present data is consistent with the findings in turtles in that during hibernation (a hypometabolic state in mammals) LDH has greater phosphorylation compared to the euthermic enzyme. However, research conducted by Dawson et al. (2013) showed that during stress, the anoxic form of turtle muscle LDH was, in fact, the low phosphate form. The reversible phosphorylation differences seen in each of these studies may reflect varying regulatory mechanisms across different species, or the need for tissue-specific differences in LDH regulation. Despite differences in phosphorylation states, a similarity between the current study and the previous ones described above is that the increase in bound phosphate on LDH consistently decreased LDH activity in the lactate-oxidizing direction.

To assess the effect of changes in phosphorylation state on the kinetic characteristics of $\mathrm{LDH}$, crude preparations of euthermic LDH were incubated under conditions that would stimulate protein kinases or phosphatases and the $K_{m}$ of lactate was assessed. Incubations that stimulated endogenous protein phosphatases caused a significant decrease in the $K_{m}$ of lactate for euthermic LDH (Fig 2.3b). Furthermore, incubations that investigated the role of specific protein kinases in altering LDH kinetics identified AMPK, CaMK, and PKA as kinases that caused an approximately 2-fold increase in the $K_{m}$ of lactate for control LDH (Fig. 2.3a). Each of these kinases has various roles in metabolism and may potentially be important regulators of LDH in vivo (Storey and Storey, 2004a). Most notably in vivo, LDH may be subject to AMPK control, AMPK being a kinase that is highly sensitive to cellular nutrient/energy status as reflected in the [AMP] to [ATP] ratio (reviewed in Hardie et al., 2006). Indeed, AMPK is often characterized as the energy sensor 
or the cell. During fasting conditions, such as in hibernation, cellular [AMP] levels rise and in turn, activate AMPK. This AMPK activation has profound effects on glycolytic activity as it has been shown to down regulate the transcription of pyruvate kinase-a key glycolytic enzyme (Kawaguchi et al., 2002). In this study, phosphorylation of LDH via AMPK may serve as a complimentary way of ensuring that pyruvate levels stay minimal during hibernation.

\section{iii. $\quad$ LDH Kinetics}

Kinetic analysis of LDH purified from euthermic and hibernating animals revealed several differences between the two enzyme states. Properties of the enzymes were analyzed at three temperatures, $37^{\circ} \mathrm{C}, 22^{\circ} \mathrm{C}$, and $5^{\circ} \mathrm{C}$, representing the approximate $\mathrm{T}_{\mathrm{b}}$ values that are reported in ground squirrels during euthermia, entrance in and out of torpor, and during hibernation, respectively. A comparison between euthermic and hibernating LDH revealed interesting findings. Most notably, at $5^{\circ} \mathrm{C}$ the $K_{m}$ of lactate was substantially higher for hibernating LDH as compared to euthermic LDH (Table 2.2). Furthermore, at this same temperature, $K_{m}$ of pyruvate was lower for hibernating LDH compared to the euthermic form (Table 2.2). Previous research has shown that $\mathrm{NAD}^{+}$concentrations in a similar hibernator entering torpor are approximately 2 times higher than that found in their active state (Serkova et al., 2007). The LDH kinetic data presented in the current study, suggests that the hibernator form of $\mathrm{LDH}$ that is active at low $\mathrm{T}_{\mathrm{b}}$ aids in the accumulation of lactate and $\mathrm{NAD}^{+}$.

The activity of ground squirrel LDH showed a linear response to temperature changes in vitro (Fig. 2.5c). Using pyruvate as a substrate, the activation energies of euthermic $(35.10 \pm 12.62 \mathrm{~kJ} / \mathrm{mol})$ and hibernating $\mathrm{LDH}(55.26 \pm 15.69 \mathrm{~kJ} / \mathrm{mol})$ were not 
significantly different from one another (Table 2.2) and are similar to that of the $\mathrm{E}_{\mathrm{a}}$ reported for human LDH-5 (40.9 kJ/mol) (Tanishima et al., 1995). Studies of the effect of temperature on $K_{m}$ for lactate revealed that a decrease in temperature from $37^{\circ} \mathrm{C}$ to $5^{\circ} \mathrm{C}$ increased binding affinity for the substrate in euthermic LDH but did not affect the binding affinity in the hibernating form (Table 2.2). This maintenance of $K_{m}$ of lactate aids in suppressing the lactate-oxidizing reaction catalyzed by $\mathrm{LDH}$ at the low body temperatures endured during torpor. Furthermore, and as expected, reaction velocities decreased approximately 2-fold for every $10^{\circ} \mathrm{C}$ drop in temperature. The effect of $\mathrm{pH}$ on $\mathrm{LDH}$ activity must also be considered as small changes in cytosolic $\mathrm{pH}$ may occur due to the effect of low temperature on cell buffering systems during hibernation.

Studies looking at muscle $\mathrm{pH}$ in the Colombian ground squirrel revealed a slight increase in cellular $\mathrm{pH}$ as the temperature decreased from $37^{\circ} \mathrm{C}(\mathrm{pH} 7.24)$ to $5^{\circ} \mathrm{C}(\mathrm{pH} 7.45)$ (McArthur et al., 1990). With this in mind, it was appropriate to look at the effect of $\mathrm{pH}$ on LDH activity in the current model. Although the increase in $\mathrm{pH}$ from 7.5 to 8.0 resulted in a greater affinity for L-lactate at $5^{\circ} \mathrm{C}$, the resulting $K_{m}$ at $\mathrm{pH} 8.0$ was higher than the $K_{m}$ values reported for euthermic $\mathrm{LDH}$ at either $\mathrm{pH}$ at $5^{\circ} \mathrm{C}$ (Figure 2.3). Therefore, at either $\mathrm{pH}$ value at $5^{\circ} \mathrm{C}$, hibernating $\mathrm{LDH}$ is more effective than its euthermic counterpart in suppressing the lactate-oxidizing reaction.

\section{iv. $\quad$ Conclusion}

Purified skeletal muscle LDH from Richardson's ground squirrels showed distinctly different structural and kinetic properties between euthemic and hibernating conditions, with hibernating LDH appearing to be less active in the lactate-oxidizing direction at a low, hibernating temperature as compared to euthermic LDH. Given that 
skeletal muscle cells are generally non-gluconeogenic and many glycolytic enzymes are suppressed during hibernation, LDH modification may be necessary to prevent the accumulation of pyruvate and help maintain $\mathrm{NAD}^{+}$levels within muscle cells. 


\section{Chapter 3}

Purification and Properties of Glycerol-3Phosphate Dehydrogenase from the Liver of the Hibernating Ground Squirrel, Urocitellus richardsonii 


\section{Introduction}

To survive harsh winter climates, many small mammals are capable entering a hypometabolic state, marked by an active suppression of their metabolic rate (MR) to limit energy expenditures and a consequent lowering of their body temperature $\left(\mathrm{T}_{\mathrm{b}}\right)($ Lyman $e t$ al., 2013). Mammals that use torpor are generally classified as either species using daily torpor (i.e. daily heterotherms that drop their $\mathrm{T}_{\mathrm{b}}$ by a few degrees Celsius during the inactive part of their day) or multi-day hibernation. Daily heterotherms typically enter torpor bouts lasting between approximately 3 and 12 hours, typically in a facultative manner responding to current environmental temperature and food conditions. In contrast, hibernators cycle through consecutive, prolonged periods (on average 1 week for ground squirrels) of torpor and show a circannual rhythm where hibernation only occurs during the winter season (Geiser and Ruf, 1995). Richardson's ground squirrels (Urocitellus richardsonii) ae seasonal hibernators that allow $\mathrm{T}_{\mathrm{b}}$ to sink to near-ambient during winter dormancy but defend a $\mathrm{T}_{\mathrm{b}}$ about $5^{\circ} \mathrm{C}$ (using low levels thermogenesis by brown adipose) if ambient temperature falls below $0^{\circ} \mathrm{C}$. Metabolic rate falls by approximately $95 \%$ relative to euthermic resting rate and overall, by hibernating, the squirrels save about $88 \%$ of the energy that would otherwise be needed to remain euthermic all winter (Wang and Lee, 1996).

Many studies have looked at the biochemical adaptations that mediate the entrance, maintenance, and exit from a hypometabolic state and regulate the enzymes associated with energy metabolism during hibernation (reviewed in Carey et al., 2003; Storey, 1997; Storey and Storey, 2010). Furthermore, hibernation is marked by the switch from carbohydrates as a main fuel source for energy to the oxidation of triglycerides, which are built up during 
a period of hyperphagy and fattening just prior to hibernation (Dark, 2005). Previous research has indicted that torpor-arousal cycles either do not occur or are interrupted if fat stores are insufficient or if the amounts of necessary polyunsaturated fatty acids are too low (Cranford, 1978; Geiser et al., 1994; Frank, 1992; Florant, 1992; Florant et al., 1993). Triglyceride oxidation produces three important metabolites that aid in survival during the winter season. First, ATP energy is generated from the $\beta$-oxidation of fatty acids (FAs); second, the generation of ketone bodies such as acetoacetate and $\beta$-hydroxybutyrate serve as fuel sources for specialized tissue that cannot catabolize long chain FAs (i.e. brain); and third, glycerol which is derived from hydrolysis of triglycerides (Carey, 1993). In several species, the ability to produce glucose from glycerol is a fundamental evolutionary adaptation in the hibernation process and allows survival during harsh conditions (Yeh et al., 1995).

Cytosolic glycerol-3-phosphate dehydrogenase (G3PDH, EC 1.1.1.8) is an important branch point enzyme connecting lipid metabolism and carbohydrate metabolism. G3PDH is responsible for a number of metabolic functions including: (a) contributing to reoxidization of the $\mathrm{NADH}$ formed at the glyceraldehyde-3-phosphate dehydrogenase (GAPDH) reaction during aerobic glycolysis, (b) G3P generation for triglyceride and phospholipid synthesis, (c) facilitating transport of G3P across the mitochondrial membrane (as a part of the G3P shuttle), and the conversion of G3P to dihydroxyacetone phosphate (DHAP) during gluconeogenesis from glycerol (Bissell et al., 1976; and reviewed in Brisson et al., 2001). In humans, under normal conditions, gluconeogenesis from glycerol contributes very little to new glucose production (less than 5\%). However, after 2-4 days of fasting, more than $20 \%$ of new glucose produced is derived from glycerol. 
Furthermore, in times of prolonged starvation glycerol can be used as the only source of glucose production since glycogen reserves are depleted within two fasting days (Bortz et al., 1972; Owen et al., 1969, Baba et al., 1994). Previous research by Berrada et al. (2000) revealed that in the hibernator, Jaculus orientalis, cytoplasmic G3PDH activity increases during the hibernation process. Given that Richardson's ground squirrels endure a period of long term starvation when they are in hibernation (as they do not eat and rely on endogenous fuel reserves over the winter), differential regulation via temperature effects and/or post-translational modifications (PTMs) of G3PDH may play an important role in modifying fuel metabolism and supporting gluconeogenesis over the winter months.

In the present study, G3PDH was purified from liver of euthermic and hibernating Richardson's ground squirrels. G3PDH regulation was evaluated with a particular focus on an analysis of the structural and functional adaptations of this enzyme and temperatureinduced effects on enzyme activity in the hibernating versus euthermic state. The structural modifications of G3PDH may be critical to the maintenance of enzyme function at low body temperatures and may aid in the metabolic plasticity that takes place during hibernation.

\section{Materials and Methods}

\section{Animals}

Richardson's ground squirrels were treated as previously described in Chapter 2.

\section{Preparation of liver tissue extracts}

Frozen liver tissue samples were homogenized 1:3 w:v in buffer A (10 mM HEPES, pH 7.2, 1 mM EDTA, 1 mM EGTA, $25 \mathrm{mM} \beta$-glycerophosphate, $5 \mathrm{mM} \beta$ - 
mercaptoethanol, 5\% v:v glycerol) and a few crystals of phenylmethylsulphonyl fluoride (PMSF) (added just prior to homogenization) using a Polytron homogenizer (Brinkmann Instruments, Rexdale, ON, Canada). Homogenates were centrifuged at 10,000 x g for 30 minutes at $5^{\circ} \mathrm{C}$, after which supernatants were decanted and held on ice until use.

\section{Purification of liver G3PDH}

A $3.0 \mathrm{~mL}$ sample of liver extract containing $\sim 70 \mathrm{mg}$ of total protein was applied to a Bio-Gel@ HTP Hydroxyapatite (HA) (BioRad) column $(1 \mathrm{~cm}$ [Diameter] X $1 \mathrm{~cm}$ [Height] $)$ previously equilibrated in buffer A. The column was then washed with $15 \mathrm{~mL}$ of buffer A and $4 \mathrm{~mL}$ fractions were collected. From each fraction, $20 \mu \mathrm{L}$ was assayed to detect G3PDH activity. The active fractions were pooled and transferred to buffer B (20 mM MES, pH 6.0, 1 mM EDTA, $1 \mathrm{mM}$ EGTA, $15 \mathrm{mM} \beta$-glycerophosphate, $10 \mathrm{mM} \beta$ mercaptoethanol, 5\% v:v glycerol) by centrifugation (1 min @ 2000 rpm) through small columns of Sephadex G-25 (Sigma-Aldrich) equilibrated in buffer B. Once in buffer B, the active fractions were applied to a $\mathrm{CM}^{-}$Sephadex (Pharmacia) column $(1 \mathrm{~cm}$ x $5 \mathrm{~cm})$. The $\mathrm{CM}^{-}$Sephadex column was washed with $30 \mathrm{~mL}$ of buffer $\mathrm{B}$ to remove unbound proteins and then a linear gradient of $0-2 \mathrm{M} \mathrm{KCl}$ was applied to elute bound proteins. Fractions of $1.20 \mathrm{~mL}$ were collected and $20 \mu \mathrm{L}$ from each fraction was assayed to detect G3PDH activity. After fractions containing maximal G3PDH activity were pooled, the sample was desalted and transferred back to buffer A via low speed centrifugation in the same manner described for the transfer to buffer B. The sample was then loaded on to a Cibacron Blue 3GA (Sigma-Aldrich) column $(1 \times 5 \mathrm{~cm})$, washed with $30 \mathrm{~mL}$ of buffer A, and bound proteins were eluted with a linear gradient of $0-3 \mathrm{M} \mathrm{KCl}$ in buffer $\mathrm{A}$. The fractions were assayed for G3PDH activity, and the active fractions were pooled and desalted using an 
Amicon ${ }^{\circledR}$ Ultra Filter (Millipore). The purity of the G3PDH sample was checked by denaturing and reducing gel electrophoresis followed by silver staining as described in Chapter 2. G3PDH from liver of euthermic and hibernating ground squirrels were purified in the same manner.

\section{Detection of G3PDH via Silver Staining Technique}

Silver staining procedure (Blum et al., 1987) is the same as previously described in Chapter 2.

\section{G3PDH assay}

G3PDH activity was measured as the rate of production NADH using a microplate based assay by measuring absorbance at $340 \mathrm{~nm}$ using a Thermo Labsystems Multiskan spectrophotometer (Thermo Scientific, Waltham, MA, USA). Optimal assay conditions for G3PDH in the G3P-oxidizing direction were 20 mM HEPES buffer ( $\mathrm{pH} 7.5$ / 8.0), $15 \mathrm{mM}$ $\mathrm{G} 3 \mathrm{P}$, and $2 \mathrm{mM} \mathrm{NAD}{ }^{+}$in a total volume of $200 \mu \mathrm{L}$, including $30 \mu \mathrm{L}$ of purified enzyme

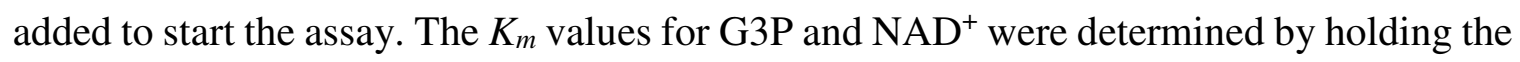
co-substrate constant at $2 \mathrm{mM} \mathrm{NAD}^{+}$, or $15 \mathrm{mM} \mathrm{G3P}$ while varying the substrate of interest. $I C_{50}$ values were obtained via the addition of increasing concentrations of inhibitor molecules (urea, guanidine $\mathrm{HCl}$ ) to purified enzyme whereas $T_{50}$ values were obtained via incubation of purified G3PDH at $50^{\circ} \mathrm{C}$ for increasing amounts of time. G3PDH activities in $I C_{50}$ and $T_{50}$ experiments were assayed at $22^{\circ} \mathrm{C}$ in $20 \mathrm{mM}$ HEPES buffer ( $\left.\mathrm{pH} 8.0\right)$ using optimal substrate concentrations described above. 


\section{SDS Polyacrylamide Gel Electrophoresis and Immunoblotting}

After concentrating 3x using a Amicon® Ultra Filter (Millipore), purified samples of euthermic and hibernating G3PDH were mixed 1:1 (v:v) with SDS loading buffer (100 mM Tris buffer, $\mathrm{pH} 6.8,4 \%$ w:v SDS, $20 \%$ v:v glycerol, $0.2 \%$ w:v bromophenol blue, and $10 \%$ v:v 2-mercaptoethanol) and boiled for 5 minutes, cooled on ice and frozen at $-20^{\circ} \mathrm{C}$ until use. SDS resolving gels (10\% v/v acrylamide, $400 \mathrm{mM}$ Tris, $\mathrm{pH} 8.8,0.1 \% \mathrm{w} / \mathrm{v}$ SDS, $0.2 \% \mathrm{w} / \mathrm{v}$ ammonium persulfate [APS], $0.04 \% \mathrm{v} / \mathrm{v}$ TEMED) were prepared with a $5 \%$ stacking gel (5\% acrylamide, $190 \mathrm{mM}$ Tris, $\mathrm{pH}$ 6.8, 0.1\% w/v SDS, 0.15\% w/v APS, $0.1 \%$ v/v TEMED). Samples were loaded onto these gels and separated electrophoretically in SDS-PAGE running buffer (25 mM Tris-base, $\mathrm{pH} 8.5,190 \mathrm{mM}$ glycine, and 0.1\% w/v SDS) at $180 \mathrm{~V}$ for $45 \mathrm{~min}$. A $2 \mu \mathrm{L}$ aliquot of protein ladder (FroggaBio) was added to one lane of every gel to provide molecular weight markers. Commercially purified rabbit muscle G3PDH (Sigma Aldrich) was also loaded onto the gel to confirm the correct location of G3PDH subunit. Following electrophoresis, proteins were electroblotted onto polyvinylidiene difluoride (PVDF) membranes (Millipore) by wet transfer and used for immunoblotting.

PVDF membranes were equilibrated in methanol before the wet transfer of proteins from 10\% SDS gels. Electroblotting was performed in transfer buffer (25 mM Tris, pH 8.5, $192 \mathrm{mM}$ glycine, and $20 \% \mathrm{v} / \mathrm{v}$ methanol) at room temperature for $1.5 \mathrm{~h}$ at $160 \mathrm{~mA}$. Following protein transfer, PVDF membranes were blocked with $2.5 \%$ skim milk for 10 minutes. Membranes were washed three times with Tris-buffered saline (100 mM Trisbase, $140 \mathrm{mM} \mathrm{NaCl}, \mathrm{pH}$ 7.6) containing $0.05 \%$ Tween-20 (TBST) for 5 min each before one of the following primary antibodies were applied: (1) rabbit anti-phosphoserine (Cat. 
\#618100, Invitrogen, Carlsbad, CA, USA); (2) rabbit anti-phosphothreonine (Cat. \#718200, Invitrogen, Carlsbad, CA, USA); (3) rabbit anti-phosphotyrosine (Cat. \#615800, Invitrogen, Carlsbad, CA, USA); (4) rabbit anti-methylated lysine (SPC-158F, StressMarq, Biosciences Inc., Victoria, BC, Canada); (5) rabbit anti-pan-acetyl (CR)-R (Cat. \# sc-8663R, Santa Cruz Biotechnology, Santa Cruz, CA, USA); or (6) rabbit anti-ubiquitin (ab19247, Abcam, Cambridge, UK). All primary antibodies were diluted 1:1000 v:v in TBST with a small amount of sodium azide added. Primary antibodies were applied to membranes and allowed to incubate overnight at $4^{\circ} \mathrm{C}$ with gentle rocking. Membranes were washed with TBST (3 x 5min), and incubated with a 1:2000 v:v dilution of goat anti-rabbit IgGperoxidase secondary antibody for $60 \mathrm{~min}$ at room temperature. Blots were washed with TBST (3 $x 5 \mathrm{~min})$ prior to chemiluminescence visualization on the ChemiGenius Bioimaging System (Syngene, Frederick, MD, USA). The band intensities were quantified using GeneTools software (Syngene, Frederick, MD, USA). To confirm equal protein loading of samples, Coomassie blue staining of membranes was subsequently performed and used to standardize immunoblot band intensities. Protein-standardized band intensities for hibernator G3PDH were then expressed relative to the standardized signal intensities for control G3PDH samples.

\section{Bioinformatics and Molecular Modeling}

Bioinformatic analyses were used to support the data obtained experimentally in this study. Since the genome for Richardson's ground squirrel is unsequenced, the predicted G3PDH sequence from thirteen-lined ground squirrel (13-LGS; I. tridecemlineatus), the only sequenced ground squirrel hibernator, was used for assessing differences in G3PDH structure. Of two predicted 13-LGS G3PDH cytoplasmic isoforms, 
X1 (Accession: XP_005324992.1) and X2 (Accession: XP_005324993.1), which have 93.8\% similarity (Supplementary Fig. S3.1), the amino acid sequence from the X1 isoform was used for subsequent analyses. To observe the conservation of G3PDH amino acid residues across different mammals, the predicted G3PDH amino acid sequence from 13LGS was aligned with naked mole rat, (Heterocephalus glaber), mouse (Mus musculus), and human (Homo sapiens) G3PDH using ClustalW2 (Larkin et al., 2007) (Supplementary Fig. S3.2). To identify possible phosphorylation sites, the predicted G3PDH amino acid sequence was inputted in to the NetPhos 2.0 server (Blom et al., 1999). Despite differences in the amino acid sequences of the G3PDH cytoplasmic isoforms, the predicted phosphorylation sites were conserved (Supplementary Fig. S3.3a,b).

The predicted tertiary and quaternary structure of G3PDH was created using the SWISS-MODEL server (http://swissmodel.expasy.org/) (Arnold et al., 2006). The crystal structure from human G3PDH (PDB identifier: 1X0V) was used to build the ground squirrel G3PDH model. Next, the protein model was protonated, optimized by energy minimization using MMFF94× force field model, and modified for phosphorylation in Molecular Operating Environment (MOE) software (v.2011.10) (Chemical Computing Group, QC).

\section{Data Analyses}

Analysis of liver G3PDH was conducted in a similar manner as described in Chapter 2. Examples of data analyses from multiple independent determinations of kinetic parameters on separate preparations of enzyme are found in the Supplementary Materials (Supplementary Fig. S3.5). 


\section{Results}

\section{Purification of G3PDH from the liver of euthermic and hibernating $U$. richardsonii}

Purification of G3PDH from the liver of euthermic and hibernating U. richardsonii was accomplished by three chromatography steps: a HA column (enzyme eluted in the unbound fraction), a $\mathrm{CM}^{-}$column (elution with a $0-2 \mathrm{M} \mathrm{KCl}$ ), and lastly, a Cibacron blue affinity column (elution with $0-3 \mathrm{M} \mathrm{KCl}$ gradient) (Table 3.1). Collection of the flowthrough fractions from the HA column resulted in a 4.82- and 4.97- fold purification of recovered activity for liver G3PDH from of euthermic and hibernating squirrels, respectively (Table 3.1). Elution of euthermic and hibernator G3PDH from the $\mathrm{CM}^{-}$column using a $\mathrm{KCl}$ gradient gave a net 21.48 - and 14.20- fold purification, respectively (Table 3.1; Fig. 3.1a). Finally, the elution of euthermic and hibernator G3PDH from the Cibacron blue column using a $\mathrm{KCl}$ gradient resulted in a net 273.51 and 272.56 -fold purification, respectively (Table 3.1; Fig. 3.1b). The final purification resulted in specific activities of 2,174 $\mathrm{mU} \mathrm{mg}^{-1}$ protein for euthermic G3PDH, and 2,900 $\mathrm{mU} \mathrm{mg}^{-1}$ for hibernator G3PDH (Table 3.1). As a result of this three-step purification scheme, G3PDH was purified to $>95 \%$ homogeneity, as determined by gel electrophoresis and staining with silver nitrate (Fig. 3.2). The purified G3PDH had an apparent subunit molecular weight of $37 \mathrm{kDa}$ (Fig. $3.2)$.

\section{Reversible post-translational modifications of liver G3PDH}

Immunoblotting was used to assess possible differences in post-translational modifications of purified liver G3PDH from euthermic and hibernating conditions. Phosphorylation at serine and threonine residues of hibernating G3PDH was not 
significantly different when compared to euthermic G3PDH ( $\mathrm{P}>0.05$, Fig. 3.3a). However, when comparing phosphorylation on tyrosine residues, there was a $1.70 \pm 0.12$ fold increase in phosphorylation of hibernating G3PDH relative to euthermic G3PDH (1.00 \pm 0.07, $\mathrm{P}<0.05$, Fig. 3.3a). A comparable analysis of post-translational modifications via methylation, acetylation, and ubiquitination revealed no significant differences between euthermic and hibernator liver G3PDH (P>0.05, Fig. 3.3b).

\section{Prediction of phosphorylated amino acid residues and molecular modeling of liver G3PDH}

To find potential reversible phosphorylation sites in Richardson's ground squirrel G3PDH, the predicted protein sequence of G3PDH in thirteen-lined ground squirrel (I. tridecemlineatus) was used since it has a sequenced genome. Analysis of the predicted 13LGS G3PDH amino acid sequence (NCBI Reference Sequence: XP_005324992.1) via the phosphorylation site predict server NetPhos 2.0 (Blom et al., 1999) indicated 7 predicted potential phosphorylation residues (Supplementary Fig. 3.3a). Interestingly, there was only one predicted potential phospho-tyrosine residue. With an increase in relative tyrosine phosphorylation in hibernating G3PDH compared to euthermic G3PDH, a molecular model was built to elucidate this difference with the inclusion of a phosphate on the predicted tyrosine ( ${ }^{83} \mathrm{Tyr}$ ) phosphorylation residue (Figure 3.4).

With respect to the primary structure of the enzyme, the amino acid sequence seems to be highly conserved across mammals (Supplementary Fig. S3.2). As depicted by MOE model, the predicted ground squirrel G3PDH has a homodimeric quaternary structure (Fig. 3.4). The tertiary structure of the enzyme consisted of a C-terminal helical substrate- 
binding domain and an eight-stranded $\beta$-sheet sandwich domain at the $\mathrm{N}$-terminal. With that being said, the predicted ground squirrel G3PDH model is highly similar to the quaternary structure of the human form of G3PDH (Supplementary Fig. S3.4).

\section{Kinetic activity of purified G3PDH from euthermic and hibernating ground squirrel} liver

i. $\quad$ Effects of reversible post-translational modifications on liver G3PDH activity

Analysis of the kinetic parameters of G3PDH from the muscle of euthermic and hibernating animals showed that G3PDH displayed hyperbolic substrate saturation curves with respect to both $\mathrm{G} 3 \mathrm{P}$ and $\mathrm{NAD}^{+}$(Fig. 3.5). In the G3P-oxidizing direction, there were significant increases in the $\mathrm{K}_{\mathrm{m}}$ values for G3P between euthermic and hibernating G3PDH at $37^{\circ} \mathrm{C}$ and $22^{\circ} \mathrm{C}$ (Table 3.2). Interestingly, at $5^{\circ} \mathrm{C}$ hiberating G3PDH had a greater affinity for $\mathrm{G} 3 \mathrm{P}$ since the $\mathrm{K}_{\mathrm{m}}$ of $\mathrm{G} 3 \mathrm{P}(0.48 \pm 0.05 \mathrm{mM})$ decreased to $58 \%$ of the euthermic value $\left(0.83 \pm 0.02 \mathrm{mM}, \mathrm{P}<0.05\right.$, Table 3.2). When looking at the co-substate, the $\mathrm{K}_{\mathrm{m}}$ values for $\mathrm{NAD}^{+}$at $22^{\circ} \mathrm{C}$ and $37^{\circ} \mathrm{C}$ were not significantly different when comparing the euthermic and hibernating conditions ( $\mathrm{P}>0.05$, Table 3.2). However, like the trend for $\mathrm{G} 3 \mathrm{P}$ at $5^{\circ} \mathrm{C}$, there was a significant decrease in the $\mathrm{K}_{\mathrm{m}}$ of $\mathrm{NAD}^{+}(0.09 \pm 0.04 \mathrm{mM})$ in the hibernating condition compared to the euthermic condition $(0.12 \pm 0.05 \mathrm{mM}, \mathrm{P}<0.05$, Table 3.2).

With respect to G3PDH reaction velocities in the G3P-oxidizing direction, the $\mathrm{V}_{\max }$ values at $37^{\circ} \mathrm{C}$ and $22^{\circ} \mathrm{C}$ decreased by $53 \%$ and $58 \%$, respectively, for hibernating G3PDH as compared to euthermic $\mathrm{G} 3 \mathrm{PDH}(\mathrm{P}<0.05$, Table 3.2$)$. However, at $5^{\circ} \mathrm{C}$, hiberating G3PDH $V_{\max }$ was not significantly different than its euthermic counterpart (Table 3.2). 
The maximal activity of euthermic and hibernator G3PDH at the three temperatures $\left(37^{\circ} \mathrm{C}, 22^{\circ} \mathrm{C}\right.$, and $\left.5^{\circ} \mathrm{C}\right)$ was analyzed. An Arrhenius plot was created to determine the activation energy $\left(E_{a}\right)$ for the G3P-oxidizing reaction of G3PDH. For hibernator G3PDH, the $\mathrm{E}_{\mathrm{a}}(38.1 \pm 2.5 \mathrm{~kJ} / \mathrm{mol})$ was significantly lower $(\mathrm{P}<0.05)$ compared to the $\mathrm{E}_{\mathrm{a}}$ for euthermic G3PDH (64.2 $\pm 12.2 \mathrm{~kJ} / \mathrm{mol}$, Table 3.2).

Last, both euthermic and hibernator G3PDH were subjected to denaturants to assess the structural stability of the two enzyme forms. When exposed to guanidine hydrochloride $(\mathrm{GuHCl})$, comparison of the $\mathrm{IC}_{50}$ values indicated that less of the denaturant was required to inhibit the hibernator form of the enzyme relative to the euthermic (Table 3.2). Despite the decrease in enzyme stability due to $\mathrm{GuHCl}$, hibernator G3PDH was found to be more thermally stable as indicated by a 2.1 -fold higher $T_{50}$ value relative to the euthermic enzyme $(\mathrm{P}<0.05$, Table 3.2).

\section{ii. Temperature effects on euthermic and hibernator forms of liver G3PDH}

As the temperature decreased from $37^{\circ} \mathrm{C}$ to $5^{\circ} \mathrm{C}$, there was a general decrease in most of the kinetic parameters in the G3P-oxidizing direction for both euthermic and hibernating G3PDH. Notably, in the hibernating state, $K_{m}$ for G3P decreased by $69 \%$ as temperature decreased from $37^{\circ} \mathrm{C}(1.56 \pm 0.14 \mathrm{mM})$ to $5^{\circ} \mathrm{C}(0.48 \pm 0.05 \mathrm{mM}, \mathrm{P}<0.05$, Table 3.2). Likewise, there was a significant decrease in the $K_{m}$ for $\mathrm{NAD}^{+}$when comparing $37^{\circ} \mathrm{C}$ to $5^{\circ} \mathrm{C}$ (Table 3.2). Furthermore, the change in temperature from $37^{\circ} \mathrm{C}$ to $5^{\circ} \mathrm{C}$ also lead to $96 \%$ and $82 \%$ decreases in the $V_{\max }$ values in the G3P-oxidizing direction for euthermic and hibernator enzymes, respectively (Table 3.2). 


\section{iii. Effect of $\mathrm{H}^{+}$concentration on euthermic and hibernator forms of G3PDH}

When comparing the change in $\mathrm{pH}$ from 8.0 to 7.5 in the G3P-oxidizing direction, euthermic G3PDH showed an increase in affinity for $\mathrm{G} 3 \mathrm{P}$ at $37^{\circ} \mathrm{C}$ as indicated by a $28 \%$ decrease in $\mathrm{K}_{m}(\mathrm{P}<0.05)$; however, this trend was reversed at $5^{\circ} \mathrm{C}$ as there was a decrease in G3P affinity with an increase in $\mathrm{H}^{+}$concentration (Table 3.3a). Changes in $\mathrm{pH}$ did not affect the enzyme's affinity for $\mathrm{G} 3 \mathrm{P}$ at $37^{\circ} \mathrm{C}$ hibernating condition; however at $22^{\circ} \mathrm{C}$, the $\mathrm{K}_{\mathrm{m}}$ for $\mathrm{G} 3 \mathrm{P}$ decreased as the buffer $\mathrm{pH}$ changed from 8.0 to 7.5 (Table 3.3b). Like the trends found for $\mathrm{G} 3 \mathrm{P}$, a change in $\mathrm{pH}$ from 8.0 to 7.5 lead to increased $\mathrm{G} 3 \mathrm{PDH}$ affinity for $\mathrm{NAD}^{+}$. With a change in $\mathrm{pH}$ from 8.0 to 7.5 at $22^{\circ} \mathrm{C}$ in the euthermic and hibernator conditions, $\mathrm{K}_{m} \mathrm{NAD}^{+}$decreased by $62 \%$ and 53\%, respectively (Table 3.3).

With respect to enzymatic reaction velocities, at $22^{\circ} \mathrm{C}, \mathrm{V}_{\max }$ decreased significantly for euthermic $\mathrm{G} 3 \mathrm{PDH}$ as $\mathrm{pH}$ decreased; however, at $37^{\circ} \mathrm{C}$ there was no significant change in $V_{\max }$ (Table 3.3a). In hibernator G3PDH, there was also a decrease in $\mathrm{V}_{\max }$ as the $\mathrm{pH}$ decreased from 8 to 7.5 although this change occurred at $37^{\circ} \mathrm{C}$ instead of $22^{\circ} \mathrm{C}$ (Table $3.3 \mathrm{~b}$ ). 
Table 3.1. Purification and yield of $U$. richardsonii G3PDH from liver of (a) euthermic and (b) hibernating animals.

(a)

\begin{tabular}{cccccc}
\hline Step & $\begin{array}{c}\text { Total Protein } \\
(\mathbf{m g})\end{array}$ & $\begin{array}{c}\text { Total Activity } \\
(\mathbf{m U})\end{array}$ & $\begin{array}{c}\text { Specific Activity } \\
(\mathbf{m U} / \mathbf{m g})\end{array}$ & $\begin{array}{c}\text { Fold } \\
\text { Purification }\end{array}$ & \%Yield \\
Crude & 69.16 & 549.51 & 7.95 & - & 100 \\
HA & 5.66 & 217.16 & 38.34 & 4.82 & 39.52 \\
CM- & 0.30 & 51.36 & 170.63 & 21.48 & 9.35 \\
$\begin{array}{c}\text { Cibacron Blue } \\
(\text { KCl) }\end{array}$ & 0.016 & 34.79 & 2174.38 & 273.51 & 6.33 \\
\hline
\end{tabular}

(b)

\begin{tabular}{cccccc}
\hline Step & $\begin{array}{c}\text { Total Protein } \\
(\mathbf{m g})\end{array}$ & $\begin{array}{c}\text { Total Activity } \\
(\mathbf{m U})\end{array}$ & $\begin{array}{c}\text { Specific Activity } \\
(\mathbf{m U} / \mathbf{m g})\end{array}$ & $\begin{array}{c}\text { Fold } \\
\text { Purification }\end{array}$ & \%Yield \\
\hline Crude & 77.88 & 828.92 & 10.64 & - & 100 \\
HA & 6.54 & 346.00 & 52.88 & 4.97 & 41.74 \\
CM- & 0.35 & 53.51 & 151.16 & 14.20 & 6.46 \\
$\begin{array}{c}\text { Cibacron Blue } \\
(\text { KCl })\end{array}$ & 0.016 & 46.40 & 2900.00 & 272.56 & 5.60 \\
\hline
\end{tabular}


Table 3.2. Kinetic parameters of purified liver G3PDH from euthermic and hibernating $U$. richardsonii.

\begin{tabular}{|c|c|c|}
\hline Enzyme parameter & Euthermic & Hibernating \\
\hline \multicolumn{3}{|c|}{ Forward reaction $(G 3 P \rightarrow D H A P, p H 8)$} \\
\hline $\mathrm{Km}$ G3P, $37^{\circ} \mathrm{C}(\mathrm{mM})$ & $0.88 \pm 0.10$ & $1.56 \pm 0.14^{a}$ \\
\hline $\mathrm{Km} \mathrm{G} 3 \mathrm{P}, 22^{\circ} \mathrm{C}(\mathrm{mM})$ & $0.57 \pm 0.02^{b}$ & $1.61 \pm 0.13^{a}$ \\
\hline $\mathrm{Km} \mathrm{G} 3 \mathrm{P}, 5^{\circ} \mathrm{C}(\mathrm{mM})$ & $0.83 \pm 0.02$ & $0.48 \pm 0.05^{a, b}$ \\
\hline $\mathrm{Km} \mathrm{NAD}, 37^{\circ} \mathrm{C}(\mathrm{mM})$ & $0.39 \pm 0.03$ & $0.32 \pm 0.02$ \\
\hline $\mathrm{Km} \mathrm{NAD}, 22^{\circ} \mathrm{C}(\mathrm{mM})$ & $0.52 \pm 0.06$ & $0.42 \pm 0.09$ \\
\hline $\mathrm{Km} \mathrm{NAD}, 5^{\circ} \mathrm{C}(\mathrm{mM})$ & $0.12 \pm 0.05^{b}$ & $0.09 \pm 0.04^{b}$ \\
\hline$V \max , 37^{\circ} \mathrm{C}(\mathrm{mU} / \mu \mathrm{g})$ & $1.61 \pm 0.28$ & $0.76 \pm 0.04^{a}$ \\
\hline $\mathrm{V} \max , 22^{\circ} \mathrm{C}(\mathrm{mU} / \mu \mathrm{g})$ & $0.77 \pm 0.13^{b}$ & $0.32 \pm 0.07^{a, b}$ \\
\hline $\mathrm{V} \max , 5^{\circ} \mathrm{C}(\mathrm{mU} / \mu \mathrm{g})$ & $0.10 \pm 0.02^{b}$ & $0.14 \pm 0.05^{b}$ \\
\hline Activation Energy $(\mathrm{kJ} / \mathrm{mol})$ & $62.4 \pm 12.2$ & $38.1 \pm 2.5^{a}$ \\
\hline $\mathrm{IC}_{50}$ urea, $22^{\circ} \mathrm{C}(\mathrm{M})$ & $2.22 \pm 0.20$ & $1.80 \pm 0.01$ \\
\hline $\mathrm{IC}_{50} \mathrm{GuHCl}, 22^{\circ} \mathrm{C}(\mathrm{M})$ & $0.69 \pm 0.02$ & $0.57 \pm 0.01^{a}$ \\
\hline $\mathrm{T}_{50}, 50^{\circ} \mathrm{C}(\mathrm{min})$ & $6.74 \pm 0.67$ & $14.31 \pm 0.25^{a}$ \\
\hline \multicolumn{3}{|c|}{$\begin{array}{l}a \text { indicates a significant difference from the corresponding euthermic } \\
\text { condition, Student's t test, two-tailed, } \mathrm{P}<0.05 \\
b \text { indicates a significant difference from } 37^{\circ} \mathrm{C} \text { within each condition, one-way } \\
\text { ANOVA with Tukey's post hoc test. } \mathrm{P}<0.05\end{array}$} \\
\hline
\end{tabular}


Table 3.3. Effects of $\mathrm{pH}$ on purified liver G3PDH from (a) euthermic and (b) hibernating U. richardsonii.

\begin{tabular}{lll|lc}
\hline Enzyme parameter & \multicolumn{2}{c}{ (a) Euthermic } & \multicolumn{2}{c}{ (b) Hibernating } \\
\hline Forward reaction $(G 3 P \rightarrow D H A P)$ & $\underline{p H 8.0}$ & $\underline{p H 7.5}$ & $\underline{p H 8.0}$ & $\underline{p H 7.5}$ \\
$\mathrm{Km} \mathrm{G} 3 \mathrm{P}, 37^{\circ} \mathrm{C}(\mathrm{mM})$ & $0.88 \pm 0.10$ & $0.63 \pm 0.01^{a}$ & $1.56 \pm 0.14$ & $1.17 \pm 0.11$ \\
$\mathrm{Km} \mathrm{G} 3 \mathrm{P}, 22^{\circ} \mathrm{C}(\mathrm{mM})$ & $0.57 \pm 0.02$ & $0.61 \pm 0.05$ & $1.61 \pm 0.13$ & $0.41 \pm 0.03^{a}$ \\
$\mathrm{Km} \mathrm{G} 3 \mathrm{P}, 5^{\circ} \mathrm{C}(\mathrm{mM})$ & $0.83 \pm 0.02$ & $1.51 \pm 0.16^{a}$ & $0.48 \pm 0.05$ & - \\
& & & & \\
$\mathrm{Km} \mathrm{NAD}, 37^{\circ} \mathrm{C}(\mathrm{mM})$ & $0.39 \pm 0.03$ & $0.50 \pm 0.05$ & $0.32 \pm 0.02$ & $0.69 \pm 0.16$ \\
$\mathrm{Km} \mathrm{NAD}, 22^{\circ} \mathrm{C}(\mathrm{mM})$ & $0.52 \pm 0.06$ & $0.20 \pm 0.04^{a}$ & $0.42 \pm 0.09$ & $0.20 \pm 0.40^{a}$ \\
& & & & \\
$\mathrm{Vmax}, 37^{\circ} \mathrm{C}(\mathrm{mU} / \mathrm{\mu g})$ & $1.61 \pm 0.28$ & $1.05 \pm 0.19$ & $0.76 \pm 0.04$ & $0.43 \pm 0.07^{a}$ \\
$\mathrm{Vmax}, 22^{\circ} \mathrm{C}(\mathrm{mU} / \mu \mathrm{g})$ & $0.77 \pm 0.13$ & $0.34 \pm 0.05^{a}$ & $0.32 \pm 0.07$ & $0.21 \pm 0.01$ \\
\hline
\end{tabular}

$a$ indicates a significant difference from $\mathrm{pH} 8.0$ in each corresponding condition, Student's t test, two-tailed, $\mathrm{P}<0.05$ 

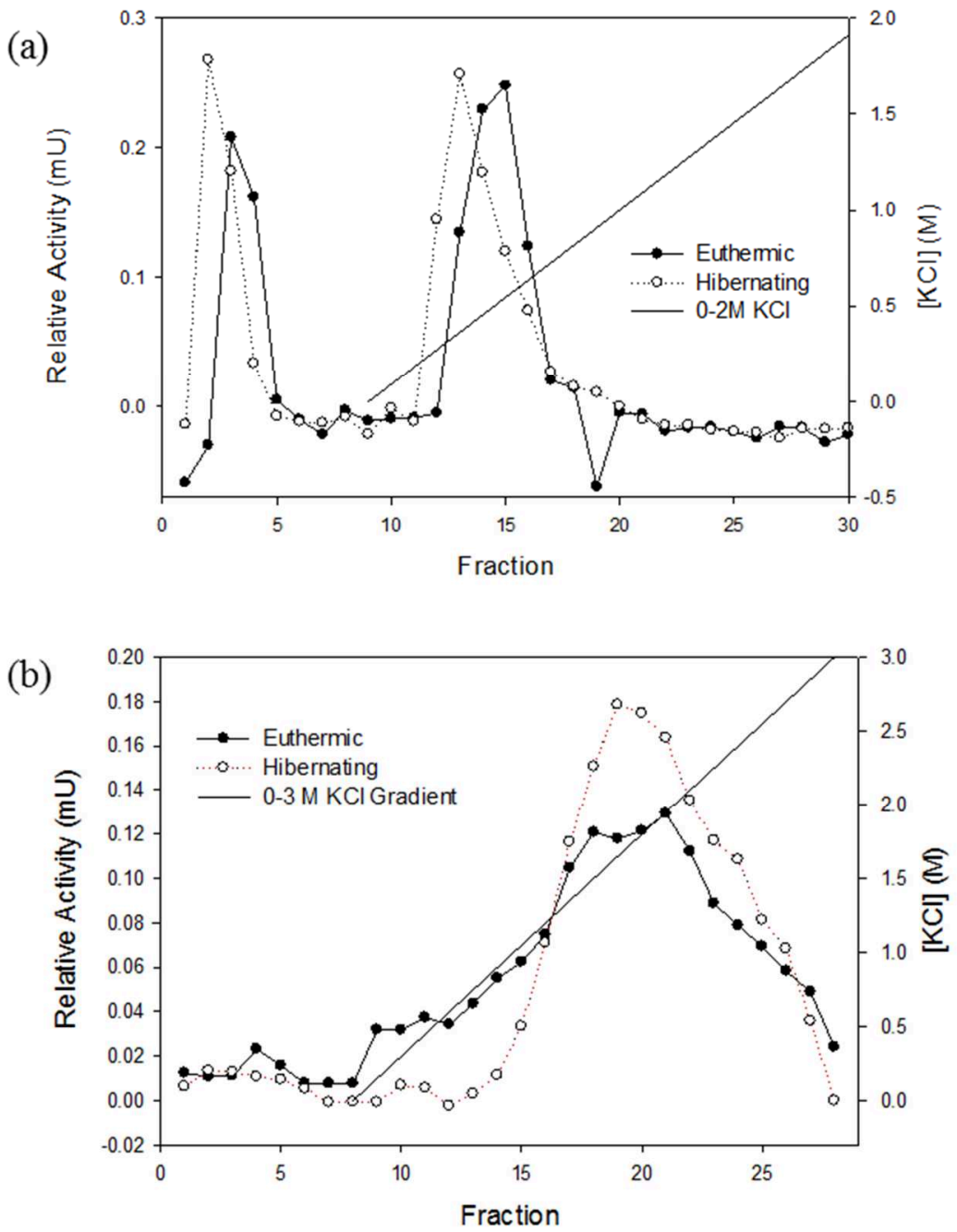

Figure 3.1. Typical elution profiles for G3PDH activity from liver of euthermic (control) and hibernating $U$. richardsonii using (a) $0-2 \mathrm{M}$ gradient of $\mathrm{KCl}$ on a $\mathrm{CM}^{-}$Sephadex column and; (b) $0-3 \mathrm{M}$ gradient of $\mathrm{KCl}$ as the elutant on a Cibacron Blue agarose column. Elution profiles are from separate runs of euthermic and hibernating enzyme but are superimposed here for viewing. 


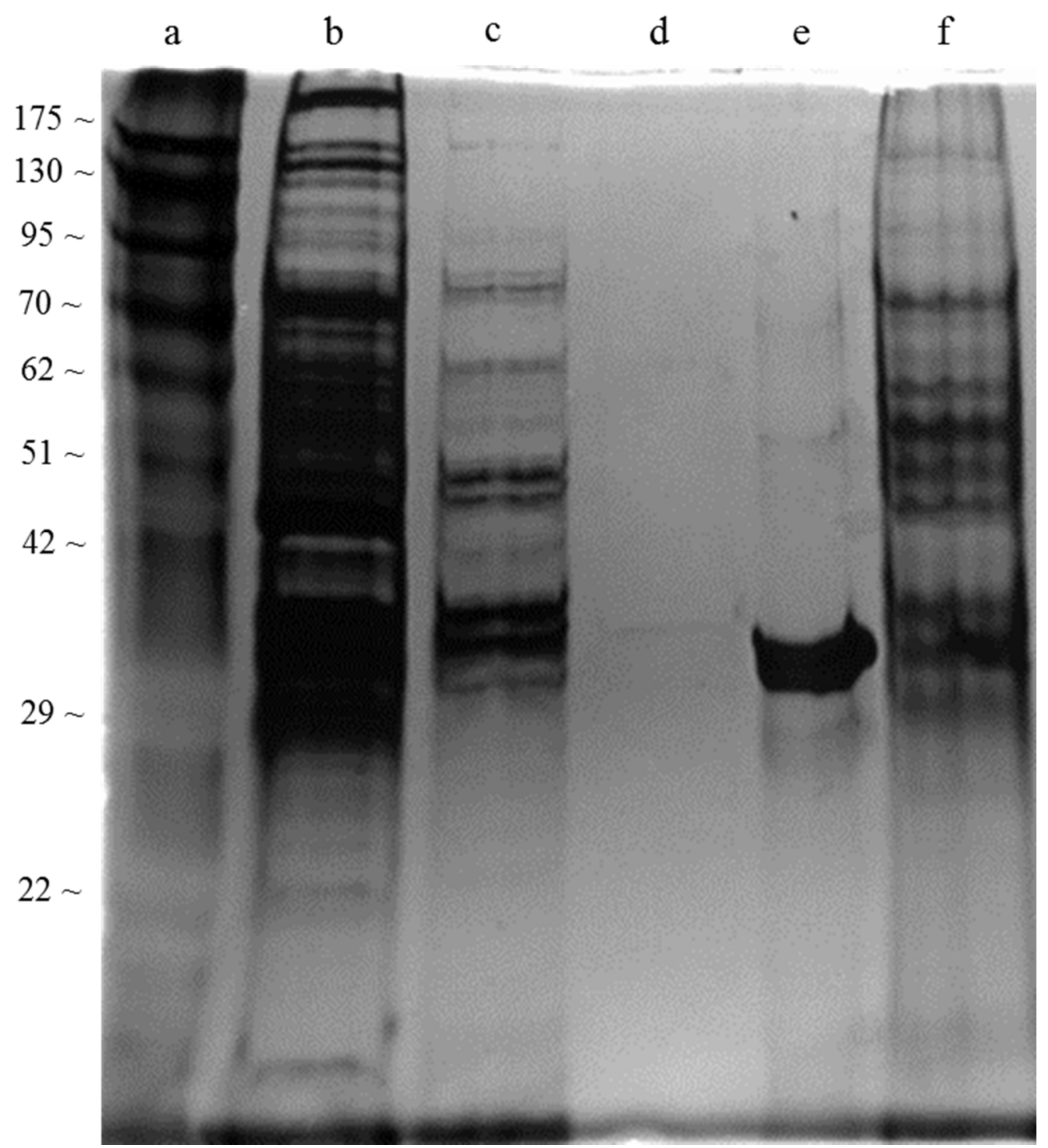

Figure 3.2. 10\% SDS-PAGE gel with silver staining of samples taken at each step in the purification of G3PDH from liver of euthermic $U$. richardsonii. Lanes (a) molecular weight ladder (FroggiaBio); (b) 1:10 diluted pooled sample from hydroxyapatite; (c) pooled G3PDH peak fractions after elution from the $\mathrm{CM}^{-}$Sephadex column with $\mathrm{KCl}$; (d) pooled G3PDH peak fractions after elution from the Cibacron Blue agarose column with $\mathrm{KCl}$; (e) purified rabbit G3PDH (positive control); (f) 1:100 crude homogenate. 


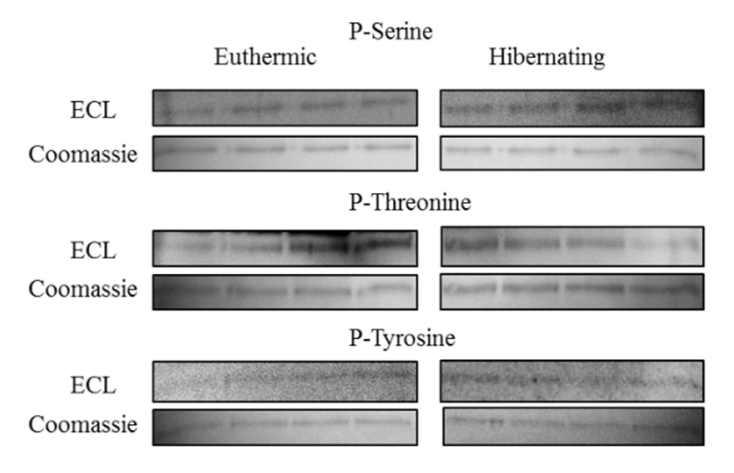

(a)

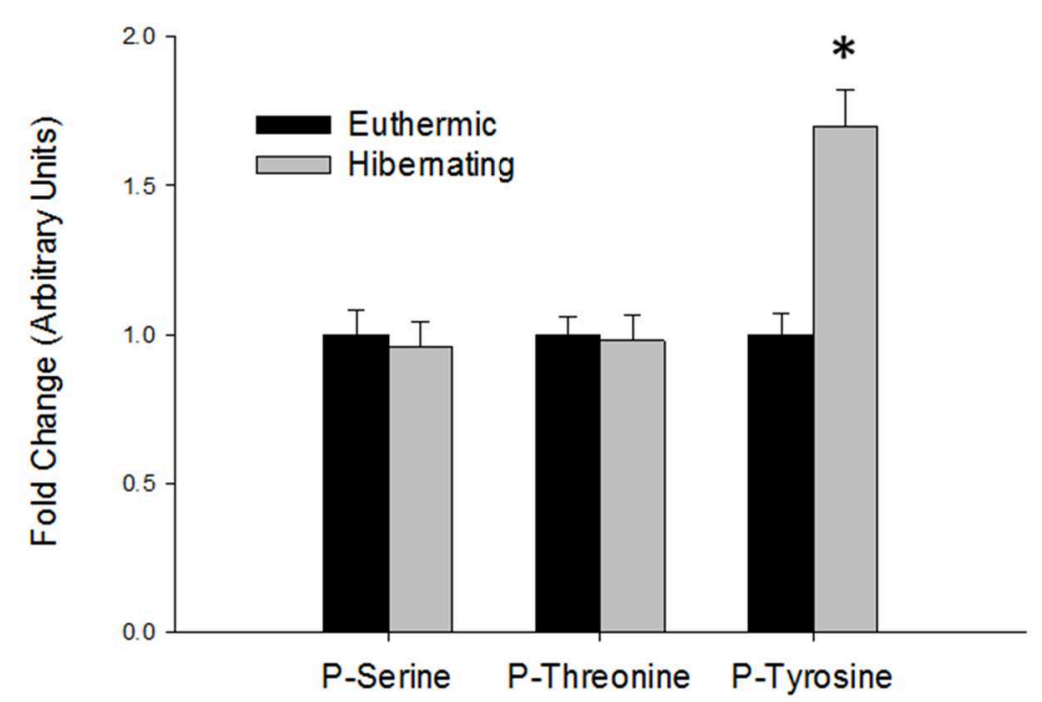

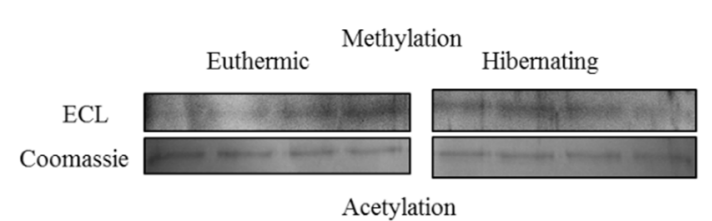

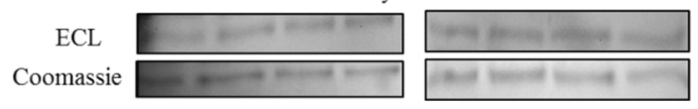

Ubiquitination

(b)

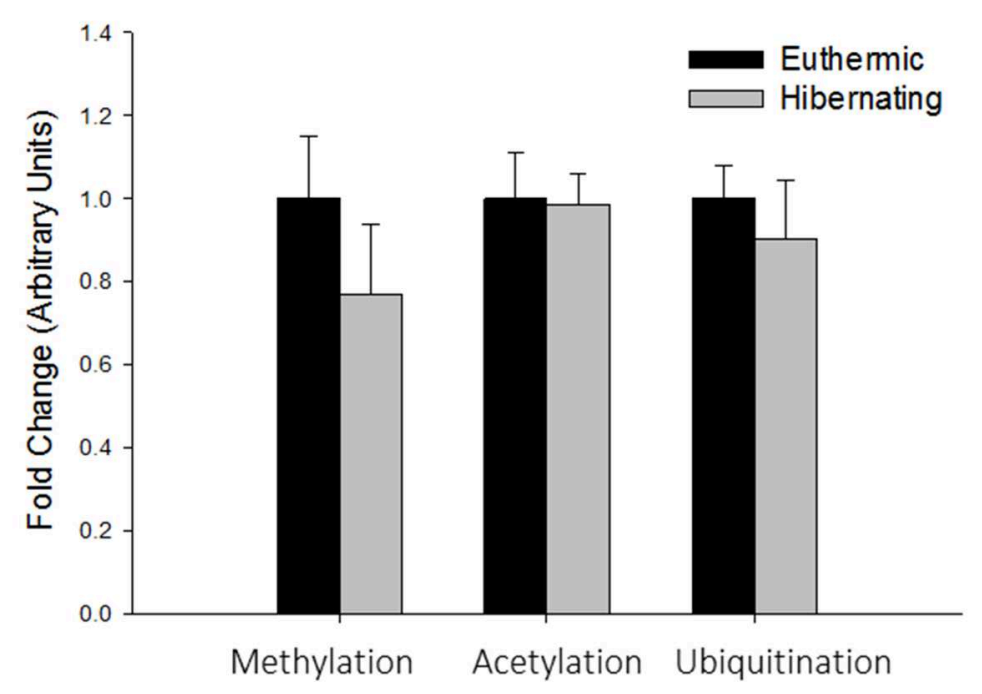

Figure 3.3. Quantification of post-translational modifications of purified G3PDH from liver of euthermic and hibernating $U$. richardsonii via (a) phosphorylation, and (b) methylation, acetylation, and ubiquitination. Chemiluminescence signal intensities were standardized to protein amount, and the value for hibernating G3PDH was expressed relative to the control value that was set to 1 . Data are mean \pm SEM, $n=3-4$ determinations on purified enzyme samples. Asterisks indicate significant differences from the corresponding euthermic G3PDH, Student's t-test, two-tailed, $\mathrm{P}<0.05$. 


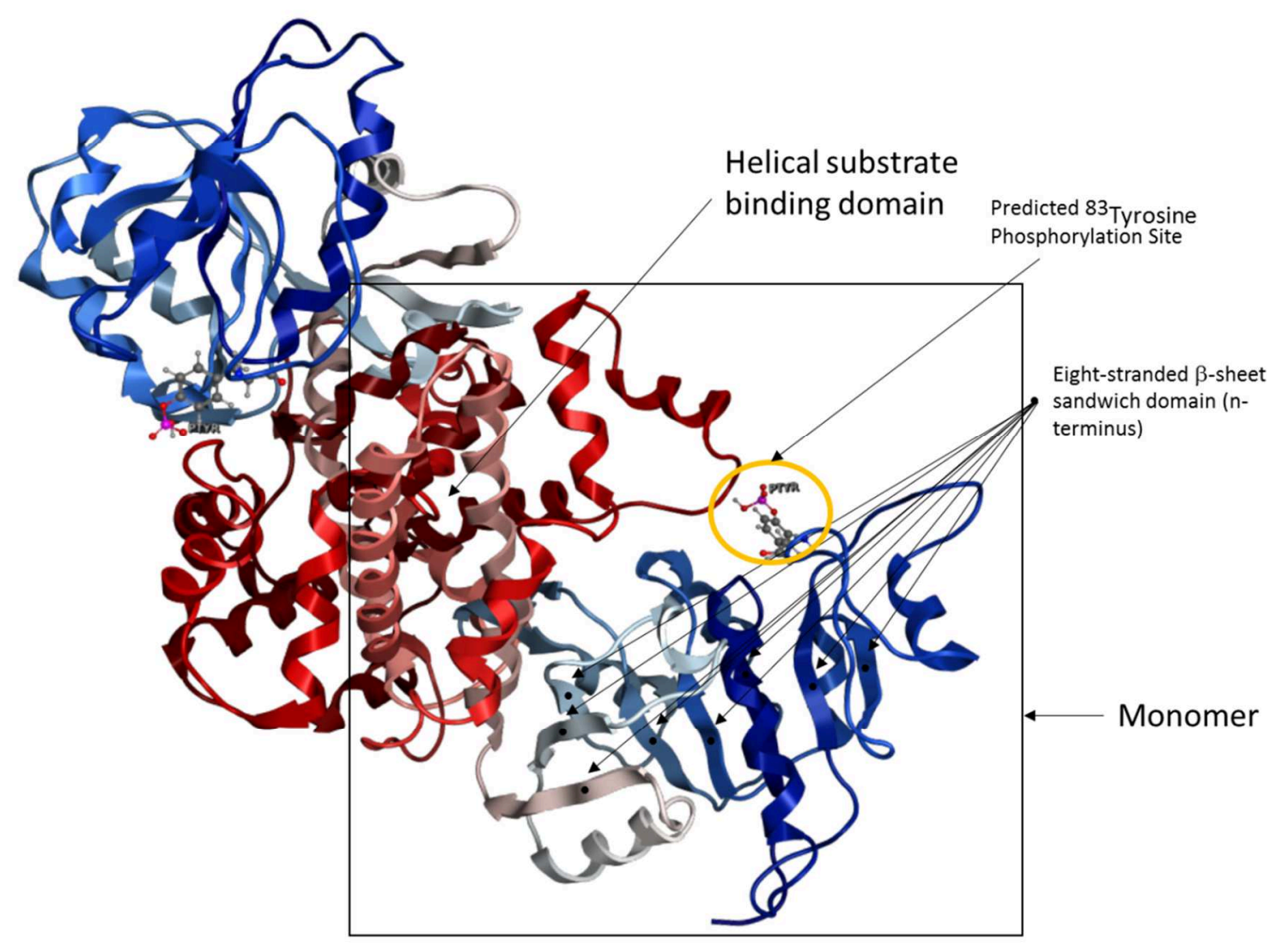

Figure 3.4. The predicted structure of G3PDH from liver of hibernating Richardson's ground squirrel using SWISS-MODEL with human G3PDH as reference (PDB identifier: 1x0v.pdb1.gz). The G3PDH dimeric structure is shown as a cartoon representation. The monomer is identified within the quaternary structure by a black box. The predicted phosphorylation site (on residue ${ }^{83}$ Tyrosine) is circled in yellow; the N-terminal eightstranded $\beta$-sheet sandwich domain (from residues 3-190) is coloured in blue and identified by a $(\bullet)$; the C-terminal helical substrate-binding domain (from residues 193-349) is coloured in red. 
(a)

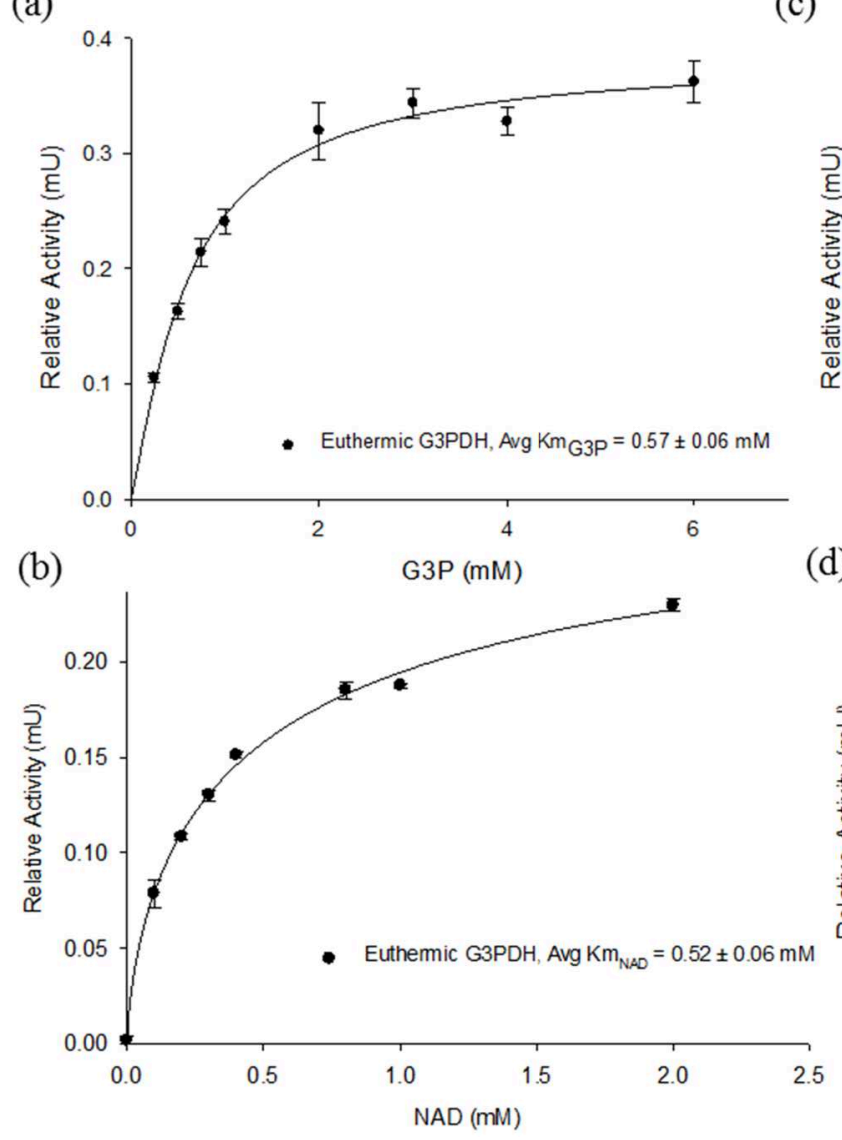

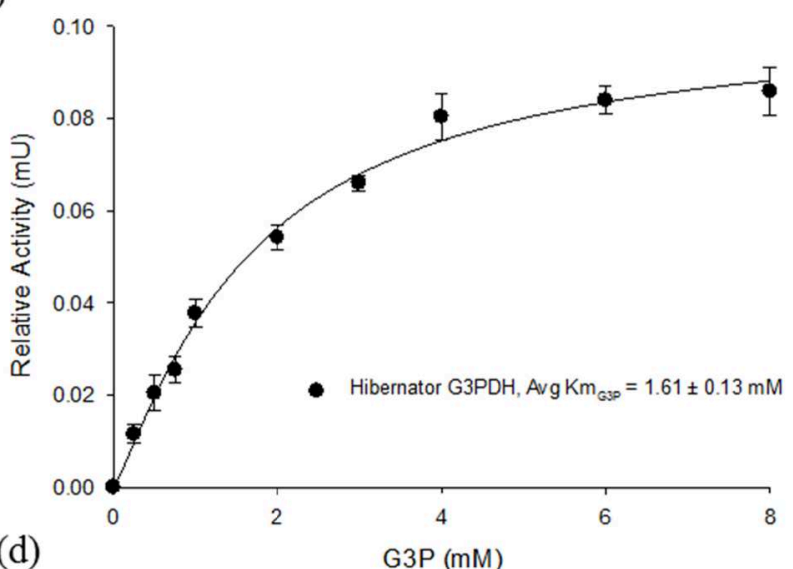

d)

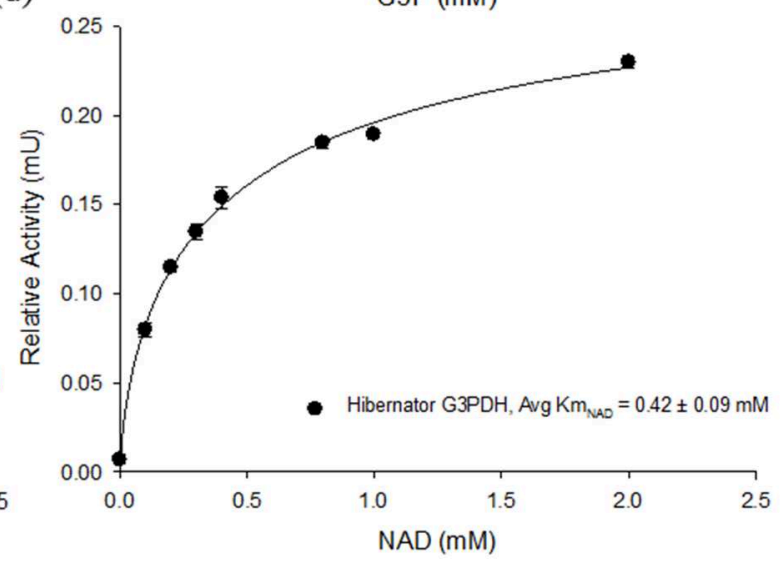

Figure 3.5. Michaelis-Menten curves for substrates of the G3P-utilizing $\left(22^{\circ} \mathrm{C}, \mathrm{pH} 8.0\right)$ reaction catalyzed by purified euthermic (a,b) and hibernating (c,d) G3PDH. Michaelis-Menten curves for G3P affinity (top panels) and NAD (lower panels) are shown. Plots are fitted with a three-parameter Hill coefficient curve using SigmaPlot 12. Data are mean \pm SEM, $\mathrm{n}=4$ individual determinations on purified enzyme samples. 


\section{Supplementary Materials}

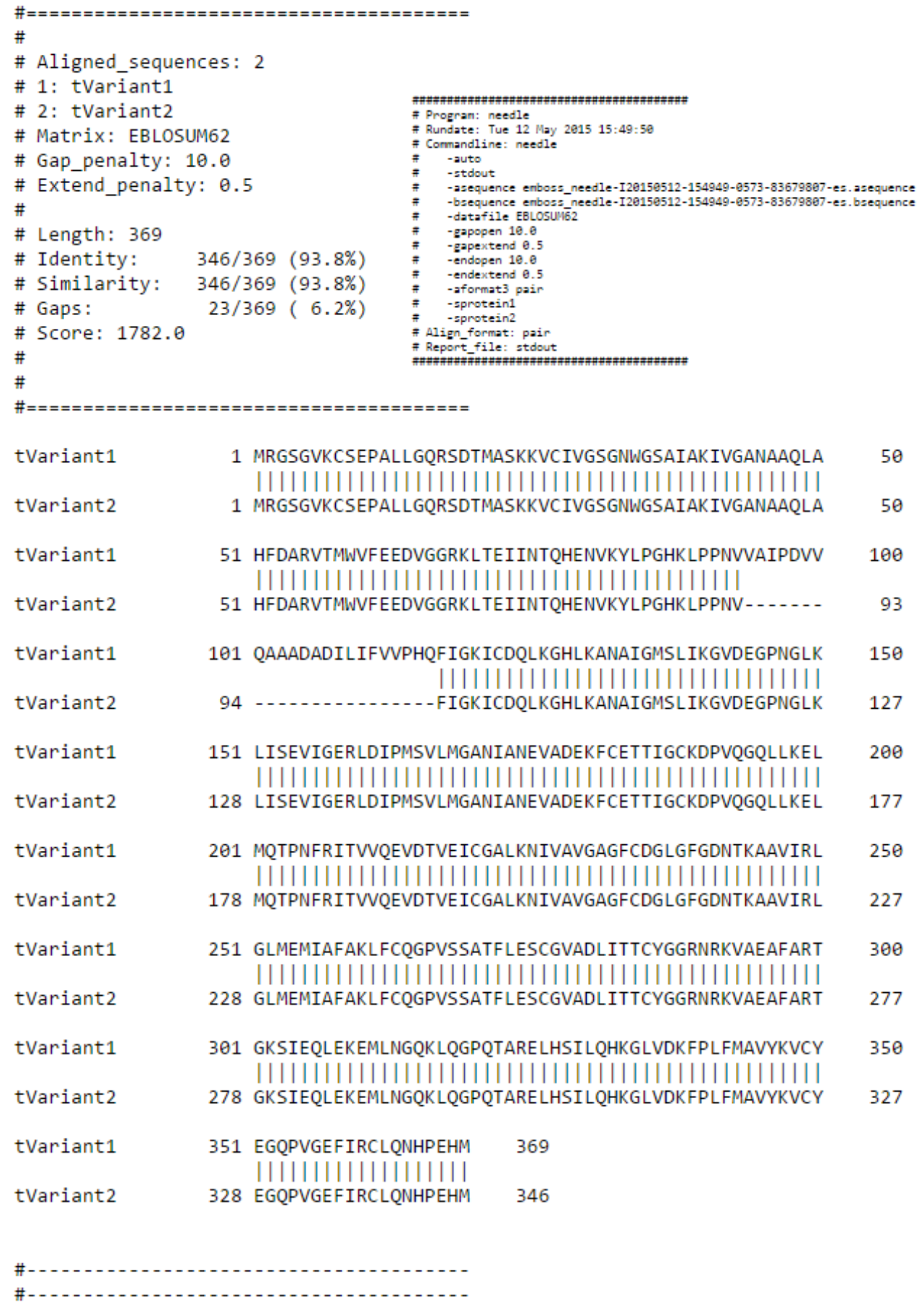

Figure S3.1. Amino acid alignment of thirteen-lined ground squirrel G3PDH cytoplasm isoform X1 (tVariant1; Accession: XP_005324992.1) with isoform X2 (tVariant2; Accession: XP_005324993.1). 
CLUSTAL 2.1 multiple sequence alignment

\begin{tabular}{|c|c|}
\hline 13LGS & MRGSGVKCSEPALLGQRSDTMASKKVCIVGSGNWGSAIAK-IVGANAAQLAHFDARVTMW 59 \\
\hline Naked & MAGAALKVCIVGSGNWGSAVAK-IIGNNVKKLQKFASTVKMW 41 \\
\hline Mouse & MAGKKVCIVGSGNWGSAIAK-IVGSNAGRLAHFDPRVTMW 39 \\
\hline \multirow[t]{2}{*}{ Human } & MAFQKAVKGTILVGGGALATVLGLSQFAHYRRKQNNLAYVIKAAD 44 \\
\hline & 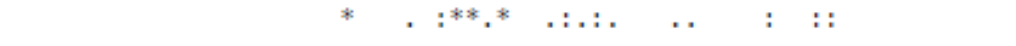 \\
\hline 13LGS & 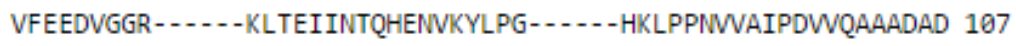 \\
\hline Naked & VFEETVNGR-- - - KLTDIINNDHENVKYLPG - - - HKLPENWVISNLSEAVQDAD 89 \\
\hline Mouse & 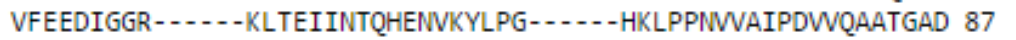 \\
\hline \multirow[t]{2}{*}{ Human } & CISEPVNREPPSREAQLLTLQNTSEFDILVIGGGATGSGCALDAVTRGLKTALVERDDFS 104 \\
\hline & $\therefore *: . . \quad::^{*} \quad: * \ldots:: \quad: *{ }^{*} \quad * \quad \cdot:$ \\
\hline 13LGS & ILIFVVPHQFIG-KICDQLKGHLKANAIGMSLIKGVDEGPNGLKLISEVIGERLDIPMSV 166 \\
\hline Naked & LLVFVIPHQFIH-RICDELTGRVPKKALGITLIKGIDEGPEGLKLISDIIREKMGIDISV 148 \\
\hline Mouse & ILVFVVPHQFIG-KICDQLKGHLKANTIGISLIKGVDEGPNGLKLISEVIGERLGIPNSV 146 \\
\hline \multirow[t]{2}{*}{ Human } & SGTSSRSTKLIHGGVRYLQKAIMKLDIEQYRMVKEALHERANLLEIAPHLSAPLPIMLPV 164 \\
\hline & 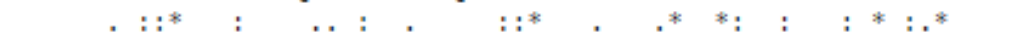 \\
\hline 13LGS & LMGANIANEVADEKFCETTIGCKDPVQGQLLKELMQTPNFRITVVQ- 212 \\
\hline Naked & LMGANIASEVAADKFCETTIGSKIMENGLLFKELLQTPNFRITVVD 194 \\
\hline Mouse & LMGANIASEVAEEKFCETTIGCKDPAQGQLLKDLMQTPNFRITVVQ- 192 \\
\hline \multirow[t]{2}{*}{ Human } & YKWWQLPYYWVGIKLYDLVAGSNCLKSSYVLSKSRALEHFPMLQKDKLVGAIVYYDGQHN 224 \\
\hline & $\therefore: \quad{ }^{*}::{ }^{*}:: \quad \ldots:: \ldots \quad: *: \quad:$ \\
\hline & EVDTVEICGALKN \\
\hline Naked & DADTVELCGALKN - . IVAVGAGFCDGLRSGDNTKAAV 229 \\
\hline Mouse & EVDTVEICGALKN- IVAVGAGFCDGLGFGDNTKAAV 227 \\
\hline \multirow[t]{2}{*}{ Human } & DARIMNLAIALTAARYGAATANYMEVSLLKKTDPQTGKVHVSGARCKDVLTGQEFDVRAK 284 \\
\hline & $\quad .::^{*}: .^{* *}: \quad: .^{* *} * *:: *$ \\
\hline 13LGS & IRLGLMEMIAFAKLFCQGPVSSATFLESCGVADLITTCYGGRNRKVAEAFARTGKSIEQL 307 \\
\hline Naked & IRLGLMEMISFAKIFCKGQVSTATFLESCGVADLITTCYGGRNRRVAEAFARTGKTIEEL 289 \\
\hline Mouse & IRLGLMEMIAFAKLFCSGIVSSATFLESCGVADLITTCYGGRNRKVAEAFARTGKSIEQL 287 \\
\hline \multirow[t]{2}{*}{ Human } & CVINATGPFTDSVRKMDDKDAAAICQPSAGVHIVMPGYYSPESMGLLDPATSDGRVIFFL 344 \\
\hline & 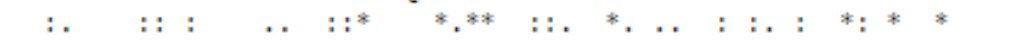 \\
\hline 13LGS & EKEMLNGQKLQGPQTARELHSILQHKGLVDKFPLFMAVYKVCYEGQPVGEFIRCLQNHPE 367 \\
\hline Naked & EKEMLNGQKLQGPQTSAEVYRILKQKGLTDKFPLFTAVYQICYEGRPISEMLSCLQSHPE 349 \\
\hline Mouse & EKEMLNGQKLQGPQTARELHSILQHKGLVDKFPLFTAVYKVCYEGQPVGEFIRCLQNHPE 347 \\
\hline \multirow[t]{2}{*}{ Human } & PWQKMTIAGTTDTPTDVTHHPIPSEEDINFILNEVRNYLSCDVEVRRGDVLAAWSGIRPL 404 \\
\hline & 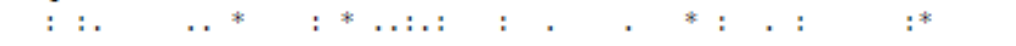 \\
\hline $13 \mathrm{~L}$ & HM-- 369 \\
\hline & НТ - - 351 \\
\hline Mouse & $\mathrm{HM}--349$ \\
\hline Human & VTDP 408 \\
\hline
\end{tabular}

Figure S3.2. Multiple alignment of the deduced amino acid sequence of thirteen-lined ground squirrel (13LGS; I. tridecemlineatus) G3PDH as compared to G3PDH sequences from three non-hibernating mammalian species. Asterisks $(*)$ denote amino acid residues that are conserved across all species; colon (:) indicates conservation between residues of strongly similar properties; period (.) indicates conservation between residues of weakly similar properties. Accession numbers for naked mole rat (Naked), mouse, and human G3PDH sequences are EHB09222.1, NP 034401.1, and AAB50200.1, respectively. 
(a)
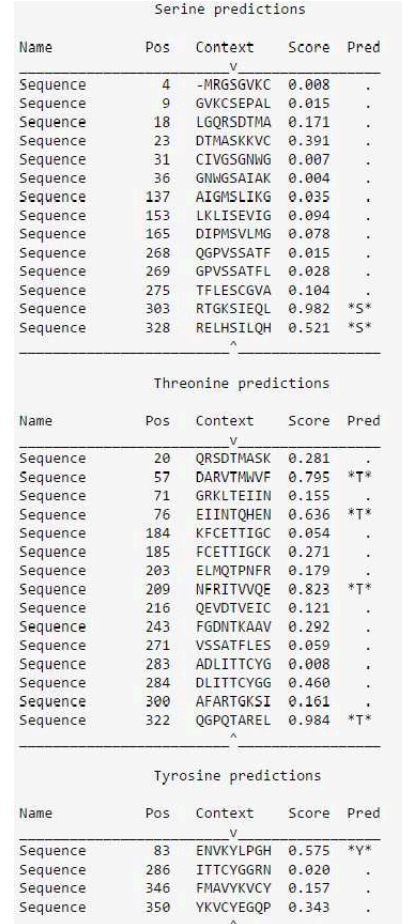

(b)
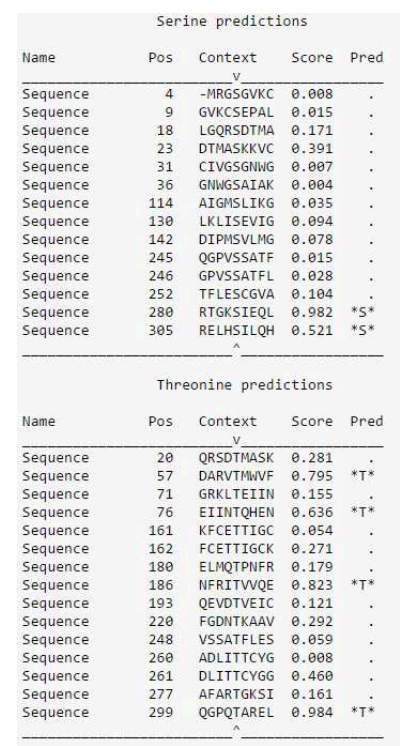

Tyrosine predictions

\begin{tabular}{lrllll} 
Name & POS & Context & Score & Pred \\
\hline Sequence & 83 & ENVKYLPGH & $\theta .575$ & ${ }^{* *}$ \\
Sequence & 263 & ITTCGGRN & $\theta .200$ &. \\
Sequence & 323 & FMAVYKVCY & $\theta .157$ & $:$ \\
Sequence & 327 & YKVCYEGQP & $\theta .343$ & $:$ \\
\hline
\end{tabular}

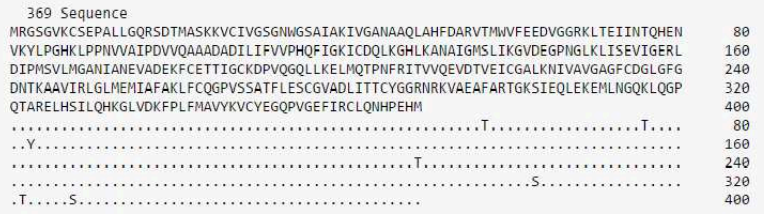

Phosphorylation sites predicted: $\quad$ Ser: 2 Thr: 4 Tyr: 1
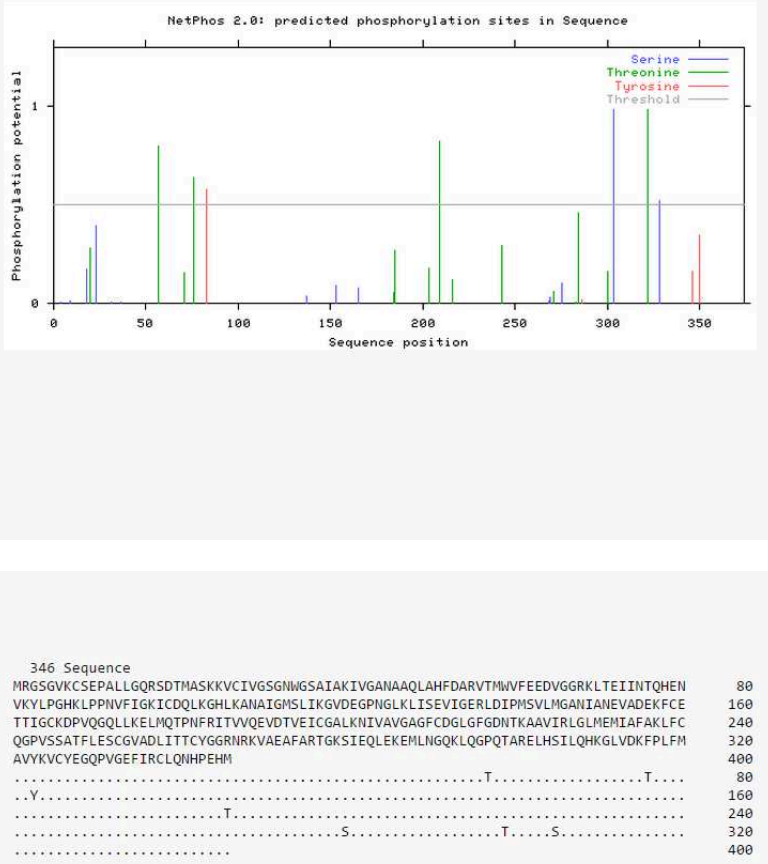

Phosphorylation sites predicted: Ser: 2 Thr: 4 Tyr: 1

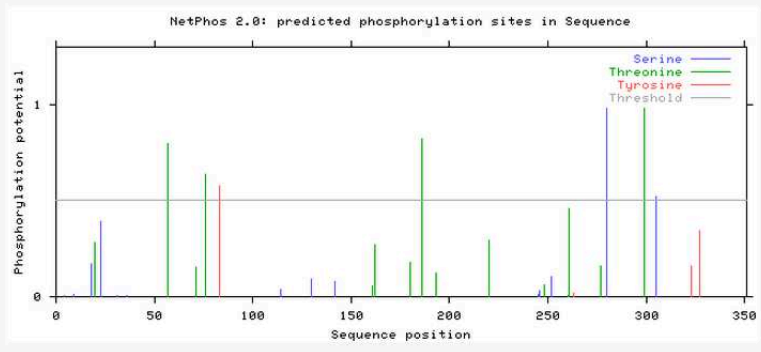

Figure S3.3. Predicted phosphorylation sites for 13-LGS G3PDH cytoplasm (a) isoform $\mathrm{X} 1$ and (b) isoform X2 using NetPhos 2.0 server (Blom et al., 1999). Dot (.) indicates residue is predicted not to be phosphorylated because the score is below the threshold value (0.500). Scores above the threshold of 0.500 are predicted to be phosphorylated and are assigned as $* \mathrm{~S} *, * \mathrm{~T} *$, or $* \mathrm{Y} *$. 


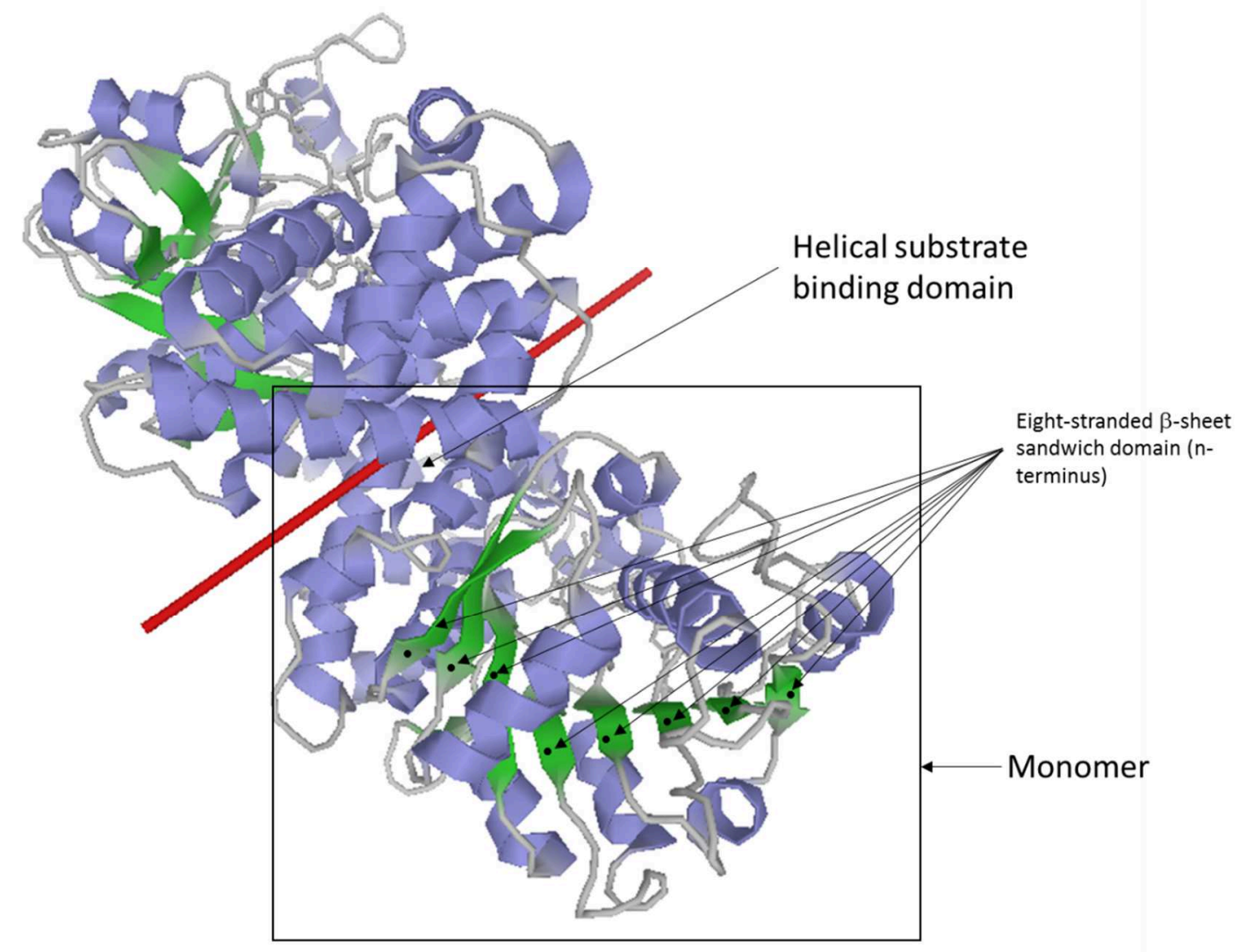

Figure S3.4. Crystal structure of human glycerol-3-phosphate dehydrogenase 1-like protein (PBD ID: 1X0V). 

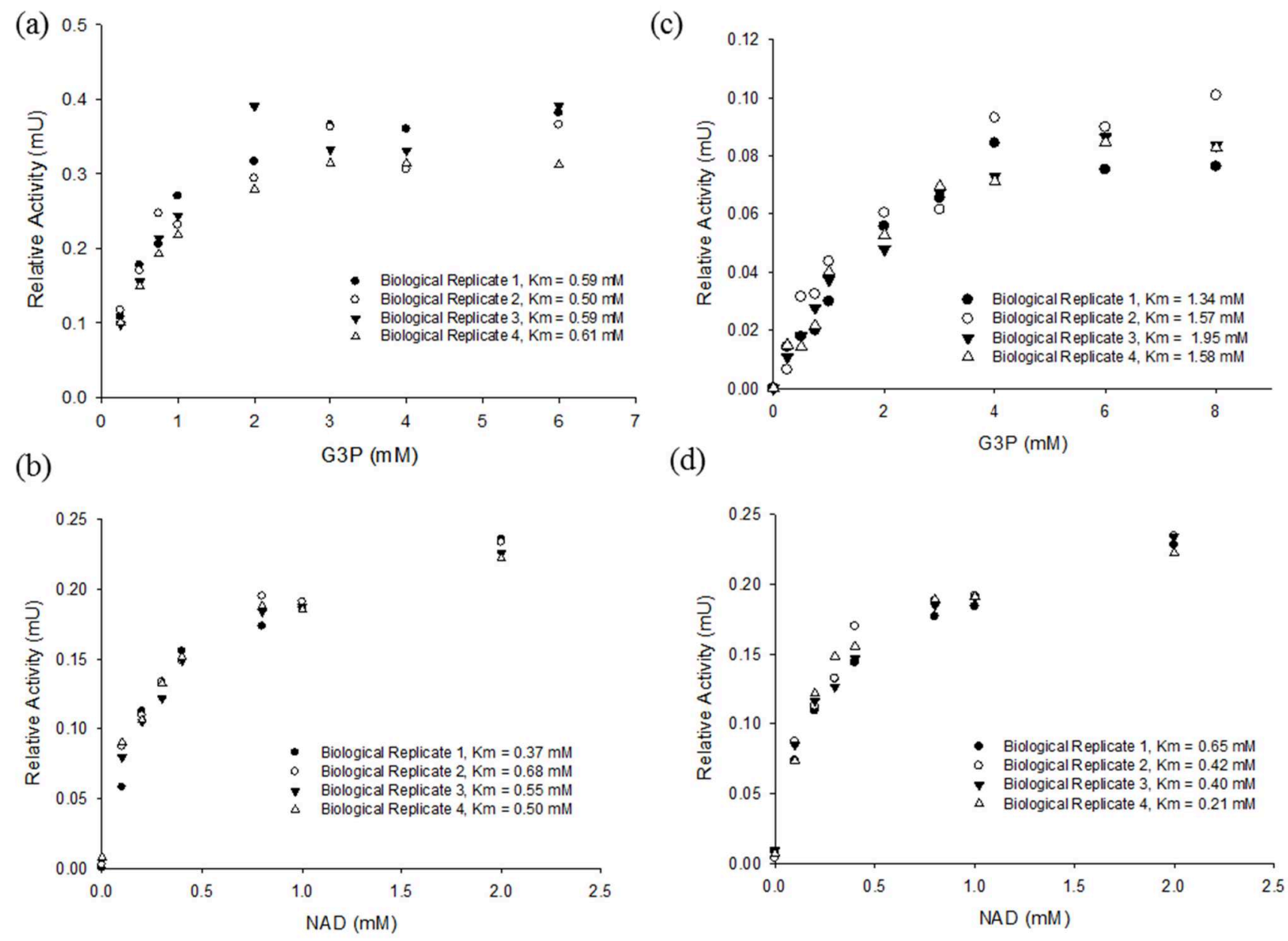

(d)

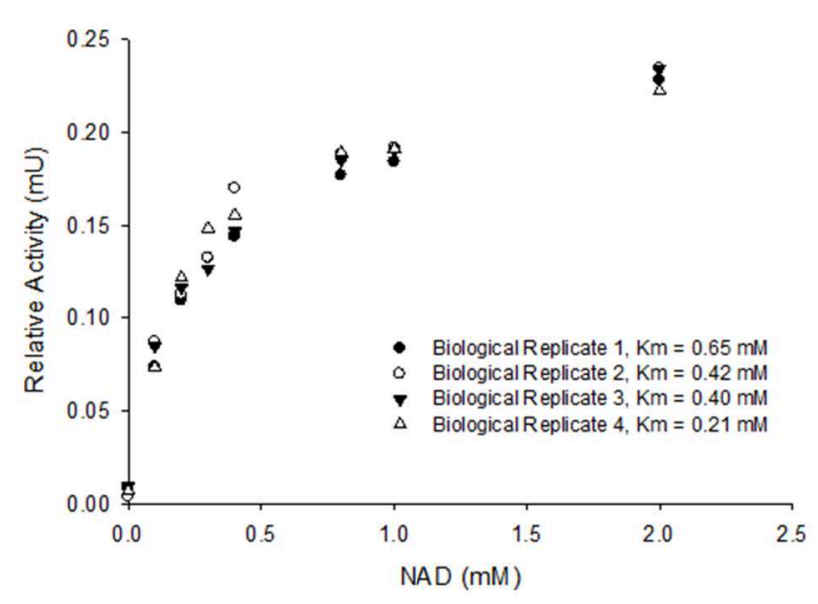

Figure S3.4. Kinetic values obtained from multiple independent determinations for the G3P-utilizing $\left(22^{\circ} \mathrm{C}\right.$, $\left.\mathrm{pH} 8.0\right)$ reaction catalyzed by purified euthermic (a,b) and hibernating (c,d) G3PDH. 


\section{Discussion}

G3PDH has been shown to play an important role in mediating lipid metabolism (Wise and Green, 1979), gluconeogenesis (Yeh et al., 1995), thermogenesis (Kozak et al., 1991 and Koza et al., 1996), and the transfer of NADH reducing equivalents to the electron transport chain (Bissell et al., 1976). As shown in this study, differential regulation of liver G3PDH from euthermic versus hibernating ground squirrels could mediate the fine control of these aforementioned processes during winter dormancy. Moreover, reversible posttranslational modification and temperature-dependent features of liver G3PDH modify its enzymatic activity to facilitate the catabolism of triglycerides shown to take place during hibernation (Dark, 2005).

Ground squirrel liver G3PDH was purified to electrophoretic homogeneity by a combination of HA, ion-exchange, and affinity chromatography (Fig 3.1). The apparent subunit molecular weight (MW) ( 37 kDa) of this dimeric enzyme was determined by SDS-PAGE and corresponds well with the MWs reported for the same enzyme in other species (Berrada et al., 2002; Koekemoer et al., 1995; Albertyn et al., 1992, de la Roche et al., 2012). The end result was an enzyme preparation that was purified $\sim 250$-fold, and showed a specific activity of $\sim 2500 \mathrm{mU} / \mathrm{mg}$ (Table 3.1). The purification scheme used in this study yielded a greater fold purification of the final enzyme as compared to other purification methods for G3PDH from hibernating mammals (Berrada et al., 2002; de la Roche et al., 2012). Thus, the purification procedure presented here indicates a novel and effective way of separating mammalian G3PDH from a complex protein mixture.

Reversible phosphorylation of proteins (RPP) has been shown to play a major regulatory role that mediates the plasticity of metabolic reactions when animals enter a 
depressed metabolic state. This process has been studied extensively in hibernating species, and is known to help control multiple processes (Storey and Storey, 2010) including the activities of ion motive ATPases (MacDonald and Storey, 1999), glycolytic enzymes (Brooks and Storey, 1992), ribosomal proteins (van Breukelen et al., 2004), and multiple transcription factors (reviewed in Carey et al., 2003; Storey, 1997) all showing differential regulation via reversible phosphorylation. The present study is the first of its kind to show the reversible phosphorylation of G3PDH as a means of regulating this enzyme during hibernation. The data presented in this study indicate that Richardson's ground squirrel liver G3PDH is a phosphoprotein (Fig. S3.3), with greater phosphorylation on tyrosine residues seen in the hibernating form of the enzyme (Fig. 3.3).

The advent mass spectrometry (MS)-based proteomics to identify and detect novel PTMs has surely contributed to the growing realization of the importance of PTMs in protein regulation. In eukaryotes, multiple frequently occurring PTMs (apart from phosphorylation) include acetylation, methylation, ubiquitylation, glycosylation, lipidation, and proteolysis (reviewed in Walsh et al., 2005). Previous research in our lab has shown differential regulation of metabolic enzymes via 'non-phospho' posttranslational modifications (Abboud and Storey, 2013; Katzenback et al., 2014). With this knowledge, the present study G3PDH for potential acetyl, methyl, and ubiquitin posttranslational modification differences between euthermic versus hibernating ground squirrels. In the present study, fluorescence values detecting relative acetyl, methyl, and ubiquitin levels for euthermic and hibernating G3PDH showed no significant differences between the two enzymatic forms (Fig 3.3b). These data suggest that these 3 posttranslational modifications do not play a role in the differential regulation of G3PDH. 
Complimentary to the experimental studies on ground squirrel G3PDH, a set of bioinformatics tools were used to analyze the G3PDH sequence using as a model the sequence from the 13-lined ground squirrel, a closely related hibernator with a sequenced genome. This analysis was aimed at identifying ground squirrel amino acid residues that are subject to tyrosine phosphorylation. Using the phosphorylation site prediction server, NetPhos2.0 (Blom et al., 1999), it was predicted that differential phosphorylation on tyrosine residue 83 may play a role in stabilizing G3PDH functionality at high versus low temperatures (Fig. S3.3, Fig. 3.4).

Kinetic analysis of G3PDH activity was measured in the G3P-oxidizing direction at a range of temperatures similar to those that ground squirrels experience during euthermia $\left(\sim 37^{\circ} \mathrm{C}\right)$, entrance and exit from torpor $\left(\sim 22^{\circ} \mathrm{C}\right)$, and during deep hibernation $\left(\sim 5^{\circ} \mathrm{C}\right)$. Arrhenius plots of G3PDH for ground squirrel liver G3PDH showed no breaks in the linear relationship and yielded a decrease in activation energy for the hibernating enzyme compared to the euthermic state (Table 3.2). Structural changes in G3PDH may account for the reduced activation energy $\left(E_{a}\right)$ of the G3P-utilizing reaction of hibernator G3PDH relative to euthermic G3PDH. Furthermore, the effect of $\mathrm{pH}$ on enzymatic activity was tested. For both euthermic and hibernator G3PDH all significant changes (except for the affinity for $\mathrm{G} 3 \mathrm{P}$ at $5^{\circ} \mathrm{C}$ of euthermic $\mathrm{G} 3 \mathrm{PDH}$ ) resulting from a drop in $\mathrm{pH}$ from 8.0 to 7.5 increased substrate affinities and reaction velocities (Table 3.3). These results contradict the findings of Berrada et al. (2002) who reported a decrease in euthermic jerboa skeletal muscle G3PDH activity as the $\mathrm{pH}$ decreased. Despite the fact that for most dehydrogenases the $\mathrm{pH}$ optimum for the lactate-utilizing reaction is close to 9 , the increase in enzymatic activity due to the effect of $\mathrm{pH}$ in liver G3PDH seen in this study compared 
skeletal muscle G3PDH in jerboa may arise from tissue-specific structural differences. Liver G3PDH from hibernating animals exhibited an increased affinity for G3P and NAD ${ }^{+}$ when assayed at $5^{\circ} \mathrm{C}$ relative to $37^{\circ} \mathrm{C}$ whereas $K_{m} \mathrm{G} 3 \mathrm{P}$ in the euthermic condition did not change with a reduction in assay temperature (Table 3.2). These findings imply functional differences between the euthermic and hibernator enzyme forms. Furthermore, G3PDH from hibernating animals also showed much stronger affinities for G3P and $\mathrm{NAD}^{+}$at low temperature compared with the euthermic form and the thermal stability (as measured by $\mathrm{T}_{50}$ - the time in which $50 \%$ of activity is lost) of hibernator $\mathrm{G} 3 \mathrm{PDH}$ at $50^{\circ} \mathrm{C}$ was much greater as indicated by a 2 -fold increase in $\mathrm{T}_{50}$ relative to euthermic G3PDH (Table 3.2). These findings indicate greater structural rigidity of the hibernator enzyme compared to the euthermic form. Furthermore, this structural rigidity could be responsible for the maintaining active site integrity with respect to changing temperatures for hibernating G3PDH.

Structure-function studies using chemical denaturants also revealed differences between the enzymes from euthermic and hibernating ground squirrels. Hibernator G3PDH showed a greater sensitivity to $\mathrm{GuHCl}$ as indicated by a lower $\mathrm{IC}_{50}$ value (the half maximal inhibitory concentration) indicative greater protein unfolding compared to euthermic G3PDH (Figure 3.2). However, despite the greater sensitivity to increasing guanidine hydrochloride concentrations of hibernator G3PDH compared to its euthermic form, the hibernating form of liver G3PDH from Richardson's ground squirrel showed greater structural stability compared to a non-hibernator (rabbit; $\mathrm{IC}_{50} \sim 0.1 \mathrm{M}$ ) and a hibernator (black-tailed prairie dog; $\mathrm{IC}_{50} \sim 0.25 \mathrm{M}$ ) (de la Roche et al., 2012). This response GuHCl indicates structural differences between the enzymes across species and reveals superior 
structural integrity of Richardson's ground squirrel G3PDH when challenged by chemical denaturation.

The present study demonstrates that liver G3PDH from euthermic and hibernating ground squirrels has different physical and functional parameters. These differences may be the result of the greater phosphorylation of hibernator G3PDH which could act to render the protein more suitable for function at the low $\mathrm{T}_{\mathrm{b}}$ that this species experiences during winter dormancy. Liver G3PDH from this hibernator maintains better functionality at low temperatures (as indicated by increased $\mathrm{G} 3 \mathrm{P}$ and $\mathrm{NAD}^{+}$affinities relative to euthermic values) and has greater temperature stability. These properties would help to sustain G3PDH function over the wide range of body temperatures encountered as ground squirrels cycle though bouts of torpor and arousal over the hibernating season.

In humans, the liver plays an important role in glucose biosynthesis from noncarbohydrate sources. With that in mind, one would expect that gluconeogenic processes in the liver would be up-regulated in a starved state, such as during hibernation. The increase in total lipid and fatty acid levels during torpor relative to summer arousal (Serkova et al., 2007) would also indicate that mammalian hibernators have sufficient lipid precursors for fuel utilization as well as for the formation of new cellular integrity components (i.e. reformation of lipid membranes to support low temperature functionality). Glycerol released from triglyceride hydrolysis in other tissues is typically transported to the liver and, together with glycerol derived from endogenous lipolysis, forms an important pool of gluconeogenic precursors. Via the action of glycerol kinase $($ glycerol + ATP $\rightarrow$ G3P + ADP), this carbon source can be re-introduced into pathways of intermediary metabolism, G3PDH being the main enzyme that connects lipid metabolism 
to carbohydrate metabolism. Hence, enhanced G3PDH activity facilitating the G3Poxidizing reaction $\left(\mathrm{G} 3 \mathrm{P}+\mathrm{NAD}^{+} \rightarrow \mathrm{DHAP}+\mathrm{NADH}\right)$ at low temperatures supports the idea of increased gluconeogenesis from glycerol released during triglyceride-fueled hibernation. The production of DHAP could also be used for the formation of plasmalogens - a unique class of membrane glycerophospholipids containing a fatty alcohol with a vinyl-ether bond at the $s n-1$ position, and enriched in polyunsaturated fatty acids at the $s n-2$ position of the glycerol backbone (reviewed in Braverman and Moser, 2012). The unique structure of these phospholipids make them particularly suitable for functionality at low temperatures due to their high degree of unsaturation. Since DHAP is a precursor to the formation of these specialized phospholipids (Brites et al., 2004), an upregulation of G3PDH could help facilitate their formation at the low $\mathrm{T}_{\mathrm{b}}$ values exhibited in ground squirrels during hibernation. 


\section{Chapter 4}

Purification and Properties of Glycerol-3Phosphate Dehydrogenase from Skeletal Muscle of the Hibernating Ground Squirrel, Urocitellus richardsonii 


\section{Introduction}

Mammalian hibernators, including ground squirrels, undergo extreme physiological and morphological changes in the attempt to conserve energy during the winter season. These changes are marked by altered body composition (e.g. extreme fattening) and a switch from summer homeothermy and winter heterothermy (reviewed in Carey et al., 2003). In preparing for this switch, hibernating ground squirrels undergo intense periods of hyperphagy during the summer months to build up large endogenous depots of triglycerides (mainly in white adipose tissue) which are then catabolized during the fasting, winter months. In addition, by lowering their body temperature $\left(\mathrm{T}_{\mathrm{b}}\right)$ during multiday torpor bouts, hibernators are capable of capitalizing on energy savings and can survive solely on endogenous fuel reserves over the winter months (Lyman, 2013).

The functions of specific tissues are temporally modified during hibernator winter dormancy, with skeletal muscle being a prime example. During arousal periods (coming out of torpor and into interbout arousal), squirrels rewarm from low $\mathrm{T}_{\mathrm{b}}\left(\sim 5^{\circ} \mathrm{C}\right)$ to euthermic $\mathrm{T}_{\mathrm{b}}\left(\sim 37^{\circ} \mathrm{C}\right)$ using endogenous mechanisms of heat production. The rewarming process is an 'explosive' event in which whole body metabolic rates can exceed basal euthermic metabolic rates sevenfold (Hampton and Andrews, 2007). A large portion of the rewarming process occurs via skeletal muscle shivering thermogenesis-a necessary component of the arousal process (Lyman and Chatfield, 1950; Hayward et al., 1965). On the other hand, during entry into torpor-and subsequent lowering of $\mathrm{T}_{\mathrm{b}}$-shivering is suppressed. Furthermore, during hibernation, muscle activity is essentially non-existent as indicated by no EMG activity (Daan et al., 1991). How skeletal muscle is capable of modifying its metabolism in each of these scenarios has prompted considerable interest. 
The ability of skeletal muscle to limit atrophy during hibernation is also a subject of interest. Long periods of skeletal muscle inactivity in non-hibernators evokes disuse atrophy; however, in hibernators, limited loss of skeletal muscle mass occurs after enduring torpor inactive periods (lasting 2 weeks in ground squirrels) (Nowell et al., 2011; Wicker et al., 1987; Steffen et al., 1991). The suppression of muscle atrophy in ground squirrels during hibernation may be simply due to a temperature-reduction of protein degradation rates as these species drop their $T_{b}$. However, research by Nowell et al. (2011) suggests that the reduced muscle atrophy seen in hibernators is most likely due to an endogenous, seasonally regulated feature of skeletal muscle.

Hibernator skeletal muscle must deal with two conflicting matters during the winter heterothermic period. First, the need to preserve contractile functionality for arousals, yet suppress contractility during both the entrance and maintenance phases of hibernation. Second, muscle maintain the ability to break down endogenous fuels for shivering and locomotion, yet limit tissue atrophy. Therefore, hibernator skeletal muscle must be capable of regulating (1) energy savings during extended inactivity, (2) the short-lived motor requirements accompanying winter arousal periods, and (3) typical activity following emergence from torpor.

To better understand the observed paradoxical function of skeletal muscle, this study focuses on the enzymatic regulation of cytosolic G3PDH—an important branch point enzyme which connects triglyceride metabolism and carbohydrate metabolism-in Richardson's ground squirrels (Urocitellus richardsonii). Studies are conducted over several temperatures that represent $T_{b}$ across the hibernator's year. Previous work by de la Roche et al. (2011) revealed that skeletal muscle G3PDH substrate affinities increased 
significantly ( $K_{m} \mathrm{G} 3 \mathrm{P}$ and DHAP decreased) at low temperature in a hibernating species, black-tailed prairie dogs (Cynomys ludivicianus), whereas $K_{m}$ NAD and DHAP in a nonhibernator (rabbit) G3PDH increased. Furthermore, skeletal muscle G3PDH activity has been shown to increase during hibernation in jerboa (Jaculus orientalis) promoting the production of dihydroxyacetone phosphate (DHAP) (Berrada et al., 2000). These findings suggest that skeletal muscle G3PDH might be subject to differential regulation during hibernation in Richardson's ground squirrel as well.

Studies of G3PDH in the liver of Richardson's ground squirrels reveal differential regulation via reversible phosphorylation during hibernation promoting the catabolism of triglycerides to be used for gluceoneogenic purposes (see Chapter 3). The fact that the principal fuel substrate used during hibernation is lipids (Willis, 1982) combined with gluconeogenic role of liver support the need for G3PDH up-regulation in liver tissue to produce the glucose for export to tissues that have little or no ability to use lipid fuels. The need for G3PDH activation in skeletal muscle, a primarily glucose utilizing tissue, may be required to not only restore glycogen stores but also for the maintenance of essential biological functions. With that said, the present study investigates the physical, kinetic, and regulatory properties of ground squirrel skeletal muscle G3PDH and presents a role for reversible phosphorylation as the main mechanism for regulating G3PDH during hibernation.

\section{Materials and Methods}

\section{Animals}

Richardson's ground squirrels were treated as previously described in Chapter 2. 


\section{Preparation of muscle tissue extracts}

Frozen muscle tissue samples were homogenized 1:3 w:v in buffer A $(10 \mathrm{mM}$ HEPES, pH 7.2, 1 mM EDTA, 1 mM EGTA, 25 mM $\beta$-glycerophosphate, $5 \mathrm{mM} \beta$ mercaptoethanol, 5\% v:v glycerol) and a few crystals of phenylmethylsulphonyl fluoride (PMSF) (added just prior to homogenization) using a Polytron homogenizer (Brinkmann Instruments, Rexdale, ON, Canada). Homogenates were centrifuged at 10,000 x g for 30 minutes at $5^{\circ} \mathrm{C}$, after which supernatants were decanted and held on ice until use.

\section{Purification of muscle G3PDH}

Purification of muscle G3PDH from euthermic and hibernating ground squirrels was done in the same manner as liver G3PDH described in Chapter 3. The purity of the G3PDH sample was checked by denaturing and reducing gel electrophoresis followed by silver staining as described in Chapter 2.

\section{Detection of G3PDH via Silver Staining Technique}

Silver staining procedure (Blum et al., 1987) is the same as previously described in Chapter 2.

\section{G3PDH assay}

Description of G3PDH assay conditions is previously described in Chapter 3.

\section{SDS Polyacrylamide Gel Electrophoresis and Immunoblotting}

Gel electrophoresis and immunoblotting procedures are the same as described previously in Chapter 3. 


\section{Bioinformatics and Molecular Modeling}

Bioinformatic analyses for G3PDH used for the predictions of potential phosphorylation sites are described in Chapter 3.

Predicted tertiary and quaternary structures of G3PDH were built using the ITASSER Protein Structure \& Function Prediction server (http://zhanglab.ccmb.med.umich.edu/I-TASSER/) (Yang et al., 2015; Roy et al., 2010; Zhang, 2008). The top G3PDH model predicted by I-TASSER was used for subsequent analyses. The protein model was protonated, optimized by energy minimization using MMFF94× force field model, and modified for the predicted phosphorylation sites in Molecular Operating Environment (MOE) software (v.2011.10) (Chemical Computing Group, QC).

\section{Data Analyses}

Maximal G3PDH activity was determined at $5^{\circ} \mathrm{C}, 22^{\circ} \mathrm{C}$ and $37^{\circ} \mathrm{C}$ using the same spectrophotometer and procedures described in Chapter 2.

Protein concentrations of all samples and fractions were measured using the BioRad protein assay dye reagent (Bio-Rad, Hercules, CA, USA) as described in Chapter 2.

Enzyme activities were analyzed with a Microplate Analysis program (Brooks, 1994) and kinetic parameters were determined using the direct-linear plot method fully described by Eisenthal (1974). Data are expressed as mean \pm S.E.M. from multiple independent determinations of kinetic parameters on separate preparations of enzyme. Data for euthermic versus hibernating comparisons, $\mathrm{pH}$ comparisons, and western blots were analyzed using the Student's t-test (two-tailed). Data for kinetic parameters in response to 
temperature changes were analyzed using one-way analysis of variance (ANOVA) followed by a Tukey post hoc test. A probability value of $<0.05$ was considered significant. Examples of data analysis from multiple independent determinations of kinetic parameters on separate preparations of enzyme are found in the Supplementary Materials (Supplementary Fig. S4.1).

\section{Results}

\section{Purification of G3PDH from the muscle of euthermic and hibernating $U$. richardsonii}

Purification of G3PDH from the liver of euthermic and hibernating U. richardsonii was accomplished by three chromatography steps: a HA column (enzyme eluted in the unbound fraction), a $\mathrm{CM}^{-}$column (elution with a $0-2 \mathrm{M} \mathrm{KCl}$ ), and lastly, a Cibacron blue affinity column (elution with $0-3 \mathrm{M} \mathrm{KCl}$ gradient) (Table 4.1). Collection of the flow through fractions from the HA column resulted in a 4.23- and 8.18- fold purification of recovered activity for the G3PDH from the muscle of euthermic and hibernating squirrels, respectively (Table 4.1). Elution of euthermic and hibernator G3PDH from the $\mathrm{CM}^{-}$column using a $\mathrm{KCl}$ gradient gave a 114.17- and 107.55- fold purification, respectively (Table 4.1). Furthermore, the elution of euthermic and hibernator G3PDH from the Cibacron blue column using a $\mathrm{KCl}$ gradient resulted in 450.38 and 622.41 - fold final purifications, respectively (Table 4.1; Fig. 4.1b). The final purification resulted in specific activities of 1,860 $\mathrm{mU} \mathrm{mg}^{-1}$ protein for euthermic G3PDH, and 2,227 $\mathrm{mU} \mathrm{mg}^{-1}$ for hibernator G3PDH (Table 4.1). As a result of this three-step purification scheme, G3PDH was purified to $>95 \%$ homogeneity, as determined by gel electrophoresis and staining with silver nitrate 
(Fig. 4.2). The purified G3PDH had an apparent subunit molecular weight of $37 \mathrm{kDa}$ (Fig. 4.2).

\section{Reversible post-translational modifications of muscle G3PDH}

Immunoblotting was used to assess possible differences in post-translational modifications of purified muscle G3PDH from euthermic and hibernating conditions. Phosphorylation at threonine and tyrosine residues of hibernating G3PDH were not significantly different when compared to euthermic G3PDH (P>0.05, Fig. 4.3). However, when comparing phosphorylation on serine residues, there was a $1.46 \pm 0.15$ fold increase in phosphorylation of hibernator G3PDH relative to euthermic G3PDH $(1.00 \pm 0.08$, $\mathrm{P}<0.05$, Fig. 4.3).

\section{Prediction of phosphorylated amino acid residues and molecular modeling of muscle G3PDH}

To find potential reversible phosphorylation sites in Richardson's ground squirrel G3PDH, the predicted protein sequence of G3PDH from thirteen-lined ground squirrels (Ictidomys tridecemlineatus) was used since this species has a sequenced genome. Analysis of the predicted 13-LGS G3PDH amino acid sequence (NCBI Reference Sequence: XP_005324992.1) via the phosphorylation site predict server NetPhos 2.0 (Blom et al., 1999) indicated 7 predicted potential phosphorylation residues, 2 of which were located on serine residues (Supplementary Fig. S3.3).

The I-TASSER Server was used to assess structural features of ground squirrel G3PDH. The overall C-score and TM-score were 0.65 and $0.80 \pm 0.09$, respectively. In short, the confidence of the model is quantitatively measured by the C-score which is 
calculated based on the significance of threading template alignments and the convergence parameters of the structure assembly simulations. The TM-score is estimated based on Cscore and protein length following the correlation observed between these qualities.

With an increase in relative serine phosphorylation in hibernator muscle G3PDH compared to euthermic G3PDH (Fig. 4.3), the top I-TASSER model was used as a template to build a molecular model to elucidate this difference. The inclusion of phosphates on the predicted serine phosphorylation residues $\left({ }^{303} \operatorname{Ser} \&{ }^{328}\right.$ Ser $)$ revealed that these modifications are located on the helical binding domain of the enzyme (Figure 3.4).

\section{Kinetic activity of purified G3PDH from euthermic and hibernating ground squirrel muscle \\ i. $\quad$ Effects of reversible post-translational modifications on muscle G3PDH activity}

In the G3P-oxidizing direction, there was a significant decrease in the $K_{m}$ values for G3P between euthermic and hibernating G3PDH at $5^{\circ} \mathrm{C}$ when measured at $\mathrm{pH} 7.5$ and $\mathrm{pH} 8.0$ (Table 4.2). At $5^{\circ} \mathrm{C}, \mathrm{pH}$, hiberating G3PDH had a greater affinity for G3P since the $K_{m}$ of $\mathrm{G} 3 \mathrm{P}(0.80 \pm 0.11 \mathrm{mM})$ was just $24 \%$ of the euthermic value $(3.39 \pm 0.76 \mathrm{mM}$, $\mathrm{P}<0.05$, Table 4.2). Likewise, at $\mathrm{pH} 7.5$ and $5^{\circ} \mathrm{C}$, the $K_{m}$ value for hibernator G3P $(0.93 \pm$ $0 . .23 \mathrm{mM})$ was $53 \%$ of the euthermic value $(1.73 \pm 0.11 \mathrm{mM}, \mathrm{P}<0.05$, Table 4.2$)$. When looking at the co-substate, the $K_{m}$ values for $\mathrm{NAD}^{+}$at $5^{\circ} \mathrm{C}$ and $37^{\circ} \mathrm{C}$ were not significantly different when comparing the euthermic and hibernating conditions $(\mathrm{P}>0.05$, Table 4.2). However, at $22^{\circ} \mathrm{C}$ and $\mathrm{pH} 7.5$, there was a significant increase in the $\mathrm{K}_{\mathrm{m}}$ of $\mathrm{NAD}^{+}(0.30 \pm$ 
$0.02 \mathrm{mM})$ in the hibernating condition compared to the euthermic condition $(0.18 \pm 0.03$ $\mathrm{mM}, \mathrm{P}<0.05$, Table 4.2).

With respect to G3PDH reaction velocities in the G3P-oxidizing direction, the $V_{\max }$ values at $37^{\circ} \mathrm{C}, 22^{\circ} \mathrm{C}$ and $5^{\circ} \mathrm{C}$ at $\mathrm{pH} 8$ were not significantly different when comparing hibernator G3PDH to euthermic G3PDH (P>0.05, Table 4.2). However, at $22^{\circ} \mathrm{C}$ and $\mathrm{pH}$ 7.5, hiberating G3PDH $V_{\max }$ was significantly different than its euthermic counterpart as it increased 1.7- fold (Table 4.2).

Last, both euthermic and hibernator G3PDH were subjected to denaturants to assess the structural stability of the two enzyme forms. When exposed to guanidine hydrochloride $(\mathrm{GuHCl})$ or urea, comparison of the $\mathrm{IC}_{50}$ values indicated that higher concentrations of the denaturants were required to inhibit the hibernator form of the enzyme relative to the euthermic (Table 4.2). Futhermore, hibernator G3PDH was found to be more thermally stable as indicated by a 1.9 -fold higher $\mathrm{T}_{50}$ value relative to the euthermic enzyme $(\mathrm{P}<0.05$, Table 4.2).

\section{ii. Temperature effects on euthermic and hibernator forms of muscle G3PDH}

When assayed at $\mathrm{pH} 8.0$, as the temperature decreased from $37^{\circ} \mathrm{C}$ to $5^{\circ} \mathrm{C}$, the affinity of the euthermic enzyme for G3P decreased. In the euthermic state, $K_{m}$ for G3P increased 2.5- fold as temperature decreased from $37^{\circ} \mathrm{C}(1.35 \pm 0.26 \mathrm{mM})$ to $5^{\circ} \mathrm{C}(3.39 \pm$ $0.05 \mathrm{mM}, \mathrm{P}<0.05$, Table 4.2). Also at $\mathrm{pH} 8.0$, there was a significant decrease in the $K_{m}$ for $\mathrm{NAD}^{+}$when comparing $37^{\circ} \mathrm{C}$ to $5^{\circ} \mathrm{C}$ (Table 4.2). Temperature changes occurring at $\mathrm{pH} 7.5$ did not have any effect on the Km for G3P for either the euthermic and hibernator forms of $\mathrm{G} 3 \mathrm{PDH}$. However, as the temperature decreased to $5^{\circ} \mathrm{C}, \mathrm{NAD}^{+}$affinity increased for both euthermic and hibernator G3PDH (Table 4.2). 
The maximal activity of euthermic and hibernator G3PDH at the three temperatures $\left(37^{\circ} \mathrm{C}, 22^{\circ} \mathrm{C}\right.$, and $\left.5^{\circ} \mathrm{C}\right)$ was analyzed. Not unexpectedly, the change in temperature from $37^{\circ} \mathrm{C}$ to $5^{\circ} \mathrm{C}$ resulted in significant decreases in the $V_{\max }$ values in the G3P-oxidizing direction for euthermic and hibernator enzymes at both $\mathrm{pH}$ values (Table 4.2). These data were graphed as an Arrhenius plot and used to calculate activation energies $\left(\mathrm{E}_{\mathrm{a}}\right)$ for euthermic and hibernator G3PDH in the G3P-oxidizing reaction. No significant differences in $\mathrm{E}_{\mathrm{a}}$ were found between the two enzymes ( $\mathrm{P}>0.05$, Table 4.2).

iii. $\quad$ Effect of $\mathrm{H}^{+}$concentration on euthermic and hibernator forms of G3PDH

When comparing the change in $\mathrm{pH}$ from 8.0 to 7.5 in the G3P-oxidizing direction, euthermic G3PDH showed an increase in affinity for $\mathrm{G} 3 \mathrm{P}$ at $5^{\circ} \mathrm{C}$ as indicated by a $51 \%$ lower $\mathrm{K}_{m}(\mathrm{P}<0.05$, Table 4.3a). Changes in $\mathrm{pH}$ did not affect the enzyme's affinity for G3P in the hibernating condition (Table 4.3b).

Like the trend found for euthermic $\mathrm{K}_{m} \mathrm{G} 3 \mathrm{P}$ at $5^{\circ} \mathrm{C}$, a change in $\mathrm{pH}$ from 8.0 to 7.5 at $22^{\circ} \mathrm{C}$ lead to increased $\mathrm{G} 3 \mathrm{PDH}$ affinity for $\mathrm{NAD}^{+}$(Table $4.3 \mathrm{a}$ ). With a change in $\mathrm{pH}$ from 8.0 to 7.5 at $22^{\circ} \mathrm{C}$ in the euthermic condition, $\mathrm{K}_{m} \mathrm{NAD}^{+}$was reduced by $51 \%$; whereas $\mathrm{K}_{m} \mathrm{NAD}^{+}$in the hibernator condition remained unchanged across the three temperatures (Table 4.3).

With respect to enzymatic reaction velocities at $22^{\circ} \mathrm{C}, \mathrm{V}_{\max }$ decreased significantly for euthermic G3PDH as $\mathrm{pH}$ decreased (Table 4.3a). In hibernator G3PDH, there was no significant change in $\mathrm{V}_{\max }$ as the $\mathrm{pH}$ decreased from 8 to 7.5 across any of the three temperatures tested (Table 4.3b). 
Table 4.1. Purification and yield of $U$. richardsonii G3PDH from skeletal muscle of (a) euthermic and (b) hibernating.

(a)

\begin{tabular}{cccccc}
\hline Step & $\begin{array}{c}\text { Total Protein } \\
(\mathbf{m g})\end{array}$ & $\begin{array}{c}\text { Total } \\
\text { Activity } \\
(\mathbf{m U})\end{array}$ & $\begin{array}{c}\text { Specific } \\
\text { Activity } \\
(\mathbf{m U} / \mathbf{m g})\end{array}$ & $\begin{array}{c}\text { Fold } \\
\text { Purification }\end{array}$ & \%Yield \\
\hline Crude & 30.04 & 124.06 & 4.13 & - & 100 \\
HA & 4.93 & 86.12 & 17.47 & 4.23 & 69.42 \\
CM- & 0.14 & 66.01 & 471.50 & 114.17 & 53.21 \\
$\begin{array}{c}\text { Cibacron Blue } \\
(\text { KCI })\end{array}$ & 0.014 & 26.04 & 1860.00 & 450.38 & 20.99 \\
\hline
\end{tabular}

(b)

\begin{tabular}{cccccc}
\hline Step & $\begin{array}{c}\text { Total Protein } \\
(\mathbf{m g})\end{array}$ & $\begin{array}{c}\text { Total } \\
\text { Activity } \\
(\mathbf{m U})\end{array}$ & $\begin{array}{c}\text { Specific } \\
\text { Activity } \\
(\mathbf{m U} / \mathbf{m g})\end{array}$ & $\begin{array}{c}\text { Fold } \\
\text { Purification }\end{array}$ & \%Yield \\
\hline Crude & 40.39 & 144.55 & 3.58 & - & 100 \\
HA & 3.77 & 110.42 & 29.29 & 8.18 & 76.39 \\
CM- & 0.22 & 84.68 & 384.91 & 107.55 & 58.58 \\
$\begin{array}{c}\text { Cibacron Blue } \\
(\text { KCl) }\end{array}$ & 0.020 & 44.55 & 2227.50 & 622.41 & 30.82 \\
\hline
\end{tabular}


Table 4.2. Kinetic parameters of purified muscle G3PDH from euthermic and hibernating U. richardsonii.

\begin{tabular}{|c|c|c|}
\hline Enzyme parameter & Euthermic & Hibernating \\
\hline \multicolumn{3}{|c|}{ Forward reaction $(G 3 P \rightarrow D H A P, p H 8)$} \\
\hline $\mathrm{Km} \mathrm{G} 3 \mathrm{P}, 37^{\circ} \mathrm{C}(\mathrm{mM})$ & $1.35 \pm 0.26$ & $1.01 \pm 0.06$ \\
\hline $\mathrm{Km} \mathrm{G} 3 \mathrm{P}, 22^{\circ} \mathrm{C}(\mathrm{mM})$ & $1.08 \pm 0.12$ & $1.12 \pm 0.18$ \\
\hline $\mathrm{Km} \mathrm{G} 3 \mathrm{P}, 5^{\circ} \mathrm{C}(\mathrm{mM})$ & $3.39 \pm 0.76^{b}$ & $0.80 \pm 0.11^{a}$ \\
\hline $\mathrm{Km}$ NAD, $37^{\circ} \mathrm{C}(\mathrm{mM})$ & $0.45 \pm 0.02$ & $0.44 \pm 0.02$ \\
\hline $\mathrm{Km} \mathrm{NAD}, 22^{\circ} \mathrm{C}(\mathrm{mM})$ & $0.37 \pm 0.07$ & $0.34 \pm 0.04$ \\
\hline $\mathrm{Km} \mathrm{NAD}, 5^{\circ} \mathrm{C}(\mathrm{mM})$ & $0.26 \pm 0.05$ & $0.27 \pm 0.02^{b}$ \\
\hline $\operatorname{Vmax}, 37^{\circ} \mathrm{C}(\mathrm{mU} / \mu \mathrm{g})$ & $0.55 \pm 0.04$ & $0.65 \pm 0.04$ \\
\hline $\operatorname{Vmax}, 22^{\circ} \mathrm{C}(\mathrm{mU} / \mu \mathrm{g})$ & $0.29 \pm 0.04^{b}$ & $0.34 \pm 0.02^{b}$ \\
\hline $\mathrm{Vmax}, 5^{\circ} \mathrm{C}(\mathrm{mU} / \mu \mathrm{g})$ & $0.09 \pm 0.02^{b}$ & $0.10 \pm 0.002^{b}$ \\
\hline Activation Energy (kJ/mol) & $40.88 \pm 4.11$ & $42.29 \pm 4.61$ \\
\hline $\mathrm{IC}_{50}$ urea, $22^{\circ} \mathrm{C}(\mathrm{M})$ & $1.49 \pm 0.05$ & $1.72 \pm 0.08^{a}$ \\
\hline $\mathrm{IC}_{50} \mathrm{GuHCl}, 22^{\circ} \mathrm{C}(\mathrm{M})$ & $0.36 \pm 0.01$ & $0.44 \pm 0.02^{a}$ \\
\hline $\mathrm{T}_{50}, 50^{\circ} \mathrm{C}(\mathrm{min})$ & $9.81 \pm 0.13$ & $19.04 \pm 0.24^{a}$ \\
\hline \multicolumn{3}{|c|}{ Forward reaction $(G 3 P \rightarrow D H A P, p H 7.5)$} \\
\hline $\mathrm{Km} \mathrm{G} 3 \mathrm{P}, 37^{\circ} \mathrm{C}(\mathrm{mM})$ & $1.34 \pm 0.26$ & $0.99 \pm 0.11$ \\
\hline $\mathrm{Km} \mathrm{G} 3 \mathrm{P}, 22^{\circ} \mathrm{C}(\mathrm{mM})$ & $1.56 \pm 0.21$ & $1.00 \pm 0.18^{a}$ \\
\hline $\mathrm{Km} \mathrm{G} 3 \mathrm{P}, 5^{\circ} \mathrm{C}(\mathrm{mM})$ & $1.73 \pm 0.11$ & $0.93 \pm 0.23^{a}$ \\
\hline $\mathrm{Km}$ NAD, $37^{\circ} \mathrm{C}(\mathrm{mM})$ & $0.43 \pm 0.05$ & $0.45 \pm 0.02$ \\
\hline $\mathrm{Km}$ NAD, $22^{\circ} \mathrm{C}(\mathrm{mM})$ & $0.18 \pm 0.03^{b}$ & $0.30 \pm 0.02^{\mathrm{a}, b}$ \\
\hline $\mathrm{Km}$ NAD, $5^{\circ} \mathrm{C}(\mathrm{mM})$ & $0.22 \pm 0.05^{b}$ & $0.28 \pm 0.04^{b}$ \\
\hline $\operatorname{Vmax}, 37^{\circ} \mathrm{C}(\mathrm{mU} / \mu \mathrm{g})$ & $0.49 \pm 0.06$ & $0.57 \pm 0.03$ \\
\hline$V \max , 22^{\circ} \mathrm{C}(\mathrm{mU} / \mu \mathrm{g})$ & $0.13 \pm 0.01^{b}$ & $0.25 \pm 0.02^{a, b}$ \\
\hline $\mathrm{V} \max , 5^{\circ} \mathrm{C}(\mathrm{mU} / \mu \mathrm{g})$ & $0.09 \pm 0.02^{b}$ & $0.07 \pm 0.01^{b}$ \\
\hline Activation Energy (kJ/mol) & $36.07 \pm 15.06$ & $46.96 \pm 2.507$ \\
\hline
\end{tabular}

$a$ indicates a significant difference from the corresponding euthermic condition, Student's $\mathrm{t}$ test, two-tailed, $\mathrm{P}<0.05$

$b$ indicates a significant difference from $37^{\circ} \mathrm{C}$ within each condition, one-way ANOVA with Tukey's post hoc test, $\mathrm{P}<0.05$ 
Table 4.3. Effects of $\mathrm{pH}$ on purified muscle G3PDH from (a) euthermic and (b) hibernating $U$. richardsonii.

\begin{tabular}{|c|c|c|c|c|}
\hline Enzyme parameter & \multicolumn{2}{|c|}{ (a) Euthermic } & \multicolumn{2}{|c|}{ (b) Hibernating } \\
\hline Forward reaction $(G 3 P \rightarrow D H A P)$ & pH 8.0 & $p H 7.5$ & pH 8.0 & $p H 7.5$ \\
\hline $\mathrm{Km} \mathrm{G} 3 \mathrm{P}, 37^{\circ} \mathrm{C}(\mathrm{mM})$ & $1.35 \pm 0.26$ & $1.34 \pm 0.26$ & $1.01 \pm 0.06$ & $0.99 \pm 0.11$ \\
\hline $\mathrm{Km} \mathrm{G} 3 \mathrm{P}, 22^{\circ} \mathrm{C}(\mathrm{mM})$ & $1.08 \pm 0.12$ & $1.56 \pm 0.21$ & $1.12 \pm 0.18$ & $1.00 \pm 0.18$ \\
\hline $\mathrm{Km} \mathrm{G} 3 \mathrm{P}, 5^{\circ} \mathrm{C}(\mathrm{mM})$ & $3.39 \pm 0.76$ & $1.73 \pm 0.11^{a}$ & $0.80 \pm 0.11$ & $0.93 \pm 0.23$ \\
\hline $\mathrm{Km} \mathrm{NAD}, 37^{\circ} \mathrm{C}(\mathrm{mM})$ & $0.45 \pm 0.02$ & $0.43 \pm 0.05$ & $0.44 \pm 0.02$ & $0.45 \pm 0.02$ \\
\hline $\mathrm{Km}$ NAD, $22^{\circ} \mathrm{C}(\mathrm{mM})$ & $0.37 \pm 0.07$ & $0.18 \pm 0.03^{a}$ & $0.34 \pm 0.04$ & $0.30 \pm 0.02$ \\
\hline $\mathrm{Km}$ NAD, $5^{\circ} \mathrm{C}(\mathrm{mM})$ & $0.26 \pm 0.05$ & $0.22 \pm 0.05$ & $0.27 \pm 0.02$ & $0.28 \pm 0.04$ \\
\hline $\operatorname{Vmax}, 37^{\circ} \mathrm{C}(\mathrm{mU} / \mu \mathrm{g})$ & $0.55 \pm 0.04$ & $0.49 \pm 0.06$ & $0.65 \pm 0.04$ & $0.57 \pm 0.03$ \\
\hline $\operatorname{Vmax}, 22^{\circ} \mathrm{C}(\mathrm{mU} / \mu \mathrm{g})$ & $0.29 \pm 0.04$ & $0.13 \pm 0.01^{a}$ & $0.34 \pm 0.04$ & $0.30 \pm 0.02$ \\
\hline$V \max , 5^{\circ} \mathrm{C}(\mathrm{mU} / \mu \mathrm{g})$ & $0.09 \pm 0.02$ & $0.09 \pm 0.02$ & $0.10 \pm 0.002$ & $0.07 \pm 0.01$ \\
\hline
\end{tabular}

$a$ indicates a significant difference from $\mathrm{pH} 8.0$ in each corresponding condition, Student's t test, twotailed, $\mathrm{P}<0.05$ 
(a)

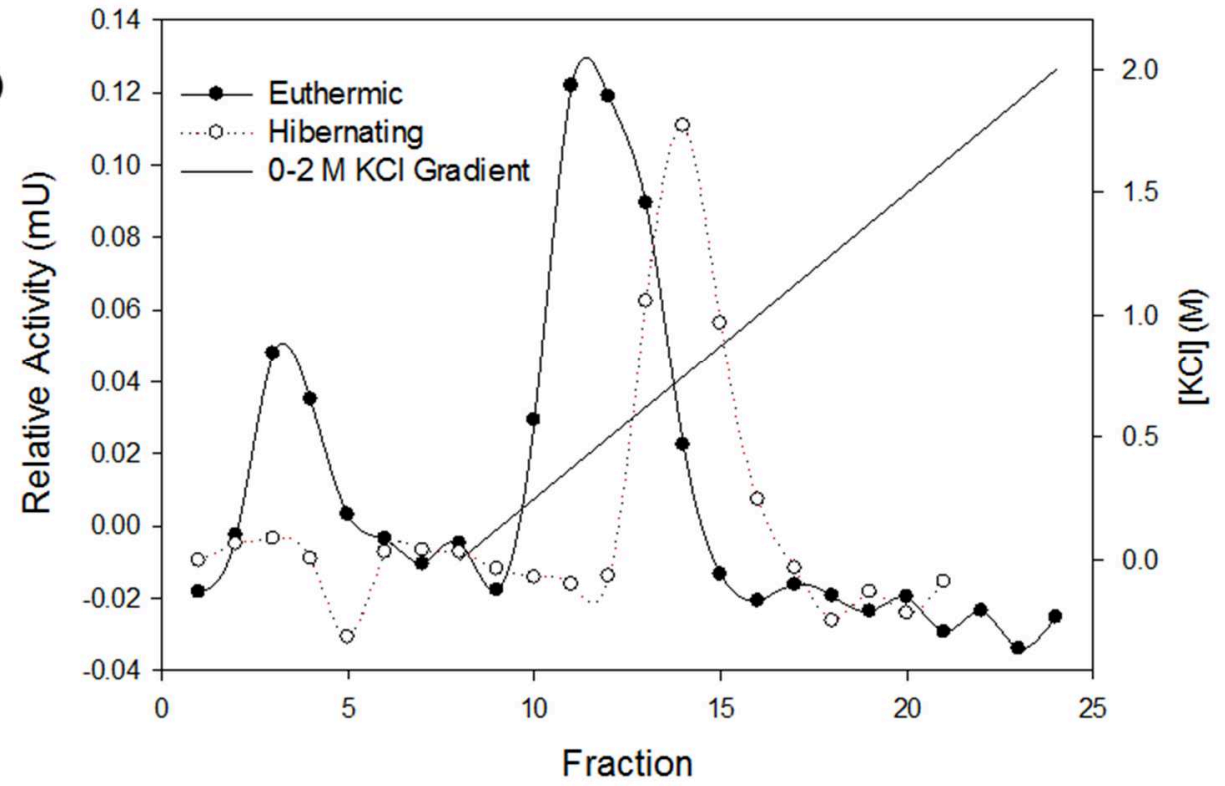

(b)

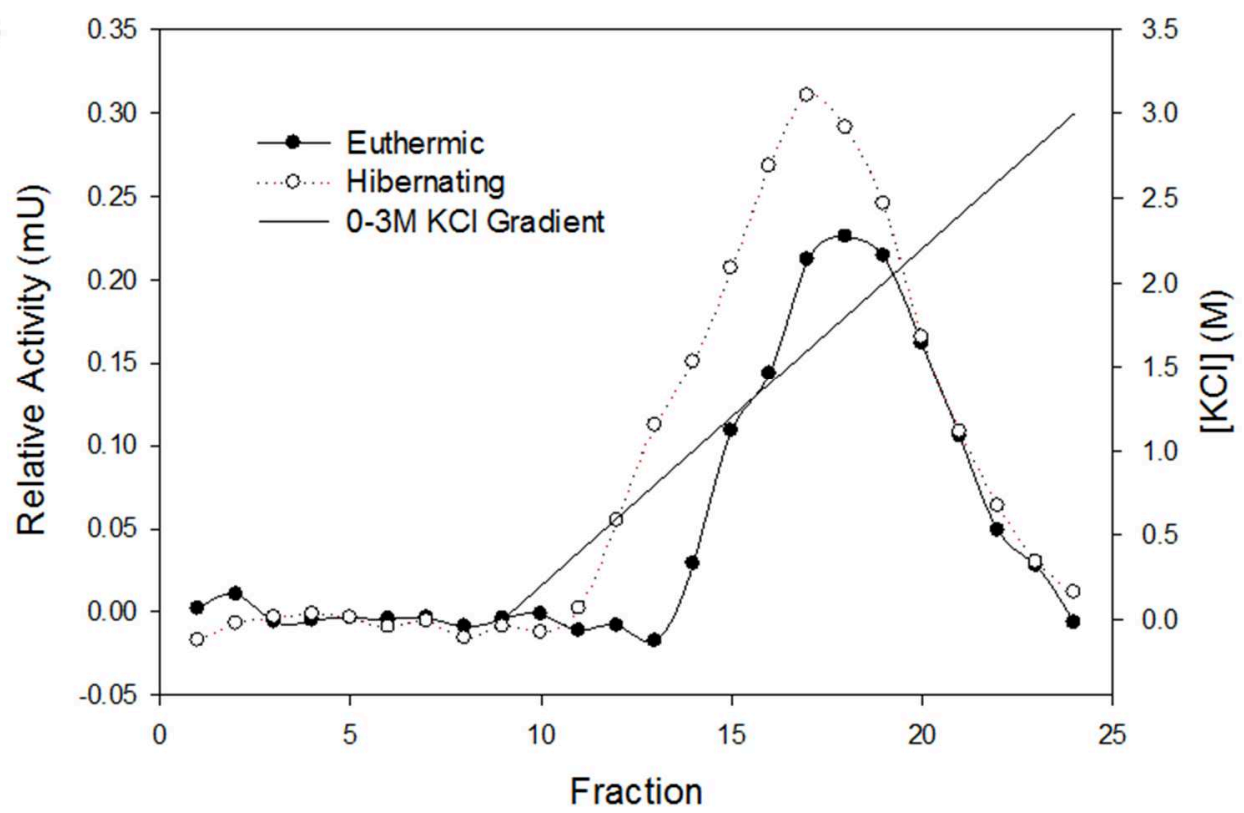

Figure 4.1. Typical elution profiles for G3PDH activity from muscle of euthermic (control) and hibernating $U$. richardsonii using (a) $0-2 \mathrm{M}$ gradient of $\mathrm{KCl}$ on a $\mathrm{CM}^{-}$Sephadex column and; (b) $0-3 \mathrm{M}$ gradient of $\mathrm{KCl}$ as the elutant on a Cibacron Blue agarose column. Elution profiles are from separate runs of euthermic and hibernating enzyme but are superimposed here for viewing. 


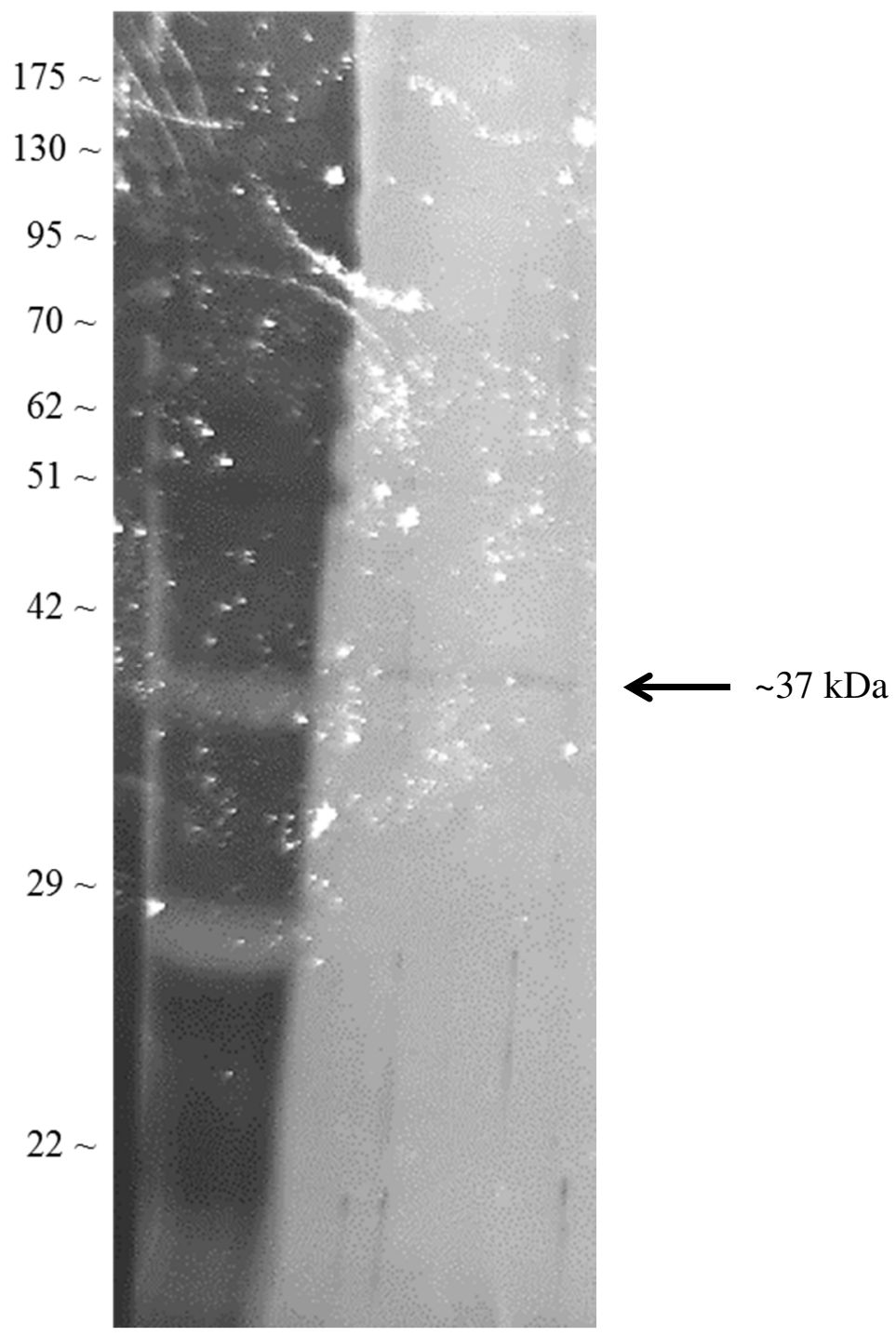

Figure 4.2. 10\% SDS-PAGE gel with silver staining showing FroggaBio molecular weight ladder (kDa) (left) and purified euthermic U. richardsonii skeletal muscle G3PDH (right). 

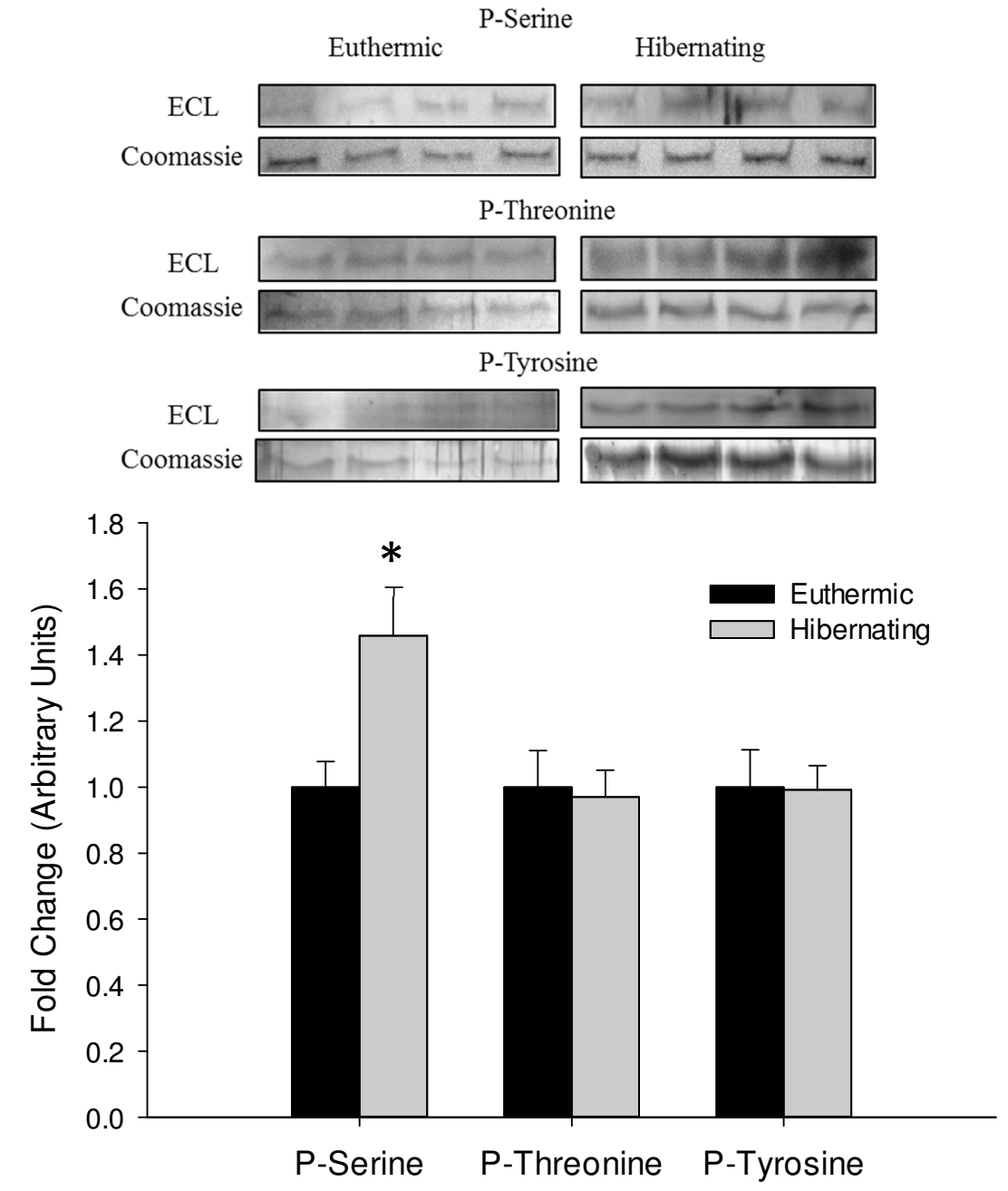

Figure 4.3. Quantification of post-translational modifications of purified G3PDH from muscle of euthermic and hibernating $U$. richardsonii via phosphorylation. Chemiluminescence signal intensities were standardized to protein amount, and the value for hibernating G3PDH was expressed relative to the control value that was set to 1. Data are mean \pm SEM, $n=3-4$ determinations on purified enzyme samples. Asterisk indicates significant differences from the corresponding control G3PDH, Student's ttest, two-tailed, $\mathrm{P}<0.05$. 
(a)

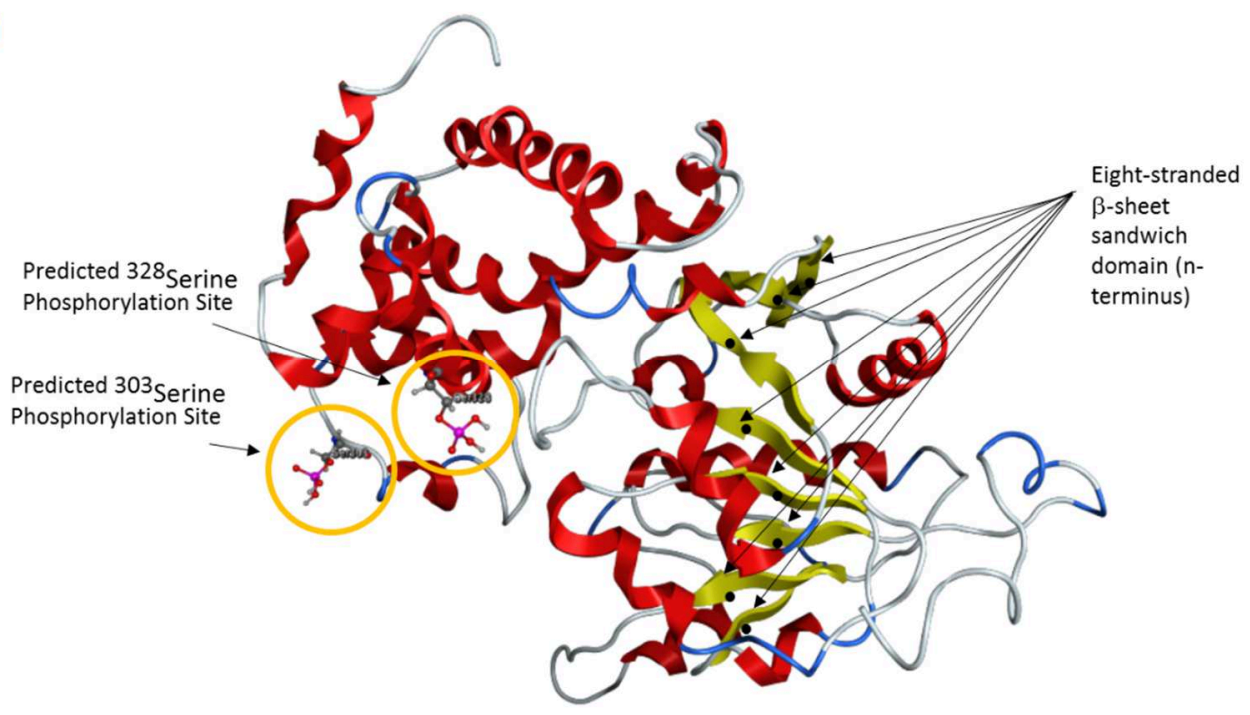

(b)

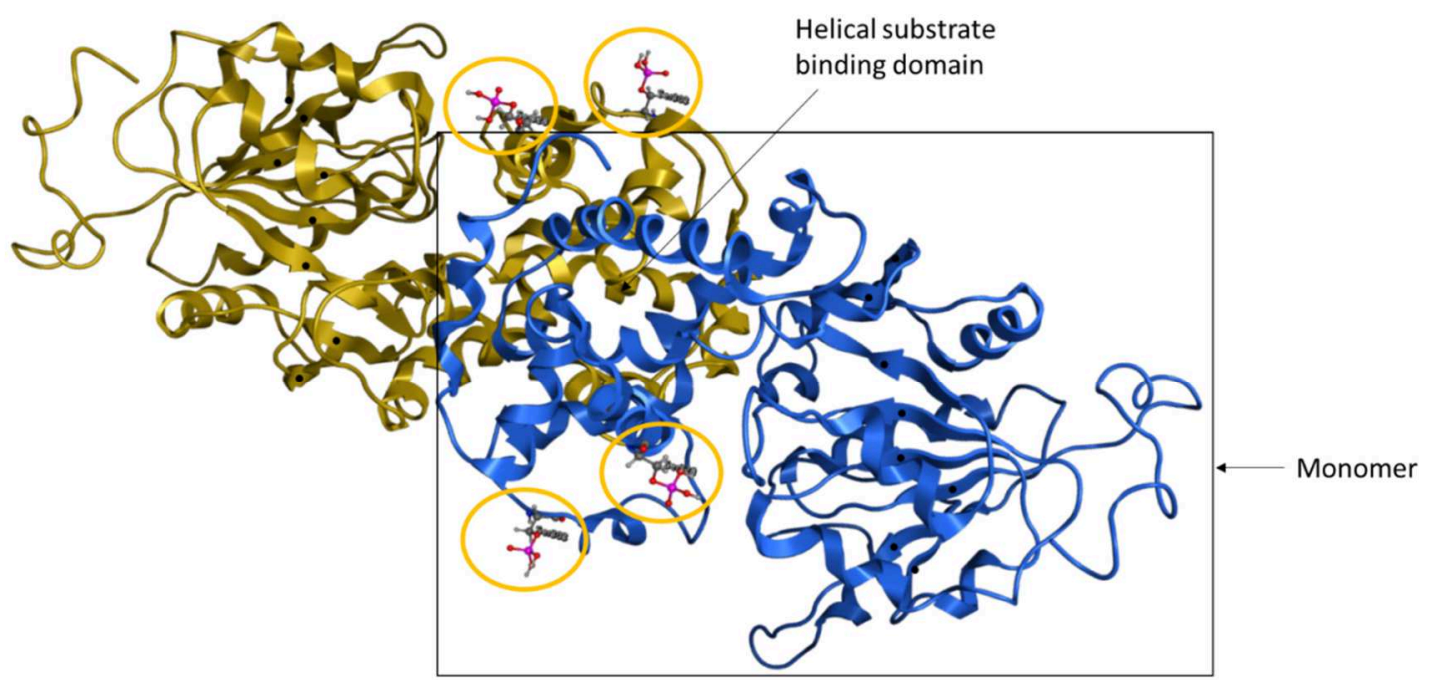

1

Figure 4.4. The predicted structure of muscle G3PDH from hibernating Richardson's ground squirrels using I-TASSER (Yang et al., 2015; Roy et al., 2010; Zhang, 2008) with the 13-LGS G3PDH amino acid sequence as reference (NCBI Reference Sequence: XP_005324992.1). Both the G3PDH (a) monomer and (b) dimeric structure are shown as cartoon representations. The monomer is identified within the quaternary structure by a black box. The predicted phosphorylation sites (on residues ${ }^{303}$ Serine \& ${ }^{328}$ Serine ) are circled in yellow; the $\mathrm{N}$-terminal eight-stranded $\beta$-sheet sandwich domain (from residues 3-190) is identified by $(\bullet)$; the C-terminal helical substrate-binding domain (from residues 193-349) is shown in the dimeric structure. 

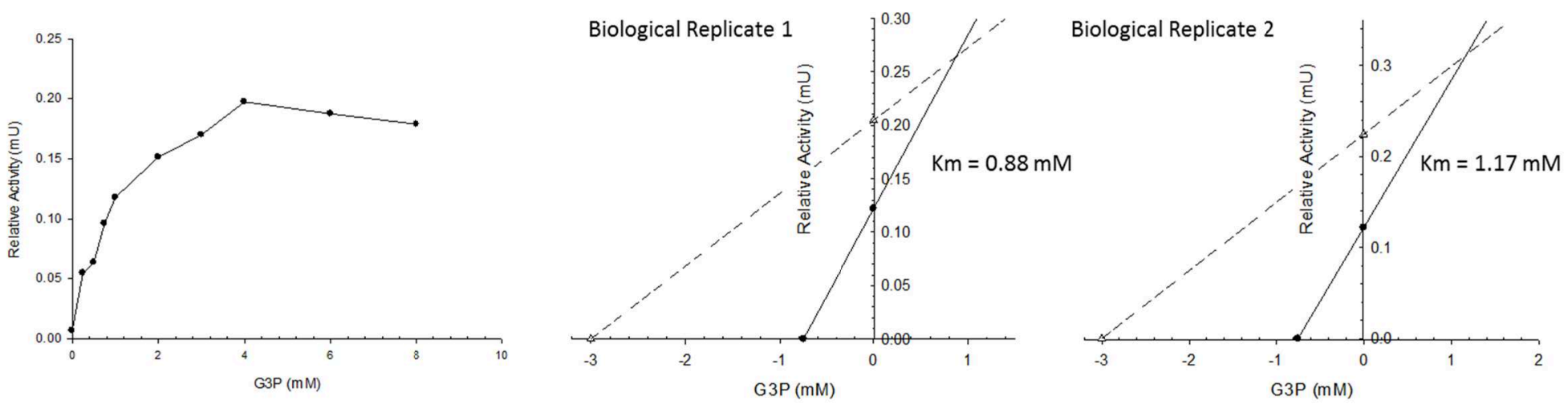


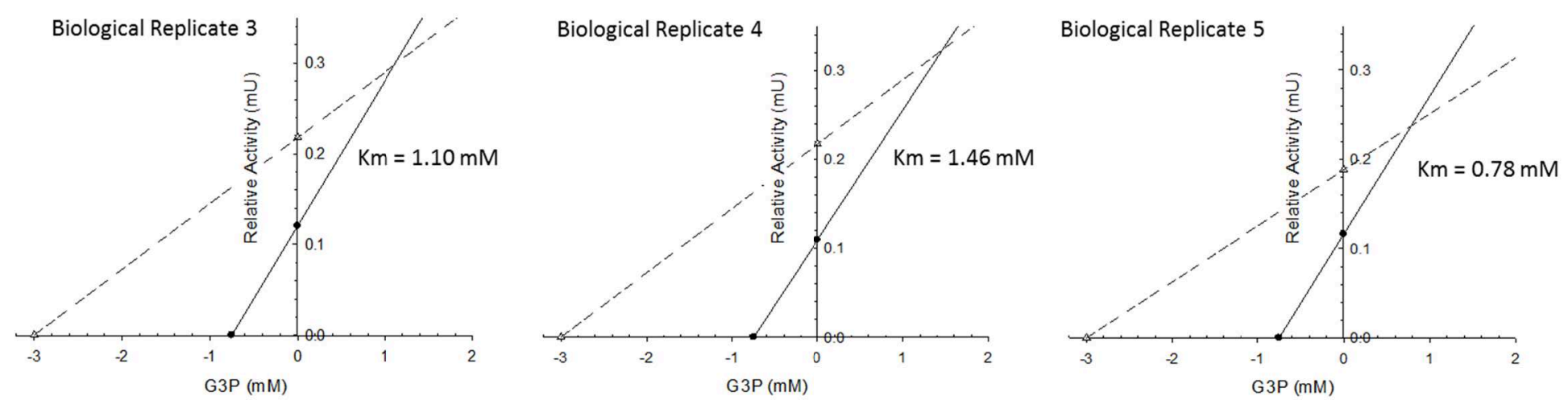

Figure S4.1. Kinetic values obtained using direct-linear plots (Eisenthal, 1974). Data shown is from multiple independent biological replicates for the G3P-utilizing $\left(22^{\circ} \mathrm{C}, \mathrm{pH} 8.0\right)$ reaction catalyzed by purified euthermic G3PDH. The $K_{m}$ values were averaged to obtain the reported $K_{m}$ value for the given condition ( $\left.1.08 \pm 0.12 \mathrm{mM}\right)$ found in Tables $4.2 \& 4.3$. This method used to obtain all subsequent kinetic values. 


\section{Discussion}

G3PDH plays an important role in metabolism serving as the bridge connecting triglyceride and carbohydrate metabolism. Previous research has elucidated this enzyme's regulatory mechanisms and temperature-dependent features that could support its role in triglyceride catabolism as an essential fuel source during mammalian hibernation (de la Roche et al., 2012; Berrada et al., 2000). More recently, G3PDH has been shown to be regulated by reversible phosphorylation in the liver of Richardson's ground squirrel (Chapter 3). These findings suggest that G3PDH could also be subject to metabolic regulation in skeletal muscle of the ground squirrel. Tight regulation of metabolic processes in this tissue should be essential during hibernation where skeletal muscle is virtually inactive during torpor but must remain 'physiologically primed' to greatly increase its metabolic rate and undertake strong shivering thermogenesis that is needed as part of the rewarming process hibernators as animals arouse out of torpor.

Since triglycerides are the primary fuel for winter survival, and given the role of G3PDH in processing the glycerol (once converted to G3P) derived from triglyceride hydrolysis (Dark, 2005), the main goal of this study was to examine the regulatory processes of this important enzyme of lipolysis, comparing euthermic and hibernating states. Specifically, G3PDH from skeletal muscle of Richardson's ground squirrels was purified to homogeneity using a three step procedure (Table 4.1). The apparent molecular weight of the subunit ( $37 \mathrm{kDa}$; Fig. 4.2) determined by SDS-PAGE was consistent with previous molecular weight determinations for this dimeric enzyme that is composed of two identical subunits (Menaya et al., 1995; Stebeck et al., 1996; Berrada et al., 2002; de la Roche et al., 2012). 
The functional and structural properties of skeletal muscle G3PDH were compared for euthermic and hibernating ground squirrels. Arrhenius plots of G3PDH showed no breaks in the linear relationship and yielded identical activation energies for the euthermic and hibernator enzymes (Table 4.2). Maximum activities of G3PDH were measured in the G3P-oxidizing direction, the direction associated with triglyceride breakdown. From these measurements, in all cases, except for euthermic $K_{m} \mathrm{G} 3 \mathrm{P}$, there was a relative increase in enzyme substrate affinity in the oxidative direction $\left(\mathrm{G} 3 \mathrm{P}+\mathrm{NAD}^{+}\right)$at $5^{\circ} \mathrm{C}$ compared to $37^{\circ}$ $\mathrm{C}$ (Table 4.2). Furthermore, distinctions between euthermic and hibernator G3PDH lie in a comparison of functional and structural parameters at $37^{\circ} \mathrm{C}, 22^{\circ} \mathrm{C}$, and $5^{\circ} \mathrm{C}$. Hibernator G3PDH exhibited increased affinities for both $\mathrm{G} 3 \mathrm{P}$ and $\mathrm{NAD}^{+}$when assayed at $5^{\circ} \mathrm{C}$ relative to the euthermic enzyme (Table 4.2). This implies functional differences between these two enzyme forms. Interestingly, the finding that a decrease in temperature promoted increased G3P affinity in the hibernating state and had the opposite effect for the euthermic species may suggest that a temperature-sensitive post-translational modification may be the cause of these opposite trends. In any case, the finding of greater G3P substrate affinity of the hibernator form at low temperature seems to be in accordance to expectations for metabolism during low $\mathrm{T}_{\mathrm{b}}$ which should predictably promote the oxidation of G3P, derived from triglyceride hydrolysis, while the ground squirrel is hibernating.

Structure-function studies using chemical denaturants and temperature perturbation also revealed differences between the skeletal muscle G3PDH from euthermic and hibernating species. Both of these perturbations induced changes in enzyme stability that were monitored by changes in $I C_{50}$ (for chemical denaturants) and $T_{50}$ (for thermal stability). Temperature induced conformational changes were monitored by incubating 
euthermic and hibernator G3PDH at $50^{\circ} \mathrm{C}$ and then measuring the time that it took for the enzyme's activity to be reduced to half of its initial $V_{\max }$. This $T_{50}$ value was 2 -fold greater relative to euthermic G3PDH indicating that the hibernator form was relatively more thermally stable enzyme. A less rigid structure could also account for the greater thermal stability of hibernator $\mathrm{G} 3 \mathrm{PDH}$ when incubated in vitro at $50^{\circ} \mathrm{C}$. With respect to chemicallyinduced changes in activity, euthermic G3PDH maximal activity was affected by guanidine hydrochloride and urea to a greater degree relative to hibernator G3PDH(Table 4.2). The responses to denaturants indicate structural differences between the two enzyme forms and suggest a greater structural integrity of hibernator G3PDH when faced with chemical denaturation.

Previous studies have shown that many enzymes are subject to reversible phosphorylation (reviewed in Storey and Storey, 2004a). As seen for ground squirrel liver G3PDH (Chapter 3), G3PDH from the skeletal muscle of Richardson's ground squirrel was differentially regulated in its euthermic and hibernating enzymatic forms via reversible protein phosphorylation. The data presented in this study indicate that $U$. richardsonii skeletal muscle G3PDH is a phosphoprotein, phosphorylated on serine residues (Fig. 4.3). The change in the phosphorylation state of G3PDH during hibernation suggests that reversible phosphorylation of G3PDH may adjust enzyme function in response to changing conditions. The kinetic alterations identified in this study suggest that skeletal muscle G3PDH from euthermic and hibernator $U$. richardsonii exists in two distinct forms. While the exact nature of the aforementioned post-translational modification is not explicitly known, it seems as though post-translational modifications of skeletal muscle G3PDH during hibernation result in an increase in the G3P-oxidizing functionality. 
Endothermic species are able to capitalize on the higher kinetic energy of molecules to increase the rate of cellular reactions via the production of endogenous heat. However, during hibernation, enzymes must function properly at low $\mathrm{T}_{\mathrm{b}}$ and also remain integrated with the activities of other enzymes in the metabolic pathways within which they function. Interestingly, an increase in G3P affinity by G3PDH seems to be occur despite the low temperatures that these ground squirrels experience during winter hibernation. This suggests that G3PDH structural modifications allow for low temperature functionality necessary to promote the maintenance of lipid derived glycerol breakdown during hibernation when glucose levels are low. In order to compliment the experimental studies on Richardson ground squirrel G3PDH, bioinformatics tools were used to analyze the G3PDH sequence from the 13-lined ground squirrel, a closely related hibernator with a sequenced genome. This analysis was aimed at identifying G3PDH amino acid posttranslational modification sites that may play a role in stabilizing enzyme functionality at high versus low temperatures. While the predicted structural changes observed for 13-LGS ground squirrel G3PDH cannot be definitively validated as also applying to the Richardson's ground squirrel model without the Richardson's G3PDH protein sequence, the experimental as well as bioinformatics comparisons to homothermic species support a less rigid conformation of the enzyme from the heterothermic, hibernating mammal (de la Roche et al., 2012). The addition of phosphate groups to the predicted serine amino acid residues may aid in promoting the enhanced G3P affinity seen at low temperatures in the hibernator form of the G3PDH.

In conclusion, differential controls on enzyme function are sometimes needed in order to achieve hibernation specific functions (reviewed in Storey, 1997). During the 
hibernating season, G3PDH catalyzes the conversion of G3P to DHAP. Once converted to DHAP this metabolite is fed into carbohydrate metabolism to be directed into either glycolysis or gluconeogenesis, the latter being the primary fate under starved conditions in mammals (ie. as in obligate hibernators) (Bortz et al., 1972, Owen et al., 1969). Even in skeletal muscle during hibernation, when skeletal muscle movement is essentially halted, the conversion of lipid-derived glycerol to carbohydrates may be essential for the maintenance of key cellular features, and ensuring that this tissue remains viable for the 'explosive events' associated with the rewarming processes and exit out of torpor. 


\section{Chapter 5}

\section{General Discussion}


The acquisition of energy from food is a ubiquitous requirement for all animals to sustain normal physiology and behavior. Over evolutionary time, natural selection has favored animals capable of adapting to environmental fluctuations in the quantity and quality of food available. With that in mind, an adaptive strategy that some animal species have mastered when faced with day to day or season to season fluctuations in food availability or hostile environmental conditions is the ability to depress their metabolic rate and enter a state of suspended animation (hypometabolism) until favourable conditions return (reviewed in Storey \& Storey, 1999, 2004; Guppy \& Withers, 1999). This thesis focused on the mammalian version of metabolic rate depression-hibernation.

Many small mammals are faced with the challenge of surviving harsh winter climates. In mammals, hibernation is one adaptive strategy used to save energy under adverse winter environmental conditions (i.e. extreme low temperatures, shortened day length, sometimes also very dry) which often leads to inadequate food intake (reviewed in Carey et al., 2003; Davis, 1976). To fight the cold and limited food resources, Richardson's ground squirrels move into underground burrows and hibernate-surviving solely on endogenous fuel resources built up in the pre-winter months (Wang, 1998) and abandoning euthermic life since the energy demands to maintain an elevated $\mathrm{T}_{\mathrm{b}}$ are too great Along with the ability to lower their $\mathrm{T}_{\mathrm{b}}$, hibernation in Richardson's ground squirrels is marked by significant decreases in all physiological processes (i.e. heart rate, breathing rate, and kidney filtration rate) and an $\sim 95 \%$ decrease in metabolic rate relative to the basal metabolic rate (Geiser, 2004). These adaptations have allowed these small mammals to survive harsh environmental conditions. 
With hibernation, a degree of metabolic plasticity is needed in most tissues in an effort to satisfy the new cellular energy demands of the hypometabolic state. With that said, during hibernation, mammals primarily use lipid fuel to satisfy their energy demands (South and House, 1967). As a consequence, carbohydrate catabolism and anabolism vary from summer arousal to torpor as indicated by tissue-specific glycolytic and gluconeogenic metabolite levels (Galaster and Morrison, 1975; Serkova et al. 2007). However, the emphasis on lipid catabolism and sparing of carbohydrate fuel does not mean that carbohydrate metabolism is completely halted. This present thesis aimed at assessing the fine interplay between lipid and carbohydrate metabolism by means of enzymatic regulation.

Despite the largely inactive state of skeletal muscle during hibernation, oxidation of glucose for energy occurs throughout the hibernation cycle (Tashima et al., 1970)— albeit at a much lower rate. Total $\mathrm{CO}_{2}$ and ATP outputs that are produced under aerobic conditions indicate that glucose makes up $\sim 10 \%$ of the metabolic energy usage during ground squirrel hibernation (Galster and Morrison, 1970; Morrison, 1960). Furthermore, evidence that glycolysis still occurs during hibernation is supported by the production of pyruvate and lactate (Galster and Morrison, 1970; Galaster and Morrison, 1975; El Hachimi et al., 1990). During arousal periods, the contribution of carbohydrates is reported to increase as animals rewarm, with glucose oxidation aiding energy production for skeletal muscle shivering thermogenesis (Buck and Barnes, 2000).

The recurring fluctuations in skeletal muscle metabolic activity makes it reasonable to hypothesize that glycolysis would be regulated over the hibernation cycle of torpor and arousal. With that in mind, a continual cycle of the production and degradation 
of proteins, including glycolytic enzymes, would be energetically costly and during a time of limited energy supply such a mechanism would not be ideal. Instead, the regulation of enzymes via reversible post-translational modifications offers a quick, energetically feasible method of control. Thus, the findings in this thesis regarding the reversible phosphorylation of LDH suggest that post-translational modifications help to regulate carbon flow through glycolysis within ground squirrel skeletal muscle during hibernation. Moreover, suppression of this enzyme coincides well with previous investigations of ground squirrel skeletal muscle hexokinase, phosphofructokinase, and glyceraldehyde 3phosphate dehydrogenase—all of which are suppressed during ground squirrel hibernation by mechanisms that include reversible phosphorylation (Abnous and Storey, 2008; Macdonald and Storey, 2005; Bell et al., 2014).

In mammalian tissue, ATP production is mostly derived from glucose and lipid oxidation (Wolfe, 1998). As alluded to previously, lipid oxidation increases during hibernation with one by-product of triglyceride oxidation being glycerol. In several species, the ability to convert glycerol to glucose is an important evolutionary adaptation in the hibernation process that provides a source of carbohydrate for tissues and processes that need it over the winter months (Yeh et al., 1995). The changes in G3PDH properties during hibernation reported in this thesis are consistent with a more active state of the enzyme and concur with previous studies that support the idea of increased gluconeogenesis during hibernation (de la Roche et al., 2012; Berrada et al., 2000). Because the liver is the primary gluconeogenic tissue in mammals, and combined with the fact that glycolysis is suppressed during hibernation, I hypothesized that the production of glucose from glycerol released from triglyceride catabolism is important for hibernation success. Gluconeogenesis can be 
important for (1) the maintenance of blood glucose levels during the hibernating fasting state, and (2) the building up of glycogen stores which can then be broken down and utilized during exit from torpor. This idea is supported as previous research has shown that skeletal muscle and heart glycogen stores increase during hibernation (Zimny and Tyrone, 1957; Hannon and Vaughan, 1961). This information, combined with the fact that there is a decreased capacity for glycogenolysis during deep torpor (Leonard and Wimsatt, 1959; Hannon and Vaughan, 1961) suggests that gluconeogenesis must be enhanced during extended periods of hibernation to maintain normal blood glucose levels. The increase in G3PDH affinity for substrate seen during hibernation in this study supports previous findings which show that there is an incorporation of glycerol derived from lipids into the gluconeogenic pathway during hibernation (Rebel et al., 1960; Burlington and Klain, 1967). With respect to the ground squirrel, the coordinated control of gluconeogenesis and glyconeogensis has seldom been studied. Future work in this area should look at the reversible phosphorylation regulation of other enzymes that facilitate the conversion of glycerol into glucose or glycogen. In particular, studies of glycerol kinase (GK) would be very important. In mammals, GK has been found in liver and kidney, and at low levels in adipose tissue as well as cardiac and skeletal muscle tissues (Lin, 1977). As with G3PDH, this enzyme may be differentially regulated throughout the hibernation cycle in ground squirrels.

Another area of future research would be to look at the regulation of the glycerolphosphate shuttle (G3P shuttle) during hibernation as an alternative means of generating ATP. This shuttle mediates the complex process used to transfer electrons from cytosolic NADH to the mitochondria where this redox species they can be used in the electron 
transport chain. In short, this process allows for ATP production from cytoplasmic NADH through oxidative phosphorylation. In insects, the G3P shuttle plays an important role in metabolic energy generation in the flight muscle and dysregulation of cytoplasmic and/or mitochondrial G3PDH leads to diminished flying capacity (Beenakkers, 1969). In mammals, the role of the G3P shuttle is much less studied. Evidence indicates that in humans the alternative malate-aspartate shuttle predominates for the transfer of reducing equivalents into the mitochondria (Lin, 1977). However, nothing is known about the importance of the G3P shuttle to hibernation or even to normal mammalian energy metabolism in general. Future work looking at the structural and functional properties of the mitochondrial form of G3PDH (also known as G3P oxidase) in hibernator tissues could help elucidate if or how the G3P shuttle mechanism contributes to ATP production during hypometabolism.

The prevalence and variety of post-translational modifications (primarily reversible phosphorylation) suggests that the regulation of protein function is a dynamic, tissue specific process. Furthermore, although reversible phosphorylation is well known to play a key role in enzyme regulation, recent research indicates that phosphorylation tends to facilitate further PTMs to proteins such as that seen in the phosphorylation dependent SUMOylation of heat shock factor protein 1 (reviewed in Hunter, 2007). With the vast amount of evidence supporting the complexity of post-translational regulation of enzymes, it is unknown how the multitude of potential modifications can affect G3PDH and LDH structure and function in ground squirrels and how these PTMs are regulated through the hibernation cycle. Future studies should focus on elucidating the interplay of posttranslational modifications and their effects on enzyme functionality. 


\section{Conclusion}

For those hibernators that survive exclusively on endogenous fuel reserves during the hibernation season, the regulation of energy production and expenditure is a vital task. The intense eating behavior that obligate hibernators, including ground squirrels, undergo in the late summer prepares them for the physiological and metabolic challenges of hibernation. Specifically, the build-up of lipid stores helps facilitate the switch from a carbohydrate-based fuel system to a fuel system derived from lipid oxidation during torpor. The de-emphasis of carbohydrate catabolism during torpor is supported by a suppression of LDH as seen in the skeletal muscle of Richardson's ground squirrels. Furthermore, the prioritization of lipid-based fuel during hibernation is supported by the altered properties of G3PDH in the liver and skeletal muscle of this hibernator. Each of these aforementioned enzymes appears to be post-translationally modified by means of reversible phosphorylation to mediate their structural and functional changes during hibernation. The

quick, energetically efficient method of dephosphorylation may be crucial to mediating the functionality switch of LDH during interbout arousals and during the seasonal exit out of torpor where carbohydrate metabolism increases again. Furthermore, dephosphorylation of G3PDH may aid in the suppression of lipid derived glycerol-oxidation during the euthermic state. Taken together the work presented in this thesis provides novel insights in to the plasticity of lipid and carbohydrate metabolism in liver and skeletal muscle during ground squirrel torpor. 


\section{References}


Abboud, J., \& Storey, K. B. (2013). Novel control of lactate dehydrogenase from the freeze tolerant wood frog: role of posttranslational modifications. PeerJ, 1, e12.

Abnous, K., \& Storey, K. B. (2008). Skeletal muscle hexokinase: regulation in mammalian hibernation. Molecular and Cellular Biochemistry, 319(1-2), 41-50.

Abnous, K., Dieni, C. A., \& Storey, K. B. (2008). Regulation of Akt during hibernation in Richardson's ground squirrels. Biochimica et Biophysica Acta (BBA)-General Subjects, 1780(2), 185-193.

Ahima, R. S., Prabakaran, D., Mantzoros, C., Qu, D., Lowell, B., Maratos-Flier, E., \& Flier, J. S. (1996). Role of leptin in the neuroendocrine response to fasting. Nature, 382, 250 - 252

Albertyn, J., van Tonder, A., \& Prior, B. A. (1992). Purification and characterization of glycerol-3-phosphate dehydrogenase of Saccharomyces cerevisiae. FEBS Letters, 308(2), 130-132.

Ambid, L., \& Agid, R. (1975). Lactates tissulaires, pH et gaz du sang chez le Lerot hibernant: evolution au cours des reveils periodiques. Comptes rendus des séances de la Société de biologie, 169, 1380-1385.

Anderson, B. D., Turner, J. J., \& Bintz, G. L. (1989). Fatty acid synthetase in control, starved and refed Richardson's ground squirrels. Comparative Biochemistry and Physiology Part A: Physiology, 93(3), 613-616.

Arnold, K., Bordoli, L., Kopp, J., \& Schwede, T. (2006). The SWISS-MODEL workspace: a web-based environment for protein structure homology modelling.Bioinformatics, 22(2), 195-201.

Asher, G., Gatfield, D., Stratmann, M., Reinke, H., Dibner, C., Kreppel, F. \& Schibler, U. (2008). SIRT1 regulates circadian clock gene expression through PER2 deacetylation. Cell, 134(2), 317-328.

Baba, H., Zhang, X. J., \& Wolfe, R. R. (1994). Glycerol gluconeogenesis in fasting humans. Nutrition (Burbank, Los Angeles County, Calif.), 11(2), 149-153.

Bauer, V. W., Squire, T. L., Lowe, M. E., \& Andrews, M. T. (2001). Expression of a chimeric retroviral-lipase mRNA confers enhanced lipolysis in a hibernating mammal. American Journal of Physiology-Regulatory, Integrative and Comparative Physiology, 281(4), R1186-R1192.

Bauman, W. A., Meryn, S., \& Florant, G. L. (1987). Pancreatic hormones in the nonhibernating and hibernating golden mantled ground squirrel. Comparative Biochemistry and Physiology Part A: Physiology, 86(2), 241-244.

Beenakkers, A. T. (1969). Carbohydrate and fat as a fuel for insect flight. A comparative study. Journal of Insect Physiology, 15(3), 353-361. 
Bell, R. A., Smith, J. C., \& Storey, K. B. (2014). Purification and properties of glyceraldehyde-3-phosphate dehydrogenase from the skeletal muscle of the hibernating ground squirrel, Ictidomys tridecemlineatus. PeerJ, 2, e634.

Bell, R. A., \& Storey, K. B. (2010). Regulation of liver glutamate dehydrogenase by reversible phosphorylation in a hibernating mammal. Comparative Biochemistry and Physiology Part B: Biochemistry and Molecular Biology, 157(3), 310-316.

Berrada, W., Naya, A., Iddar, A., \& Bourhim, N. (2002). Purification and characterization of cytosolic glycerol-3-phosphate dehydrogenase from skeletal muscle of jerboa (Jaculus orientalis). Molecular and cellular biochemistry, 231(1-2), 117-127.

Berrada, W., Naya, A., Ouafik, L. H., \& Bourhim, N. (2000). Effect of hibernation, thyroid hormones and dexamethasone on cytosolic and mitochondrial glycerol-3phosphate dehydrogenase from jerboa (Jaculus orientalis). Comparative Biochemistry and Physiology Part B: Biochemistry and Molecular Biology, 125(4), 439-449.

Bissell, M. J., Rambeck, W. A., White, R. C., \& Bassham, J. A. (1976). Glycerol phosphate shuttle in virus-transformed cells in culture. Science, 191(4229), 856858.

Blom, N., Gammeltoft, S., \& Brunak, S. (1999). Sequence and structure-based prediction of eukaryotic protein phosphorylation sites. Journal of Molecular Biology, 294(5), 1351-1362.

Blum, H., Beier, H., \& Gross, H. J. (1987). Improved silver staining of plant proteins, RNA and DNA in polyacrylamide gels. Electrophoresis, 8(2), 93-99.

Bortz, W. M., Paul, P., Haff, A. C., \& Holmes, W. L. (1972). Glycerol turnover and oxidation in man. Journal of Clinical Investigation, 51(6), 1537.

Braverman, N. E., \& Moser, A. B. (2012). Functions of plasmalogen lipids in health and disease. Biochimica et Biophysica Acta (BBA)-Molecular Basis of Disease, 1822(9), 1442-1452.

Brisson, D., Vohl, M. C., St-Pierre, J., Hudson, T. J., \& Gaudet, D. (2001). Glycerol: a neglected variable in metabolic processes? Bioessays, 23(6), 534-542.

Brites, P., Waterham, H. R., \& Wanders, R. J. (2004). Functions and biosynthesis of plasmalogens in health and disease. Biochimica et Biophysica Acta (BBA)Molecular and Cell Biology of Lipids, 1636(2), 219-231.

Brooks, S. P. (1992). A simple computer program with statistical tests for the analysis of enzyme kinetics. Biotechniques, 13(6), 906-911. 
Brooks, S. P., \& Storey, K. B. (1992). Mechanisms of glycolytic control during hibernation in the ground squirrel Spermophilus lateralis. Journal of Comparative Physiology B, 162(1), 23-28.

Buck, C. L., \& Barnes, B. M. (2000). Effects of ambient temperature on metabolic rate, respiratory quotient, and torpor in an arctic hibernator. American Journal of Physiology-Regulatory, Integrative and Comparative Physiology, 279(1), R255R262.

Buck, M. J., Squire, T. L., \& Andrews, M. T. (2002). Coordinate expression of the PDK4 gene: a means of regulating fuel selection in a hibernating mammal. Physiological Genomics, 8(1), 5-13.

Burlington, R. F., \& Klain, G. J. (1967). Gluconeogenesis during hibernation and arousal from hibernation. Comparative Biochemistry and Physiology, 22(3), 701-708.

Cai, D., McCarron, R. M., Erik, Z. Y., Li, Y., \& Hallenbeck, J. (2004). Akt phosphorylation and kinase activity are down-regulated during hibernation in the 13-lined ground squirrel. Brain Research, 1014(1), 14-21.

Cantó, C., Gerhart-Hines, Z., Feige, J. N., Lagouge, M., Noriega, L., Milne, J. C., \& Auwerx, J. (2009). AMPK regulates energy expenditure by modulating NAD $^{+}$ metabolism and SIRT1 activity. Nature, 458(7241), 1056-1060.

Carey, C. (Ed.). (1993). Life in the Cold: Ecological, Physiological, and Molecular Mechanisms. Westview Press.

Carey, H. V., Andrews, M. T., \& Martin, S. L. (2003). Mammalian hibernation: cellular and molecular responses to depressed metabolism and low temperature. Physiological Reviews, 83(4), 1153-1181.

Chaudhary, N., \& Pfluger, P. T. (2009). Metabolic benefits from Sirt1 and Sirt1 activators. Current Opinion in Clinical Nutrition \& Metabolic Care, 12(4), 431437.

Cohen, P. (2002). The origins of protein phosphorylation. Nature Cell Biology,4(5), E127-E130.

Considine, R. V., Sinha, M. K., Heiman, M. L., Kriauciunas, A., Stephens, T. W., Nyce, M. R.,\& Caro, J. F. (1996). Serum immunoreactive-leptin concentrations in normal-weight and obese humans. New England Journal of Medicine, 334(5), 292-295.

Cowan, K. J., \& Storey, K. B. (2003). Mitogen-activated protein kinases: new signaling pathways functioning in cellular responses to environmental stress. Journal of Experimental Biology, 206(7), 1107-1115. 
Cranford, J. A. (1978). Hibernation in the western jumping mouse (Zapus princeps). Journal of Mammalogy, 496-509.

Daan, S., Barnes, B. M., \& Strijkstra, A. M. (1991). Warming up for sleep?-ground squirrels sleep during arousals from hibernation. Neuroscience Letters, 128(2), 265-268.

Dark, J. (2005). Annual lipid cycles in hibernators: integration of physiology and behavior. Annual Review of Nutrition, 25, 469-497.

Davis, D. E. (1976). Hibernation and circannual rhythms of food consumption in marmots and ground squirrels. Quarterly Review of Biology, 477-514.

Dawson, N. J., Bell, R. A., \& Storey, K. B. (2013). Purification and properties of white muscle lactate dehydrogenase from the anoxia-tolerant turtle, the red-eared slider, Trachemys scripta elegans. Enzyme Research, 2013.

De la Roche, M., Tessier, S. N., \& Storey, K. B. (2012). Structural and functional properties of glycerol-3-phosphate dehydrogenase from a mammalian hibernator. The Protein Journal, 31(2), 109-119.

Eisenthal, R. (1974). The direct linear plot. A new graphical procedure for estimating enzyme kinetic parameters. Biochemical. Journal, 139, 715-720.

El Hachimi, Z., Tijane, M. H., Boissonnet, G., Benjouad, A., Desmadril, M., \& Yon, J. M. (1990). Regulation of the skeletal muscle metabolism during hibernation of Jaculus orientalis. Comparative Biochemistry and Physiology Part B:

Comparative Biochemistry, 96(3), 457-459.

Epperson, L. E., Dahl, T. A., \& Martin, S. L. (2004). Quantitative analysis of liver protein expression during hibernation in the golden-mantled ground squirrel. Molecular \& Cellular Proteomics, 3(9), 920-933.

Feist, D. D. (1970). Blockade of arousal from hibernation by inhibition of norepinephrine synthesis in the golden hamster. Life Sciences, 9(19), 1117-1125.

Florant, G. L. (1998). Lipid metabolism in hibernators: the importance of essential fatty acids. American Zoologist, 38(2), 331-340.

Florant, G. L., Hester, L., Ameenuddin, S., \& Rintoul, D. A. (1993). The effect of a low essential fatty acid diet on hibernation in marmots. American Journal of Physiology-Regulatory, Integrative and Comparative Physiology, 264(4), R747R753.

Fahlman, A., Storey, J. M., \& Storey, K. B. (2000). Gene up-regulation in heart during mammalian hibernation. Cryobiology, 40(4), 332-342. 
Frank, C. L. (1992). The influence of dietary fatty acids on hibernation by goldenmantled ground squirrels (Spermophilus lateralis). Physiological Zoology, 906920.

Frank, C. L., Karpovich, S., \& Barnes, B. M. (2008). Dietary fatty acid composition and the hibernation patterns in free-ranging Arctic ground squirrels. Physiological and Biochemical Zoology, 81(4), 486-495.

French, A. R. (1985). Allometries of the durations of torpid and euthermic intervals during mammalian hibernation: a test of the theory of metabolic control of the timing of changes in body temperature. Journal of comparative Physiology $B$, 156(1), 13-19.

French, A. R. (1988). The patterns of mammalian hibernation. American Scientist, 76, 568-575.

Galster, W. A., \& Morrison, P.R. (1970). Cyclic changes in carbohydrate concentrations during hibernation in the arctic ground squirrel. American Journal of Physiology 218(4), 1228-1232.

Galster, W., \& Morrison, P. R. (1975). Gluconeogenesis in arctic ground squirrels between periods of hibernation. American Journal of Physiology, 228(1), 325330 .

Geiser, F. (2004). Metabolic rate and body temperature reduction during hibernation and daily torpor. Annu. Rev. Physiol., 66, 239-274.

Geiser, F., McAllan, B. M., \& Kenagy, G. J. (1994). The degree of dietary fatty acid unsaturation affects torpor patterns and lipid composition of a hibernator. Journal of Comparative Physiology B, 164(4), 299-305.

Geiser, F., \& Ruf, T. (1995). Hibernation versus daily torpor in mammals and birds: physiological variables and classification of torpor patterns. Physiological Zoology, 935-966.

Guppy, M., \& Withers, P. (1999). Metabolic depression in animals: physiological perspectives and biochemical generalizations. Biological Reviews of the Cambridge Philosophical Society, 74(01), 1-40.

Hannon, J. P., \& Vaughan, D. A. (1961). Initial stages of intermediary glucose catabolism in the hibernator and nonhibernator. American Journal of Physiology, 201(2), 217-223.

Hampton, M., \& Andrews, M. T. (2007). A simple molecular mathematical model of mammalian hibernation. Journal of Theoretical Biology, 247(2), 297-302. 
Hardie, D. G., Hawley, S. A., \& Scott, J. W. (2006). AMP-activated protein kinasedevelopment of the energy sensor concept. Journal of Physiology, 574(1), 7-15.

Harlow, H. J., \& Frank, C. L. (2001). The role of dietary fatty acids in the evolution of spontaneous and facultative hibernation patterns in prairie dogs. Journal of Comparative Physiology B, 171(1), 77-84.

Hayward, J. S., Lyman, C. P., \& Taylor, C. R. (1965). The possible role of brown fat as a source of heat during arousal from hibernation. Annals of the New York Academy of Sciences, 131(1), 441-446.

Hittel, D. S., \& Storey, K. B. (2002). Differential expression of mitochondria-encoded genes in a hibernating mammal. Journal of Experimental Biology, 205(11), 16251631.

Hochachka, P. W., \& Somero, G. N. (2014). Biochemical Adaptation. Princeton University Press.

Hunter, T. (2007). The age of crosstalk: phosphorylation, ubiquitination, and beyond. Molecular Cell, 28(5), 730-738.

Imai, S. I., Armstrong, C. M., Kaeberlein, M., \& Guarente, L. (2000). Transcriptional silencing and longevity protein Sir2 is an NAD-dependent histone deacetylase. Nature, 403(6771), 795-800.

Karpovich, S. A., Tøien, Ø., Buck, C. L., \& Barnes, B. M. (2009). Energetics of arousal episodes in hibernating arctic ground squirrels. Journal of Comparative Physiology B, 179(6), 691-700.

Katzenback, B. A., Dawson, N. J., \& Storey, K. B. (2014). Purification and characterization of a urea sensitive lactate dehydrogenase from the liver of the African clawed frog, Xenopus laevis. Journal of Comparative Physiology B, 184(5), 601-611.

Kawaguchi, T., Osatomi, K., Yamashita, H., Kabashima, T., \& Uyeda, K. (2002). Mechanism for fatty acid "sparing" effect on glucose-induced transcription regulation of carbohydrate-responsive element-binding protein by AMP-activated protein kinase. Journal of Biological Chemistry, 277(6), 3829-3835.

Koekemoer, T. C., Litthauer, D., \& Oelofsen, W. (1995). Isolation and characterization of adipose tissue glycerol-3-phosphate dehydrogenase. The International Journal of Biochemistry \& Cell Biology, 27(6), 625-632.

Koza, R. A., Kozak, U. C., Brown, L. J., Leiter, E. H., MacDonald, M. J., \& Kozak, L. P. (1996). Sequence and tissue-dependent RNA expression of mouse FAD-linked glycerol-3-phosphate dehydrogenase. Archives of Biochemistry and Biophysics, 336(1), 97-104. 
Kozak, L. P., Kozak, U. C., \& Clarke, G. T. (1991). Abnormal brown and white fat development in transgenic mice overexpressing glycerol 3-phosphate dehydrogenase. Genes \& Development, 5(12a), 2256-2264.

Kronfeld-Schor, N., Richardson, C., Silvia, B. A., Kunz, T. H., \& Widmaier, E. P. (2000). Dissociation of leptin secretion and adiposity during prehibernatory fattening in little brown bats. American Journal of Physiology-Regulatory, Integrative and Comparative Physiology, 279(4), R1277-R1281.

Laplante, M., \& Sabatini, D. M. (2010). mTORC1 activates SREBP-1c and uncouples lipogenesis from gluconeogenesis. Proceedings of the National Academy of Sciences, 107(8), 3281-3282.

Larkin, M. A., Blackshields, G., Brown, N. P., Chenna, R., McGettigan, P. A., McWilliam, H., \& Higgins, D. G. (2007). Clustal W and Clustal X version 2.0.Bioinformatics, 23(21), 2947-2948.

Leonard, S. L., \& Wimsatt, W. A. (1959). Phosphorylase and glycogen levels in skeletal muscle and liver of hibernating and nonhibernating bats. American Journal of Physiology, 197(5), 1059-1062.

Lin, E. C. C. (1977). Glycerol utilization and its regulation in mammals. Annual Review of Biochemistry, 46(1), 765-795.

Luu, B. E., Tessier, S. N., Duford, D. L., \& Storey, K. B. (2014). The Regulation of Troponins I, C and ANP by GATA4 and Nkx2-5 in Heart of Hibernating Thirteen-Lined Ground Squirrels, Ictidomys tridecemlineatus. PLOS ONE 10(2): e0117747. doi:10.1371/journal.pone.0117747.

Lyman, C. P. (2013). Hibernation and torpor in mammals and birds. Elsevier.

Lyman, C. P., \& Chatfield, P. O. (1950). Mechanisms of arousal in the hibernating hamster. Journal of Experimental Zoology, 114(3), 491-515.

MacDonald, J. A., \& Storey, K. B. (1998). cAMP-dependent protein kinase from brown adipose tissue: temperature effects on kinetic properties and enzyme role in hibernating ground squirrels. Journal of Comparative Physiology B,168(7), 513525 .

MacDonald, J. A., \& Storey, K. B. (1999). Regulation of ground squirrel $\mathrm{Na}^{+} \mathrm{K}^{+}$-ATPase activity by reversible phosphorylation during hibernation. Biochemical and Biophysical Research Communications, 254(2), 424-429.

MacDonald, J. A., \& Storey, K. B. (2005). Temperature and phosphate effects on allosteric phenomena of phosphofructokinase from a hibernating ground squirrel (Spermophilus lateralis). FEBS Journal, 272(1), 120-128. 
Maffei, M., Halaas, J., Ravussin, E., Pratley, R. E., Lee, G. H., Zhang, Y., \& Friedman, J. M. (1995). Leptin levels in human and rodent: measurement of plasma leptin and ob RNA in obese and weight-reduced subjects. Nature Medicine, 1(11), 11551161.

Markert, C. L., \& Møller, F. (1959). Multiple forms of enzymes: tissue, ontogenetic, and species specific patterns. Proceedings of the National Academy of Sciences of the United States of America, 45(5), 753.

McArthur, M. D., Hanstock, C. C., Malan, A., Wang, L. C. H., \& Allen, P. S. (1990). Skeletal muscle $\mathrm{pH}$ dynamics during arousal from hibernation measured $b \mathrm{y}^{31} \mathrm{P}$ NMR spectroscopy. Journal of Comparative Physiology B, 160(4), 339-347.

McArthur, M. D., \& Milsom, W. K. (1991). Changes in ventilation and respiratory sensitivity associated with hibernation in Columbian (Spermophilus columbianus) and golden-mantled (Spermophilus lateralis) ground squirrels. Physiological Zoology, 940-959.

Melvin, R. G., \& Andrews, M. T. (2009). Torpor induction in mammals: recent discoveries fueling new ideas. Trends in Endocrinology \& Metabolism, 20(10), 490-498.

Menaya, J., González-Manchón, C., Parrilla, R., \& Ayuso, M. S. (1995). Molecular cloning, sequencing and expression of a cDNA encoding a human liver NADdependent $\alpha$-glycerol-3-phosphate dehydrogenase. Biochimica et Biophysica Acta (BBA) Gene Structure and Expression, 1262(1), 91-94.

Michener, G. R. (1983). Spring emergence schedules and vernal behavior of Richardson's ground squirrels: why do males emerge from hibernation before females?. Behavioral Ecology and Sociobiology, 14(1), 29-38.

Moreau-Hamsany, C., Castex, C., Hoo-Paris, R., Kacemi, N., \& Suiter, B. (1988). Hormonal control of lipolysis from the white adipose tissue of hibernating jerboa (Jaculus orientalis). Comparative Biochemistry and Physiology Part A: Physiology, 91(4), 665-669.

Morrison, P. (1960). Some interrelations between weight and hibernation function. Bulletin of the Museum of Comparative Zoology, 124, 75-91.

Mostafa, N., Everett, D. C., Chou, S. C., Kong, P. A., Florant, G. L., \& Coleman, R. A. (1993). Seasonal changes in critical enzymes of lipogenesis and triacylglycerol synthesis in the marmot (Marmota flaviventris). Journal of Comparative Physiology B, 163(6), 463-469.

Nowell, M. M., Choi, H., \& Rourke, B. C. (2011). Muscle plasticity in hibernating ground squirrels (Spermophilus lateralis) is induced by seasonal, but not low 
temperature, mechanisms. Journal of Comparative Physiology B, 181(1), 147164.

Owen, O. E., Felig, P., Morgan, A. P., Wahren, J., \& Cahill Jr, G. F. (1969). Liver and kidney metabolism during prolonged starvation. Journal of Clinical Investigation, 48(3), 574.

Pilkis, S. J., \& Claus, T. H. (1991). Hepatic gluconeogenesis/glycolysis: regulation and structure/function relationships of substrate cycle enzymes. Annual Review of Nutrition, 11(1), 465-515.

Porstmann, T., Santos, C. R., Griffiths, B., Cully, M., Wu, M., Leevers, S., \& Schulze, A. (2008). SREBP activity is regulated by mTORC1 and contributes to Aktdependent cell growth. Cell metabolism, 8(3), 224-236.

Postnikova, G. B., Tselikova, S. V., Kolaeva, S. G., \& Solomonov, N. G. (1999). Myoglobin content in skeletal muscles of hibernating ground squirrels rises in autumn and winter. Comparative Biochemistry and Physiology Part A: Molecular \& Integrative Physiology, 124(1), 35-37.

Prendergast, B. J., Freeman, D. A., Zucker, I., \& Nelson, R. J. (2002). Periodic arousal from hibernation is necessary for initiation of immune responses in ground squirrels. American Journal of Physiology-Regulatory, Integrative and Comparative Physiology, 282(4), R1054-R1062.

Rebel, G., Weill, J., Mandel, P., \& Kayser, C. (1960). Is there formation of glycogen from fatty acids in hibernating animals during winter sleep? Comptes Rendus des Séances de la Société de Biologie et de Ses Filiales, 154, 2118.

Roy, A., Kucukural, A., \& Zhang, Y. (2010). I-TASSER: a unified platform for automated protein structure and function prediction. Nature Protocols, 5(4), 725738.

Serkova, N. J., Rose, J. C., Epperson, L. E., Carey, H. V., \& Martin, S. L. (2007). Quantitative analysis of liver metabolites in three stages of the circannual hibernation cycle in 13-lined ground squirrels by NMR. Physiological Genomics, 31(1), 15-24.

South, F. E., \& House, W. A. (1967). Energy metabolism in hibernation. Reprints-US Department of Agriculture, Agricultural Research Service.

Staples, J. F., \& Brown, J. C. (2008). Mitochondrial metabolism in hibernation and daily torpor: a review. Journal of Comparative Physiology B, 178(7), 811-827.

Stebeck, C. E., Frevert, U., Mommsen, T. P., Vassella, E., Roditi, I., \& Pearson, T. W. (1996). Molecular characterization of glycosomal NAD ${ }^{+}$-dependent glycerol 3- 
phosphate dehydrogenase from Trypanosoma brucei rhodesiense. Molecular and Biochemical Parasitology, 76(1), 145-158.

Steffen, J. M., Koebel, D. A., Musacchia, X. J., \& Milsom, W. K. (1991). Morphometric and metabolic indices of disuse in muscles of hibernating ground squirrels. Comparative Biochemistry and Physiology Part B: Comparative Biochemistry, 99(4), 815-819.

Stewart, J. M., English, T. E., \& Storey, K. B. (1998). Comparisons of the effects of temperature on the liver fatty acid binding proteins from hibernator and nonhibernator mammals. Biochemistry and cell biology, 76(4), 593-599.

Storey, K. B. (1997). Metabolic regulation in mammalian hibernation: enzyme and protein adaptations. Comparative Biochemistry and Physiology Part A: Physiology, 118(4), 1115-1124.

Storey, K. B., \& Storey, J. M. (1990). Metabolic rate depression and biochemical adaptation in anaerobiosis, hibernation and estivation. Quarterly Review of Biology, 145-174

Storey, K. B., \& Storey, J. M. (2004a). Metabolic rate depression in animals: transcriptional and translational controls. Biological Reviews, 79(1), 207-233.

Storey, K.B., and Storey, J. M. (2004b). "Mammalian hibernation: biochemical adaptation and gene expression," in Functional Metabolism: Regulation and Adaptation, pp. 443-471, John Wiley \& Sons, New York, NY, USA.

Storey, K. B., \& Storey, J. M. (2007). Tribute to PL Lutz: putting life on 'pause'molecular regulation of hypometabolism. Journal of Experimental Biology, 210(10), 1700-1714.

Storey, K. B., \& Storey, J. M. (2010). Metabolic rate depression: the biochemistry of mammalian hibernation. Advances in Clinical Chemistry, 52, 78.

Stralfors, P., \& Honnor, R. C. (1989). Insulin-induced dephosphorylation of hormonesensitive lipase. European Journal of Biochemistry, 182(2), 379-385.

Takahashi, J. S., Hong, H. K., Ko, C. H., \& McDearmon, E. L. (2008). The genetics of mammalian circadian order and disorder: implications for physiology and disease. Nature Reviews Genetics, 9(10), 764-775.

Tanishima, K., Gao, S. X., Yamamoto, R., \& Yoshida, H. (1995). Biochemical and enzymological study of lactate dehydrogenase isoenzymes from commercial quality control sera and several animal tissue sources. Clinical Chemistry and Laboratory Medicine, 33(11), 865-868. 
Tashima, L. S., Adelstein, S. J., \& Lyman, C. P. (1970). Radioglucose utilization by active, hibernating, and arousing ground squirrels. American Journal of Physiology--Legacy Content, 218(1), 303-309.

Tessier, S.N., Zhang, J., Biggar, K.K, Wu, C.W., Pifferi, F., Perret, M., \& Storey, K.B. (2015). Regulation of the PI3K/AKT pathway and fuel utilization during primate torpor in the grey mouse lemur, Microcebus murinus. Genomics, Proteomics and Bioinformatics, in press.

Tessier, S. N., \& Storey, K. B. (2014). Transitioning between entry and exit from mammalian torpor: The involvement of signal transduction pathways.Temperature, 1(2), 92-93.

Thatcher, B. J., \& Storey, K. B. (2001). Glutamate dehydrogenase from liver of euthermic and hibernating Richardson's ground squirrels: evidence for two distinct enzyme forms. Biochemistry and Cell Biology, 79(1), 11-19.

Tokuyama, K., Galantino, H. L., Green, R., \& Florant, G. L. (1991). Seasonal glucose uptake in marmots (Marmota flaviventris): the role of pancreatic hormones. Comparative Biochemistry and Physiology Part A: Physiology, 100(4), 925-930.

Turner, J. J., Anderson, B. D., \& Bintz, G. L. (1989). Whole-body lipids and fatty acid synthetase activity in Richardson's ground squirrels, Spermophilus richardsonii. Physiological Zoology, 1383-1397.

van Breukelen, F., Sonenberg, N., \& Martin, S. L. (2004). Seasonal and state-dependent changes of eIF4E and 4E-BP1 during mammalian hibernation: implications for the control of translation during torpor. American Journal of PhysiologyRegulatory, Integrative and Comparative Physiology, 287(2), R349-R353.

Wang, L. C. (1979). Time patterns and metabolic rates of natural torpor in the Richardson's ground squirrel. Canadian Journal of Zoology, 57(1), 149-155.

Wang, L.C.H., \& Lee, T.F. (1996). Torpor and hibernation in mammals: metabolic, physiological, and biochemical adaptations. In: Fregley, M.J., Blatteis, C.M., (eds) Handbook of Physiology: Environmental Physiology, section 4, vol 1. Oxford University Press, New York, pp. 507-532.

Walsh, C. T., Garneau-Tsodikova, S., \& Gatto, G. J. (2005). Protein posttranslational modifications: the chemistry of proteome diversifications. Angewandte Chemie International Edition, 44(45), 7342-7372.

Wickler, S. J., Horwitz, B. A., \& Kott, K. S. (1987). Muscle function in hibernating hamsters: a natural analog to bed rest? Journal of Thermal Biology, 12(2), 163166.

Wickler, S. J., Hoyt, D. F., \& van Breukelen, F. (1991). Disuse atrophy in the hibernating 
golden-mantled ground squirrel, Spermophilus lateralis. American Journal of Physiology-Regulatory, Integrative and Comparative Physiology, 261(5), R1214R1217.

Willis, J.S. (1982). Intermediary metabolism in hibernation. In Lyman, C.P., Willis, J.S., Malan, A., Wang, L.C.H (Eds.), Hibernation and Torpor in Mammals and Birds, Academic Press, New York, pp. 124-139.

Wise, L. S., \& Green, H. (1979). Participation of one isozyme of cytosolic glycerophosphate dehydrogenase in the adipose conversion of 3T3 cells. Journal of Biological Chemistry, 254(2), 273-275.

Wolfe, R. R. (1998). Metabolic interactions between glucose and fatty acids in humans. The American Journal of Clinical Nutrition, 67(3), 519S-526S.

Xiong, Z. J., \& Storey, K. B. (2012). Regulation of liver lactate dehydrogenase by reversible phosphorylation in response to anoxia in a freshwater turtle. Comparative Biochemistry and Physiology Part B: Biochemistry and Molecular Biology, 163(2), 221-228.

Yang, J., Yan, R., Roy, A., Xu, D., Poisson, J., \& Zhang, Y. (2015). The I-TASSER Suite: protein structure and function prediction. Nature Methods, 12(1), 7-8.

Yeh, I., Tam, C. F., Catuira, E., Le, T. T., Papa, V., Pena, L. \& Lopez, G. A. (1995). Changes in various plasma lipid components, glucose, and insulin in Spermophilus lateralis during hibernation. Comparative Biochemistry and Physiology Part B: Biochemistry and Molecular Biology, 111(4), 651-663.

Zatzman, M. L. (1984). Renal and cardiovascular effects of hibernation and hypothermia. Cryobiology, 21(6), 593-614.

Zhang, Y. (2008). I-TASSER server for protein 3D structure prediction. BMC Bioinformatics, 9(1), 40.

Zimny, M. L., \& Tyrone, V. (1957). Carbohydrate metabolism during fasting and hibernation in the ground squirrel. American Journal of Physiology, 189(2), 297300 . 


\section{Appendix I}

\section{Communications at Scientific Meetings}




\section{List of Conferences}

Ruberto, A.A., and Storey, K.B. Regulation of muscle lactate dehydrogenase in a hibernating mammal. 17 $7^{\text {th }}$ Annual Chemistry and Biochemistry Graduate Research Conference. Concordia University, Montreal, Quebec, Canada. November 28, 2014.

Ruberto, A.A., and Storey, K.B. Regulation of muscle lactate dehydrogenase in a hibernating mammal. $13^{\text {th }}$ Annual Ottawa-Carleton Institute of Biology Symposium. Carleton University, Ottawa, Canada. April 29-30 2015. 
Appendix II

$R$ you ready for this? A Biochemist's Guide to Enzyme Kinetic Parameter Analyses Using the Programme R 


\section{General Introduction}

Research is composed of two steps: data collection, and data analysis. As a biochemist studying the functional and structural properties of metabolic proteins (enzymes), the purification process alone-a prerequisite for data collection - can be a lengthy, time-consuming task. Furthermore, once an enzyme of interest is purified, numerous assays must be conducted with the enzyme's substrates to calculate different kinetic parameters such as maximal activity $\left(V_{\max }\right)$, half-saturation constant $\left(K_{m}\right.$ or $\left.S_{0.5}\right)$, activation $\left(K_{a}\right)$, and/or inhibition $\left(I_{50}\right)$. Whether or not an enzyme is being compared to another enzyme of interest, these kinetic parameter assays must be conducted multiple times on individual determinations of the purified enzyme sample in order to obtain statistical significance. Once the data collection is finished, one can easily have to analyze data from over 100 different assays (See Figure 1). It is safe to say that more assays means more data, and more data means more quantification/analysis. Often times this analysis process can be just as lengthy as the data collection process. This report is a biochemists guide which focuses on how to use some useful scripts and packages from the open source programme and environment $\mathrm{R}$ http://www.rproject.org/in order to analyze kinetic data as well as to generate figures to effectively communicate one's findings.

\begin{tabular}{|c|c|c|c|c|c|c|c|}
\hline Enzyme: Eut & ic LDH & & & Enzyme: Hib & $\lg \mathrm{LDH}$ & & \\
\hline Kinetic Parat & $\mathrm{Km}$ & & & Kinetic Parat & $\mathrm{Km}$ & & \\
\hline Substrate & $\mathrm{pH}$ & Temperature & $\mathrm{n}$ & Substrate & $\mathrm{pH}$ & Temperature & $\mathrm{n}$ \\
\hline & 7.5 & 5 & 4 & & 7.5 & 5 & 4 \\
\hline & & 22 & 4 & & & 22 & 4 \\
\hline Lactate & & 37 & 4 & Lactate & & 37 & 4 \\
\hline & 8 & 5 & 4 & & 8 & 5 & 4 \\
\hline & & 22 & 4 & & & 22 & 4 \\
\hline & & 37 & 4 & & & 37 & 4 \\
\hline & 7.5 & 5 & 4 & & 7.5 & 5 & 4 \\
\hline & & 22 & 4 & & & 22 & 4 \\
\hline NAD & & 37 & 4 & NAD & & 37 & 4 \\
\hline & 8 & 5 & 4 & & 8 & 5 & 4 \\
\hline & & 22 & 4 & & & 22 & 4 \\
\hline & & 37 & 4 & & & 37 & 4 \\
\hline & 7.5 & 5 & 4 & & 7.5 & 5 & 4 \\
\hline & & 22 & 4 & & & 22 & 4 \\
\hline Pyruvate & & 37 & 4 & Pyruvate & & 37 & 4 \\
\hline & 8 & 5 & 4 & & 8 & 5 & 4 \\
\hline & & 22 & 4 & & & 22 & 4 \\
\hline & & 37 & 4 & & & 37 & 4 \\
\hline Kinetic Paran & I50 & & & Kinetic Parar & I50 & & \\
\hline Substrate & $\mathrm{pH}$ & Temperature & $\mathrm{n}$ & Substrate & $\mathrm{pH}$ & Temperature & $\mathrm{n}$ \\
\hline & 7.5 & 5 & 4 & & 7.5 & 5 & 4 \\
\hline & & 22 & 4 & & & 22 & 4 \\
\hline Pyruvate & & 37 & 4 & Pyruvate & & 37 & 4 \\
\hline & 8 & 5 & 4 & & 8 & 5 & 4 \\
\hline & & 22 & 4 & & & 22 & 4 \\
\hline & & 37 & 4 & & & 37 & 4 \\
\hline & & & 96 & & & & 96 \\
\hline Total numbe & ssays: & & 96 & & & & 96 \\
\hline & & & & Euthermic + & ating & I Assays: & 192 \\
\hline & & & & & & & \\
\hline
\end{tabular}

Figure 1. The data collection process for a biochemist can be a lengthy due to purification and assay requirements. This figure sheds light on the various assays conducted to compare the different kinetic parameters between euthermic and hibernating lactate dehydrogenase in Richardson's ground squirrel. In total, 192 assays were analyzed. With $R$, the generation of various scripts could be used to expedite the data analysis task. 
Why R?

Like learning any new language, one must be willing to spend time using $\mathrm{R}$ in order to become proficient. Furthermore, the $\mathrm{R}$ language has syntax and structure that cannot be violated. As a new user of $\mathrm{R}$ with no previous programming background, the task of learning this new language was at times frustrating as there is no doubt a steep learning curve. However, as I became more familiar with the language interface I was able to very easily conduct calculations, apply statistical techniques, create elaborate graphs, and use packages created by other R programmers to analyze enzyme kinetic data. I will admit that I am no expert in using the program, and to this day I am still learning new things. The most important thing that you need when learning this language is patience!

Perhaps one of the most beneficial things that I found about using $\mathrm{R}$ is its reproducibility. Therefore, once you learn to apply, for example, a non-linear regression such as that seen in Michaelis-Menten kinetics, modifying the code so that it does generalized non-linear modeling, requires only the modification of a few small changes in the formula. As you will see in the scripts provided in this document, the reproducible nature of the code makes analyzing vast amounts of data quick and easy.

In addition to the quick, reproducible nature of scripts that can be generated in the program, $\mathrm{R}$ has excellent statistical facilities. Thanks to R's main package and user-contributed packages, nearly everything you may need in terms of statistics has already been programmed and made available in $R$. The fact that these statistical tests can be ran in an open source program that is free to download eliminates the need to purchase data analysis software.

\section{Analyzing Data Step 1: Organizing your data}

Before using R to work with your data, take some time to organize it in an Excel file to make your life easier once the data needs to analyzed. Figure 2 shows the subset of data that was used to generate $\mathrm{km}$ values and curves in the programme $\mathrm{R}$.

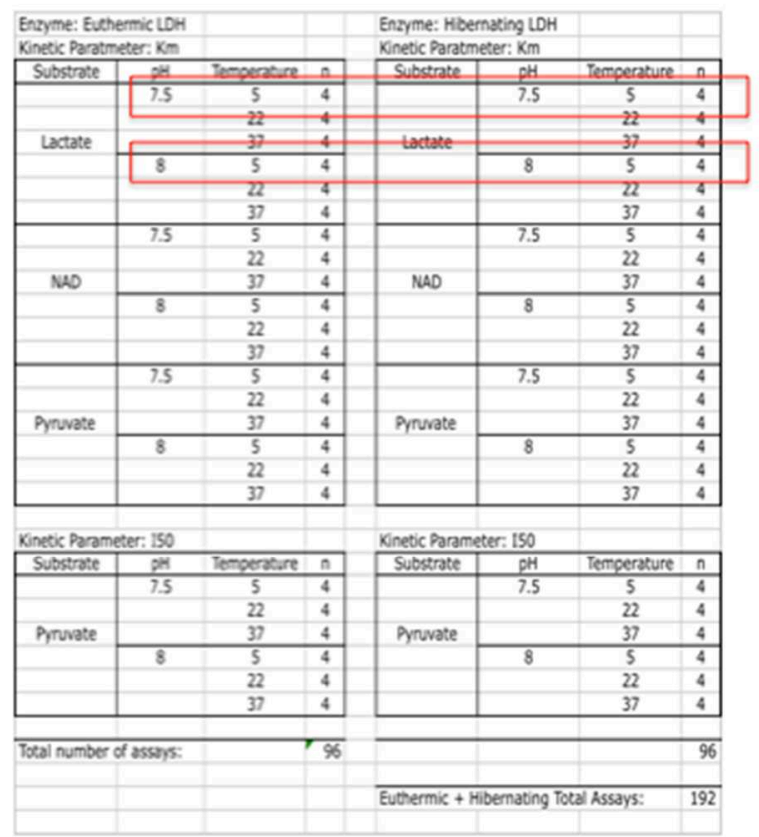

Label columns accordingly to make your life easier!

\begin{tabular}{|c|c|c|c|c|c|c|}
\hline & $\mathrm{N}$ & Condition & Temperature & $\mathrm{pH}$ & Lactate_mM. & Activity \\
\hline 1 & 1 & tutherste & 5 & 7,5 & 8 & 0.06060609 \\
\hline 2 & 1 & Euthersic & 5 & 7.5 & 2 & 0.07453948 \\
\hline 3 & 1 & futhersic & 5 & 7.5 & 4 & e.1164226e \\
\hline 4 & 1 & Euthernic & 5 & 7.5 & 8 & e.126secse \\
\hline 5 & 1 & tuthersic & 5 & 7.5 & 10 & e.15eckzese \\
\hline 6 & 1 & Euthernic & 5 & 7.5 & 12 & e.138s6eee \\
\hline 7 & 1 & tuthersic & 5 & 7.5 & 16 & 0.1593esece \\
\hline 8 & 1 & Euthernic & 5 & 7.5 & 24 & e.169e17se \\
\hline 9 & 1 & futhersic & 5 & 7.5 & 28 & e.1721121e \\
\hline 10 & 1 & Euthersic & 5 & 7.5 & $3 e$ & e.1664127e \\
\hline 11 & 2 & futhersic & 5 & 7.5 & - & 0. есесееке \\
\hline 12 & 2 & Euthersic & 5 & 7.5 & 2 & e. 07377565 \\
\hline 13 & 2 & futhersic & 5 & 7.5 & 4 & 6.11esesse \\
\hline 14 & 2 & Euthersic & 5 & 7.5 & 8 & e.1441esse \\
\hline 15 & 2 & futhersic & 5 & 7.5 & 10 & e.17necace \\
\hline 16 & 2 & tuthersic & 5 & 7.5 & 12 & e.137e6sse \\
\hline 17 & 2 & futhersic & 5 & 7.5 & 16 & C.169sesee \\
\hline 18 & 2 & tuthersic & 5 & 7.5 & 24 & e.18e1zase \\
\hline 19 & 2 & futhernic & 5 & 7.5 & 28 & e.157922se \\
\hline 20 & 2 & futhersic & 5 & 7.5 & 30 & 6.16747886 \\
\hline 21 & 2 & tuthersic & s & 7.5 & 60 & C.14eecere \\
\hline 22 & 3 & tuthersic & 5 & 7.5 & e & e. еอесеесе \\
\hline 23 & 3 & futhersic & s & 7.5 & 2 & e.errsecas \\
\hline
\end{tabular}

Figure 2. Data in LactateKm5.csv 
Once your data is organized in a way that makes sense, save it as a .csv file and then you can upload it in to $\mathrm{R}$ using the read.csv() function. To ensure your data was uploaded in to R correctly, use View() to generate a table as shown in Figure 2 (table on the right).

You will now be ready to use the $\mathrm{R}$ platform to start manipulating and analyzing your data. The first thing I like to do is sub-set my data. In the LactateKm5.csv file there are 166 entries. To analyze each biological replicate from their respective condition, name each subset accordingly. For example for the first biological replicate $(\mathrm{N})$ in the euthermic condition at pH 7.5, I named it ph75euthl (Figure 3).

Continue sub-setting your data until each biological replicate $(\mathrm{N})$ is accounted for. Below is the script used to separate each biological replicate in each condition to have them stored in the R global environment.

\author{
\#\#set working directory \\ setwd(" /Dropbox/R programming") \\ \#\#Load data in to program \\ KmLac <-read.csv(file.choose("LactateKm5.csv")) \\ View $($ KmLac $)$ \\ \#\#To get a summary of these data, you can use the summary \\ function \\ summary $(\mathrm{KmLac})$
}

\begin{tabular}{|r|l|l|l|l|l|l|}
\hline & $\mathrm{N}$ & Condition & Temperature & $\mathrm{pH}$ & Lactate..mM. & Activity \\
\hline 1 & 1 & Euthermic & 5 & 7.5 & 0 & 0.0000000 \\
\hline 2 & 1 & Euthermic & 5 & 7.5 & 2 & 0.07453948 \\
\hline 3 & 1 & Euthermic & 5 & 7.5 & 4 & 0.11442160 \\
\hline 4 & 1 & Euthermic & 5 & 7.5 & 8 & 0.14658480 \\
\hline 5 & 1 & Euthermic & 5 & 7.5 & 10 & 0.15868280 \\
\hline 6 & 1 & Euthermic & 5 & 7.5 & 12 & 0.13886000 \\
\hline 7 & 1 & Euthermic & 5 & 7.5 & 16 & 0.15930800 \\
\hline 8 & 1 & Euthermic & 5 & 7.5 & 24 & 0.16901750 \\
\hline 9 & 1 & Euthermic & 5 & 7.5 & 28 & 0.17211210 \\
\hline 10 & 1 & Euthermic & 5 & 7.5 & 30 & 0.16641270 \\
\hline
\end{tabular}

Figure 3. ph75euth1, subset of LactateKm5.csv data.

\#\#To insure that the data was imported correctly you can you the list()function to view your data set

\#\#Subset data to analyze biological replicates in each condition. $\mathrm{pH} 75<-$ subset $(\mathrm{KmLac}, \mathrm{pH}==7.5)$ ph75euth <-subset(pH75,Condition=="Euthermic") ph75euth1<-subset(ph75euth, N=="1") ph75euth2<-subset(ph75euth, $\mathrm{N}==" 2 ")$ ph75euth3<-subset(ph75euth, N=="3") ph75euth4<-subset(ph75euth, $\mathrm{N}==" 4 ")$ ph75hib <-subset(pH75,Condition=="Hibernating") ph75hib1<-subset(ph75hib, N=="1") ph75hib2<-subset(ph75hib, N=="2") ph75hib3<-subset(ph75hib, N=="3") ph75hib4<-subset(ph75hib, N=="4") $\mathrm{pH} 8<-$ subset $(\mathrm{KmLac}, \mathrm{pH}==8.0)$ ph8euth <-subset $(\mathrm{pH} 8$,Condition=="Euthermic") ph8euth1<-subset(ph8euth, N=="1") ph8euth2<-subset(ph8euth, $\mathrm{N}==" 2 "$ ) ph8euth3<-subset(ph8euth, $\mathrm{N}==" 3 "$ ) ph8euth4<-subset(ph8euth, $\mathrm{N}==" 4 ")$ ph8euth5<-subset(ph8euth, $\mathrm{N}==" 5 ")$ ph8hib <-subset(pH8,Condition=="Hibernating") ph8hib1<-subset(ph8hib, $\mathrm{N}==" 1 ")$ ph8hib2<-subset(ph8hib, $\mathrm{N}==" 2 ")$ ph8hib3<-subset(ph8hib, N=="3") ph8hib4<-subset(ph8hib, N=="4")

\begin{tabular}{|c|c|c|}
\hline Environment & History Presentation $x$ & $=9$ \\
\hline \multicolumn{3}{|c|}{ @ $\rightrightarrows$ Import Dataset. $\&$ Clear (s) } \\
\hline \multicolumn{3}{|c|}{3 Global Environment - } \\
\hline \multicolumn{3}{|l|}{ Data } \\
\hline (1) KmLac & 166 obs. of 6 variables & 国 \\
\hline (9) 75 & 78 obs. of 6 variables & 䦥 \\
\hline (1) ph75euth & 42 obs. of 6 variables & $\boxplus$ \\
\hline (1) ph75euth1 & 10 obs. of 6 variables & $\boxplus$ \\
\hline (1) ph75euth2 & 11 obs. of 6 variables & 四 \\
\hline ph75euth3 & 11 obs. of 6 variables & 四 \\
\hline (1) ph75euth4 & 10 obs. of 6 variables & 间 \\
\hline ph75hib & 36 obs. of 6 variables & 国 \\
\hline (1) ph75hib1 & 8 obs. of 6 variables & 国 \\
\hline ph75hib2 & 10 obs. of 6 variables & 国 \\
\hline (1) ph75hib3 & 10 obs. of 6 variables & 四 \\
\hline (1) ph75hib4 & 8 obs. of 6 variables & 国 \\
\hline (1) pH8 & 88 obs. of 6 variables & 四 \\
\hline ph8euth & 48 obs. of 6 variables & 国 \\
\hline (1) ph8euth1 & 10 obs. of 6 variables & 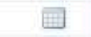 \\
\hline (1) ph8euth2 & 10 obs. of 6 variables & 国 \\
\hline ph8euth3 & 10 obs. of 6 variables & 国 \\
\hline ph8euth4 & 10 obs. of 6 variables & 国 \\
\hline (1) ph8euth5 & 8 obs. of 6 variables & 四 \\
\hline ph8hib & 40 obs. of 6 variables & $\Phi$ \\
\hline ph8hib1 & 10 obs. of 6 variables & 闻 \\
\hline ph8hib2 & 10 obs. of 6 variables & 田 \\
\hline ph8hib3 & 10 obs. of 6 variables & 国 \\
\hline ph8hib4 & 10 obs. of 6 variables & 国 \\
\hline
\end{tabular}

Figure 4. Sub-setted data from LactateKm5.csv 


\section{Analyzing Data Step 2: Plotting Kinetic Data}

An area in which $\mathrm{R}$ is very strong is in its graphical visualization capabilities. Using the KmLac data that was subsetted previously, this section shows the code used to generate concentration versus activity curves. Each plot is separated by its condition (euthermic/ hibernating) and $\mathrm{pH}(7.5 / 8.0)$. Furthermore, each biological replicate is plotted in their respective condition and is given a different point / line type (pch=, lty=) to distinguish them from one another.

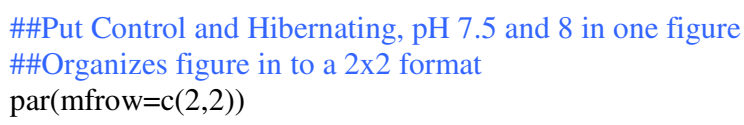

\#\#Plot raw data from euthermic $\mathrm{pH} 7.5$ replicates plot(Activity Lactate..mM.,data $=$ ph75euth1,pch=20, col=TRUE, xlim $=c(0,60)$, ylim $=c(0,0.20)$, xlab = "Lactate $(\mathrm{mM}) "$, ylab = "Activity (mU)", main="Euthermic, pH 7.5") points(Activity Lactate..mM.,data $=$ ph75euth2, pch=15) points(Activity Lactate..mM.,data $=$ ph75euth3,pch=6) points(Activity Lactate..mM.,data $=$ ph75euth4,pch=1) lines(Activity Lactate..mM.,data $=$ ph75euth1, lty=20) lines(Activity $\sim$ Lactate..mM.,data $=$ ph75euth2, lty $=15$ ) lines(Activity $\sim$ Lactate..mM.,data $=$ ph75euth3, lty=6) lines(Activity Lactate..mM.,data $=$ ph75euth4, lty=1)

\#\#Plot raw data from hibernating $\mathrm{pH} 7.5$ replicates plot(Activity Lactate..mM.,data $=$ ph75hib1, pch $=20$, col=TRUE, $x \lim =\mathrm{c}(0,35), \mathrm{ylim}=\mathrm{c}(0,0.20), \mathrm{xlab}=$ "Lactate $(\mathrm{mM}) "$, ylab = "Activity (mU)", main="Hibernating, $\mathrm{pH} 7.5 ")$ points(Activity Lactate..mM.,data $=$ ph75hib2, pch=15) points(Activity Lactate..mM.,data $=$ ph75hib3,pch=6) points(Activity Lactate..mM.,data $=$ ph75hib4,pch=1) lines(Activity Lactate..mM.,data $=$ ph75hib1, lty=20) lines(Activity $\sim$ Lactate..mM.,data $=$ ph75hib2, lty $=15$ ) lines(Activity Lactate..mM.,data $=$ ph75hib3, lty=6) lines(Activity $\sim$ Lactate..mM.,data $=$ ph75hib4, lty=1)

\#\#Plot raw data from euthermic $\mathrm{pH} 8.0$ replicates plot(Activity Lactate..mM.,data $=$ ph8euth1, pch=20, col=TRUE, xlim=c $(0,35), y \lim =c(0,0.25)$, xlab = "Lactate $(\mathrm{mM}) "$, ylab = "Activity (mU)", main="Euthermic, $\mathrm{pH} 8.0 ")$ points(Activity $\sim$ Lactate..mM.,data $=$ ph8euth2, pch=15) points(Activity $\sim$ Lactate..mM.,data $=$ ph8euth3,pch=6) points(Activity $\sim$ Lactate..mM.,data $=$ ph8euth $4, p c h=1$ ) points(Activity $\sim$ Lactate..mM.,data $=$ ph8euth5,pch=22) lines(Activity Lactate..mM.,data $=$ ph8euth1, lty=20) lines(Activity Lactate..mM.,data $=$ ph8euth2, lty $=15$ ) lines(Activity Lactate..mM.,data $=$ ph8euth3, lty=6) lines(Activity $\sim$ Lactate..mM.,data $=$ ph8euth4, lty $=1$ ) lines (Activity $\sim$ Lactate..mM.,data $=$ ph8euth5, lty=22)

\#\#Plot raw data from hibernating $\mathrm{pH} 8.0$ replicates plot(Activity Lactate..mM.,data $=$ ph8hib1,pch=20, col=TRUE, xlim=c(0,35), ylim=c(0,0.30), xlab = "Lactate $(\mathrm{mM}) "$, ylab = "Activity (mU)", main="Hibernating, $\mathrm{pH} 8.0 ")$ points(Activity Lactate..mM.,data $=$ ph8hib2, pch=15) points(Activity $\sim$ Lactate..mM.,data $=$ ph8hib3,pch=6) points(Activity Lactate..mM.,data $=$ ph8hib4,pch=1) lines(Activity $\sim$ Lactate..mM.,data $=$ ph8hib2, lty=20) lines(Activity $\sim$ Lactate..mM.,data $=$ ph8hib3, lty=15) lines(Activity $\sim$ Lactate..mM.,data $=$ ph8hib1, lty $=1$ ) lines(Activity $\sim$ Lactate..mM.,data $=$ ph8hib4, lty=6)
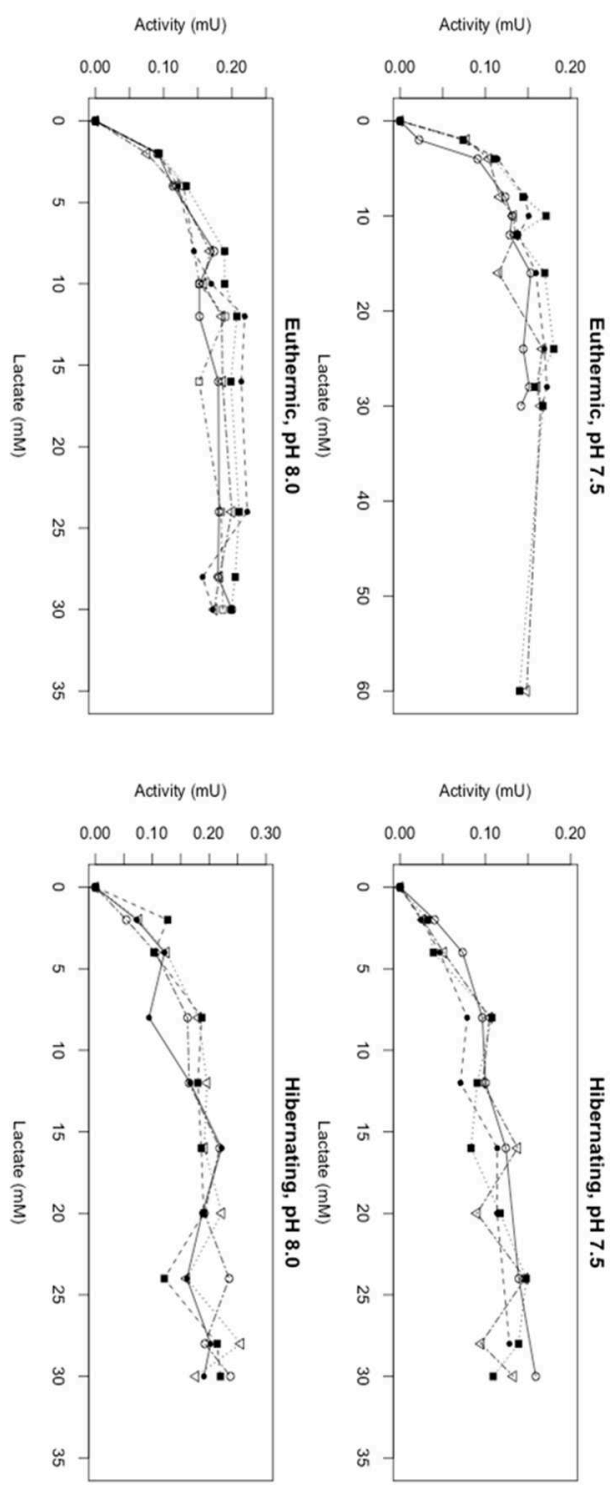

Figure 5. Michaelis-Menten curves for the forward (lactate- utilizing) reaction by purified euthermic and hibernating LDH. 
Although the base installation of $\mathrm{R}$ has great graphic capabilities, producing half decent graphs typically requires quite a bit of code. One package that was introduced to us by Dr. Morin's presentation, $R$ Survivor Guide for Physiologist, was ggplot2 (Wickham, 2009). This package allows one to make complex plots with minimal coding. To show the plotting power of this package, I used data generated from incubating endogenous kinases and phosphatases with LDH from crude euthermic and hibernating Richardson's ground squirrels (LDHinc37.csv, see Supplementary Data 2). The enzyme reaction was assayed at $37^{\circ} \mathrm{C}$ to see if there were any significant changes in activity from the control (STOP) condition. The code below uses the ggplot2 package to generate a plot showing the average km (grey bar) and SEM (red line) for each condition.

$\mathrm{rm}(\mathrm{list}=\mathrm{ls}($ all=TRUE $)$

\#\#Load data and ggplot2 package in to $\mathrm{R}$

LDHincu37 <-read.csv(file.choose("LDHinc37"))

library(ggplot2)

\#\#LDHinc37

summary(LDHincu37)

\#set up X and Y axis, and source of data

\#\# save this graph template into a working object called $\mathrm{d}$

$\mathrm{d}<-$ ggplot(data=LDHincu37, aes $(\mathrm{x}=$ Treatment, $\mathrm{y}=$ Km.Lactate $)$ )

\#\# add a layer showing the data points

$\mathrm{d}<-\mathrm{d}+$ geom_point ()

\#\# and split the graph according to sub-experiment

$\mathrm{d}<-\mathrm{d}+$ facet_grid(Condition .)

\# overlay, in red, the mean, and a $95 \%$ CI obtained by bootstrap

$\mathrm{d}<-\mathrm{d}+$ stat_summary(fun.data = "mean_cl_boot", colour = "red")

\#\#remove unnecessary ink, increase axis label size, make custom ordering

$\mathrm{d}<-\mathrm{d}+$ theme_classic(base_size $=13$, base_family $=$ "")

\#\# REORDER variables inside the dataframe with STOP, kinase,

then phosphatase incubation on graphs

LDHincu37\$myorder <- factor(LDHincu37\$Treatment,

levels=c("STOP", "AMPK", "CAMK", "PKA", "PKG", "PKC", "Tkin",

"PP1", "PP2A", "PP2B", "PP2C", "TPPase"))

\# change label value "tkin" to "TKin"levels(LDHincu37\$myorder)[levels(LDHincu37\$myorder)=="Tkin"] <- "TKin"

\#set up $\mathrm{X}$ and $\mathrm{Y}$ axis, and source of data

\# save this graph template into a working object called $\mathrm{d}$

$\mathrm{d}<$-ggplot(data=LDHincu37, aes $(\mathrm{x}=$ myorder, $\mathrm{y}=$ Km.Lactate $))$

$\mathrm{d}<-\mathrm{d}+$ geom_point()

d

\# add a layer showing the data points to $\mathrm{d}$

\# and split the graph d according to sub-experiment, Euthermic/ Hibernating

$\mathrm{d}<-\mathrm{d}+$ facet_grid(Condition .)

\#\#\# overlay, in red, the mean, and a 95\% CI obtained by bootstrap

$\mathrm{d}<-\mathrm{d}+$ stat_summary(fun.y="mean", geom="bar", aes(width=0.5), fill="\#CCCCCC") +

geom_point ()$+$

stat_summary(fun.data = "mean_cl_boot", colour = "red", geom="linerange")

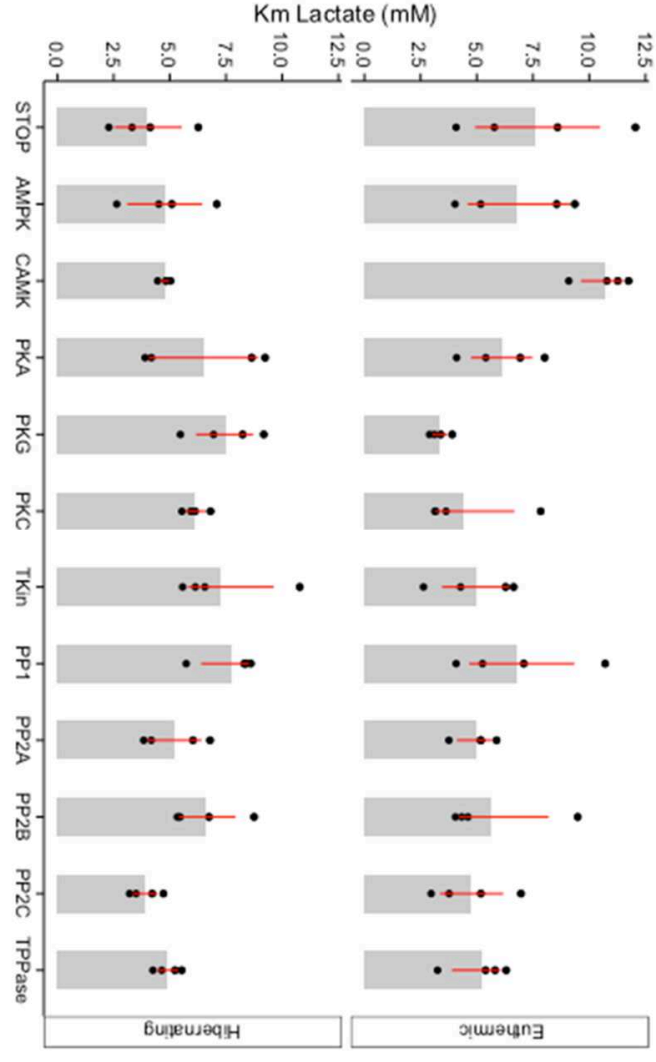

Figure 6. Effects of in vitro incubations to stimulate the activities of endogenous protein kinases or phosphatases on the Km of L-Lactate for LDH in Richardson's ground squirrel muscle extracts. Crude extracts were incubated for $24 \mathrm{~h}$ before assaying at $37^{\circ} \mathrm{C}$. Data are means \pm SEM, with at least $\mathrm{n}=3$ separate determinations on enzyme isolated from different individuals. 


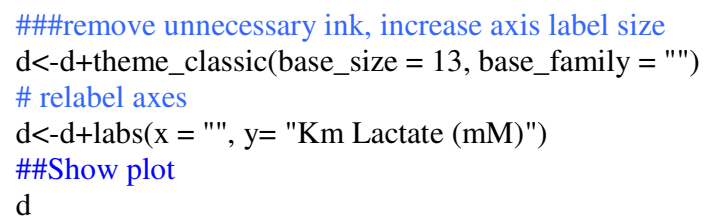

Out with the old and in with the new: Kinetic Analysis using drc package in $R$.

Enzyme kinetics in the Storey Lab are determined by first assaying enzyme reactions on the microplate readers, followed by analyzing the data and calculating parameters such as those for maximal activity $\left(V_{\max }\right)$, half-saturation constant $\left(K_{m}\right.$ or $\left.S_{0.5}\right)$, activation $\left(K_{a}\right)$, inhibition $\left(I_{50}\right)$. We accumulate enzyme activity data using the Multiskan software for the Thermo Multiskan Spectrum. However, this software program is not used for data analysis.

Calculating kinetic parameters has two main steps. The first is the calculation of individual initial velocities $\left(v_{i}\right)$ for each assay well, representing a velocity for the given conditions in each well. Once all of these $v_{i}$ values have been calculated for a given concentration range of the parameter being tested (e.g. the range of substrate concentrations for $\mathrm{K}_{\mathrm{m}}$ determination), then they can be plugged into a kinetics program, and a given kinetic parameter can be calculated.

The two programs we use for this were both designed by Steve Brooks (a former PhD student in the Storey Lab) and are found on our lab computers. They are the Microplate Analysis Program (MPA) and Kinetics, respectively. The task of typing in each velocity value for its respective concentration to generate a $\mathrm{km}$ value in the kinetics programme can be time-consuming and is prone to error while inputting the values. Thanks to the Dose Response Curve ( $d r c$ ) package in R (Ritz \& Streibig, 2005), one can generate accurate $\mathrm{km}$ values and easily communicate this information in figures which can also be generated from this package.

The $d r c$ package has a general function for Michaelis-Menten (MM.2()) curves, a versatile regression curve used in enzymology. With minimal code, one can find the $K_{m}$ and $V_{\max }$ of an enzyme. In the example below, I use the Michaelis-Menten function to find the kinetic parameters for euthermic LDH test at $\mathrm{pH} 7.5$ and $5^{\circ} \mathrm{C}(\mathrm{n}=4)$.
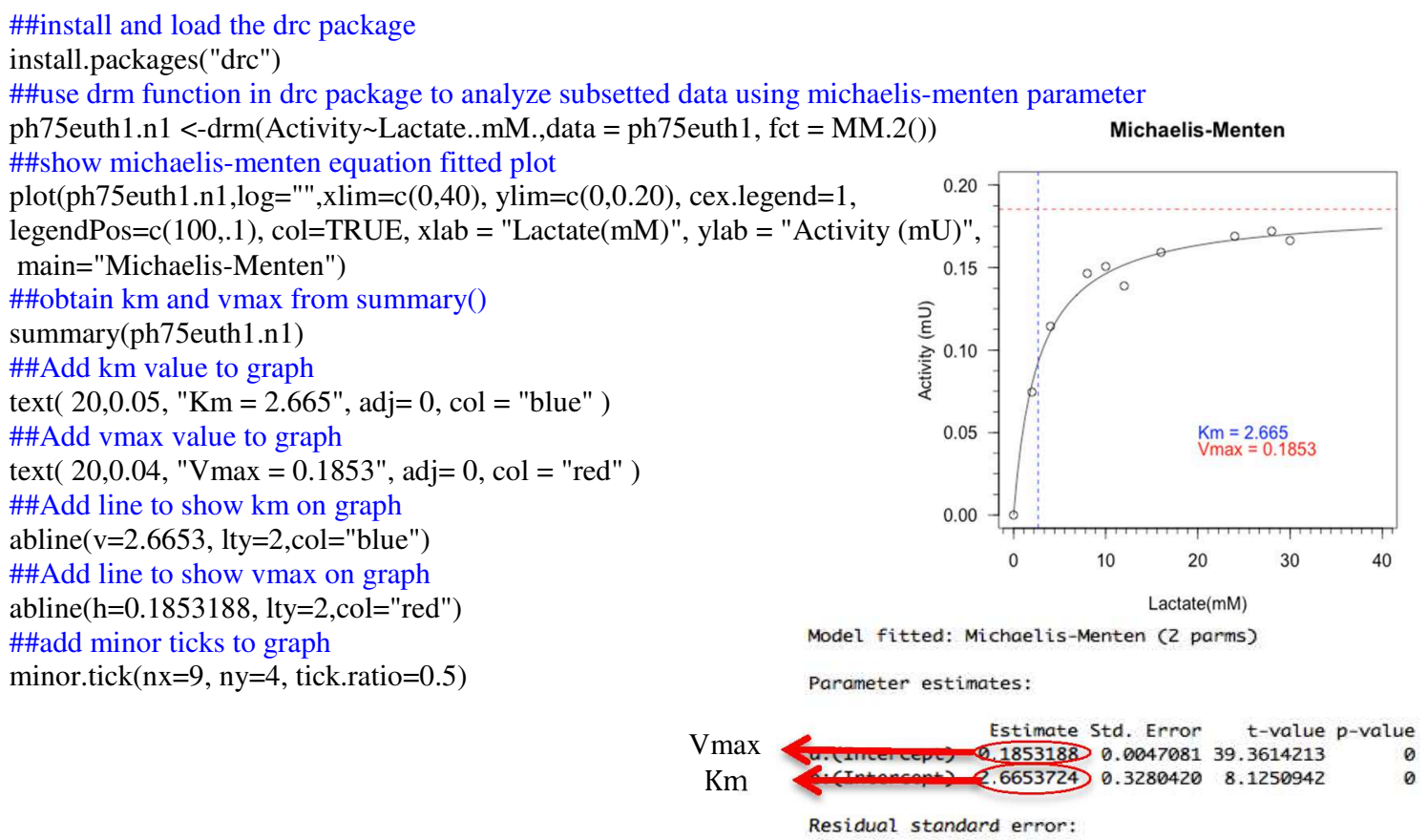

Figure 7. Michaelis-Menten curve for ph75euth1.n1 annontated with $\mathrm{km}$ and vmax value found from summary of drc fct=MM.2(). 
The following code contains the summaries and plots for the 4 biological replicates from the euthermic $\mathrm{LDH}$ test at $\mathrm{pH} 7.5$ and $5^{\circ} \mathrm{C}$. After collecting the data for each of the biological replicates one can find the averages for each of the kinetic parameters. The kinetic data is summarized in Figure 9.

ph75euth2.n2 <-drm(Activity Lactate..mM.,data $=$ ph75euth2, fct $=$ MM.2())

plot(ph75euth2.n2,log="",xlim=c(0,40), ylim=c(0,0.20), cex.legend=1, legendPos=c(100,.1), col=TRUE, $x$ lab = "Lactate $(\mathrm{mM}) "$, ylab = "Activity $(\mathrm{mU}) ")$

summary(ph75euth2.n2)

ph75euth3.n3 <-drm(Activity Lactate..mM.,data $=$ ph75euth3, fct $=$ MM.2())

plot(ph75euth3.n3,log="",xlim=c(0,70), ylim=c(0,0.20), cex.legend=1, legendPos=c(100,.1), col=TRUE, $x l a b=$

"Lactate $(\mathrm{mM}) "$, ylab = "Activity $(\mathrm{mU}) ")$

summary(ph75euth3.n3)

ph75euth4.n4 <-drm(Activity Lactate..mM.,data = ph75euth4, fct = MM.2())

plot(ph75euth4.n4,log="",xlim=c(0,40),ylim=c(0,0.20), $\mathrm{pch}=1$, cex.legend=1, legendPos=c(100,.1), col=TRUE, $x l a b=$ "Lactate $(\mathrm{mM}) "$, ylab = "Activity $(\mathrm{mU}) ")$

summary(ph75euth4.n4)

\#\#show all 4 biological replicates on one screen

$\operatorname{par}(\mathrm{mfrow}=\mathrm{c}(2,2))$

plot(ph75euth1.n1,log="",xlim=c(0,40), ylim=c(0,0.20), cex.legend=1, legendPos=c(100,.1), col=TRUE, xlab =

"Lactate $(\mathrm{mM}) "$, ylab = "Activity $(\mathrm{mU}) ")$

plot(ph75euth2.n2,log="",xlim=c(0,40), ylim=c(0,0.20), cex.legend=1, legendPos=c(100,.1), col=TRUE, xlab =

"Lactate $(\mathrm{mM}) "$, ylab = "Activity $(\mathrm{mU}) ")$

plot(ph75euth3.n3,log="",xlim=c(0,70), ylim=c(0,0.20), cex.legend=1, legendPos=c(100,.1), col=TRUE, xlab =

"Lactate $(\mathrm{mM}) "$, ylab = "Activity $(\mathrm{mU}) ")$

plot(ph75euth4.n4,log="",xlim=c(0,40),ylim=c(0,0.20), $\mathrm{pch}=1$, cex.legend=1, legendPos=c $(100, .1), \mathrm{col}=\mathrm{TRUE}, \mathrm{xlab}=$ "Lactate (mM)" , ylab = "Activity (mU)")
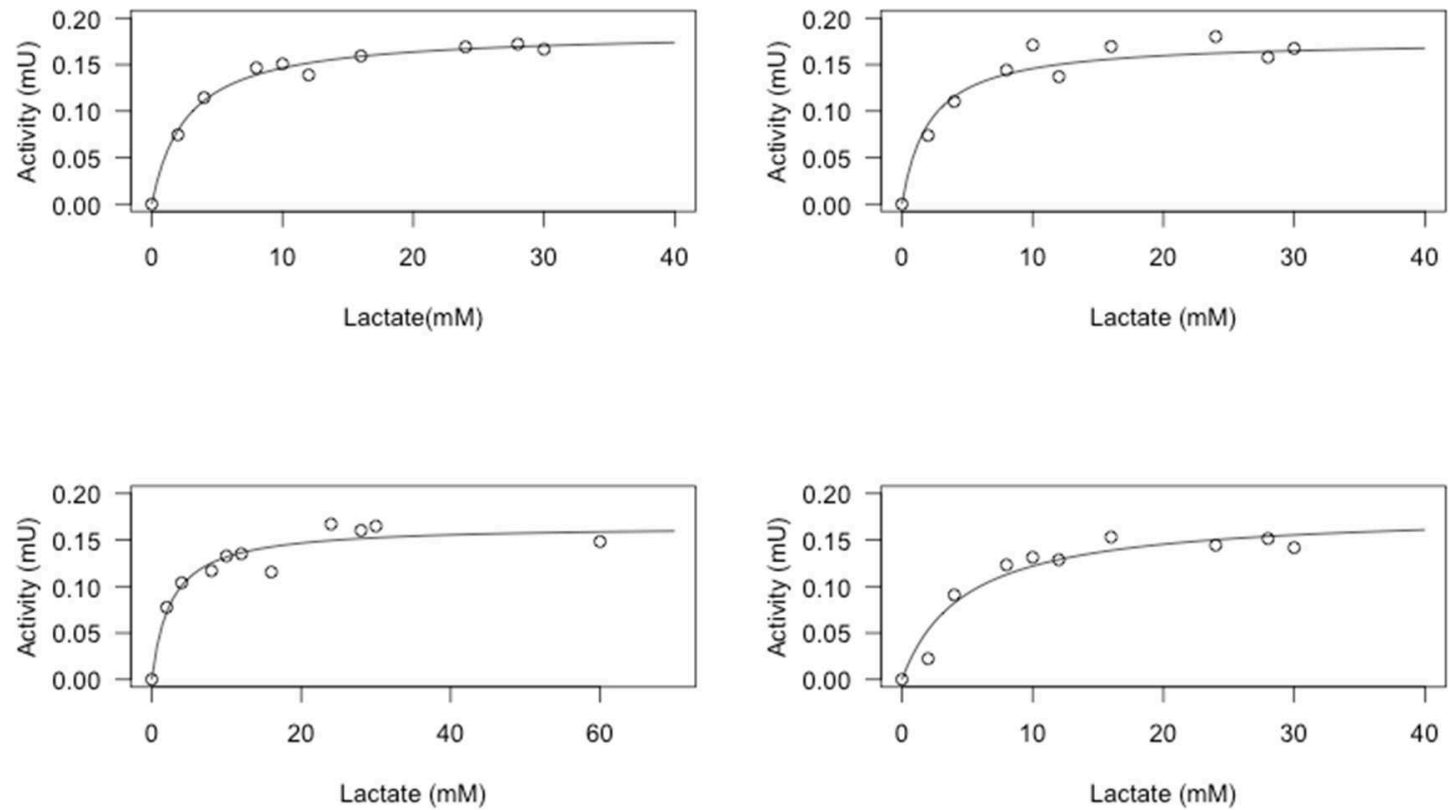

Figure 8. Michaelis-Menten curves for each of the 4 biological replicates of euthermic LDH assayed at $\mathrm{pH}$ 7.5 and $5^{\circ} \mathrm{C}$. 


\begin{tabular}{|c|c|c|c|c|}
\hline & R Code & $\mathrm{fct}=\mathrm{MM} \cdot 2()$ & Brooks & MM \\
\hline $\mathrm{N}$ & $\mathrm{km}$ & vmax & $\mathrm{Km}$ & Vmax \\
\hline 1 & 2.665 & 0.1853 & 2.66508 & 0.1853 \\
\hline 2 & 2.105 & 0.1764 & 2.105 & 0.17639 \\
\hline 3 & 2.569 & 0.165 & 2.57 & 0.1654 \\
\hline 4 & 4.765 & 0.18 & 4.768 & 0.18003 \\
\hline Average & 3.026 & 0.176675 & 3.02702 & 0.17678 \\
\hline STD & 1.18483923 & 0.00859898 & 1.18617032 & 0.00842238 \\
\hline SEM & 0.59241961 & 0.00429949 & 0.59308516 & 0.00421119 \\
\hline
\end{tabular}

Figure 9. Comparison of kinetic parameters values $\left(K_{m}\right.$ and $\left.V_{\max }\right)$ for each of the biological replicates of euthermic $\mathrm{LDH}$ assayed at $\mathrm{pH} 7.5$ and $5^{\circ} \mathrm{C}$ quantified in $\mathrm{R}$ and with the program used in the Storey Lab (Brooks).

\#\#Next step, run a statistical test to see if there is a signinficant difference in the kms\#\# \#\#Km data for euthermic condition seen in figure 9

euth $=\mathrm{c}(2.665,2.105,2.569,4.765)$

\#\#Km data for hibernating condition found in supplementary data

hib $=c(13.1964,8.6277,5.98,7.74)$

t.test(euth,hib)

As seen in Figure 9, the data obtained from the MM.2() function in the R program spits out the same data as the Brooks Kinetics program. So why use R instead of Steve Brooks Kinetics program? The scripts generated in $\mathrm{R}$ allows anyone who is curious to look into the engine room of $\mathrm{R}$ to make sure the calculations are right. With Kinetics, the engine room of the programme cannot be accessed. Therefore, the transparency and reproducibility of the code makes quantifying kinetic data in $\mathrm{R}$ ideal.

If one wants to graphically represent kinetic parameters of two conditions (ie. euthermic versus hibernating) in one figure it can be done quite easily. Below are the steps that should be used to do this.

\#\#load data file in .csv format into $\mathrm{R}$

kmlac5<-read.csv("KmLactate5rawdata.csv")

View(kmlac5)

\#\#\#plot the data using the michaelis menten function kmlac5.m1 <-drm(Activity Lactate,

Condition, data $=\mathrm{kmlac5}$, fct $=$ MM.2())

plot $($ kmlac5.m1,log="",xlim=c(0,100), ylim=c(0,0.20), cex.legend $=1$, legendPos $=c(100, .1), c o l=T R U E$, xlab $=$ "[Lactate $](\mathrm{mM}) "$, ylab = "Activity $(\mathrm{mU}) ")$

Nelch Two Sample t-test

data: euth and hib

$t=-3.5545, d f=3.87, p$-value $=0.02504$

alternative hypothesis: true differerce in means is not equal to 0

95 percent confidence interval:

$-10.498412-1.221638$

sample estimates:

mean of $x$ mean of $y$

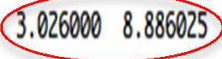

Significant difference between euthermic and hibernating LDH (pH7.5) assayed at 5 degrees Celsius.

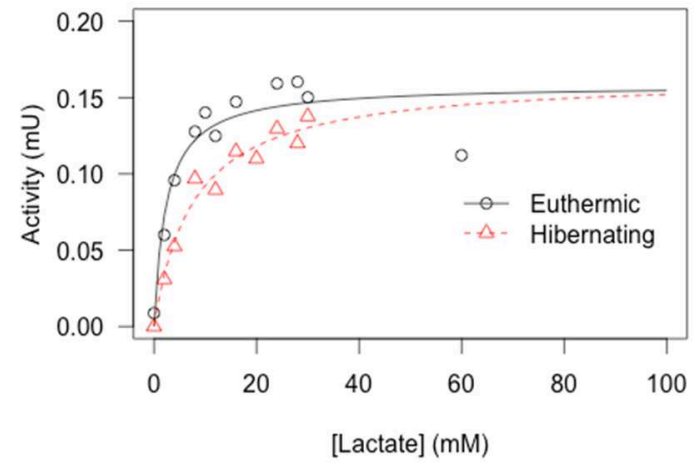

Figure 10. Michaelis-Menten curves for the forward (lactate-utilizing) reaction catalyzed by purified euthermic and hibernating $\mathrm{LDH}$ (pH 7.5) assayed at $5^{\circ} \mathrm{C}$. 
Once the Vmax and Km values are found, one can generate other plots used in biochemistry to graphically represent one's data. Below is the code used to generate four different plots using the ph75euthl.nl kinetic data.

$\mathrm{S}=\mathrm{c}(0,2,4,8,10,12,16,24,28,30)$

$\mathrm{Km}=2.665$ \#\#value found from summary(ph75euth1.n1)

$\mathrm{Vmax}=.1853$ \#\#value found from summary(ph75euth1.n1)

$\mathrm{v}=\mathrm{Vmax} * \mathrm{~S} /(\mathrm{Km}+\mathrm{S})$

$\operatorname{par}(\mathrm{mfrow}=\mathrm{c}(2,2))$ \# Set up $2 \times 2$ plot figure

plot(S,v,type="o", main="Michaelis-Menten")

plot(1/S,1/v, type="o", main="Lineweaver-Burk")

plot(v/S,v,type="o", main="Eadie-Hofstee")

$\operatorname{plot}(\mathrm{S}, \mathrm{S} / \mathrm{v}$, type="o", main="Hanes-Woolf")

$\operatorname{par}(\mathrm{mfrow}=\mathrm{c}(1,1))$ \# Return to single plot
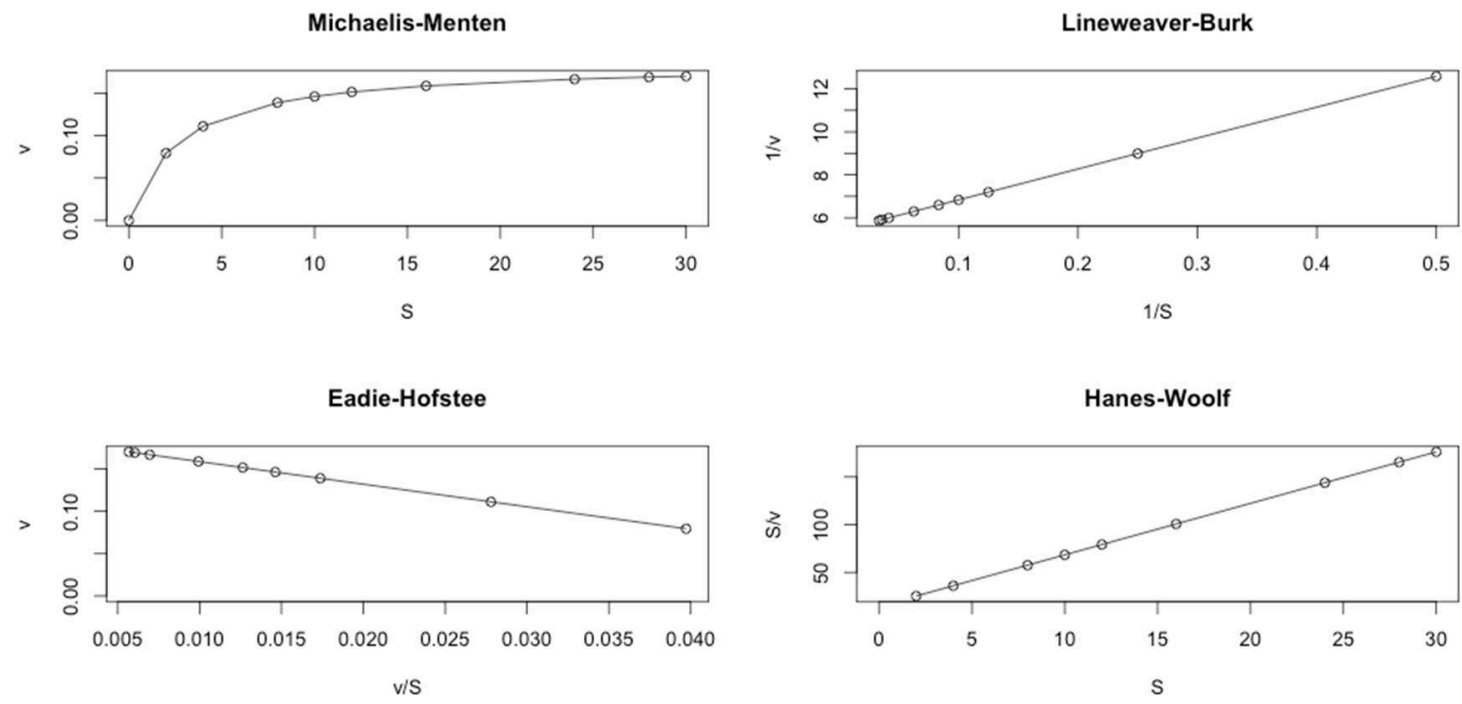

Figure 11. Four different graphical representations used to show kinetic parameters. Data used is from $p h 75$ euth1.n1.

\section{Closing Remarks}

The packages used to generate the scripts in this document shed light on the usefulness of $\mathrm{R}$ when it comes to analyzing data generated by biochemists. Surely, the examples used represent a small sample of the various ways one can use the programme R. With a little bit of patience and searching for help guides written by other R users, the programme can become a useful, and time saving tool.

\section{References}

Brooks,S.P. (1992). A simple computer program with statistical tests for the analysis of enzyme kinetics. Biotechniques 13(6):906-911

R Core Team (2014). R: A language and environment for statistical computing. $R$ Foundation for Statistical Computing, Vienna, Austria. URL http://www.R-project.org/.

Ritz, C. \& Streibig, J. C. (2005). Bioassay Analysis using R. J. Statist. Software, Vol 12, Issue 5.

Wickham, H. (2009). ggplot2: elegant graphics for data analysis. Springer, New York. 